\author{
Hausarbeit \\ zur Erlangung des Magistergrades (M.A.) \\ am Fachbereich Sozialwissenschaften \\ der Universität Göttingen
}

\title{
Der Ostseerat - \\ ein Beitrag zur Zivilisierung des internationalen Systems?
}

\author{
vorgelegt von \\ Karla Prigge \\ aus Hassel
}

Betreuung der Arbeit:

Prof. Dr. Ernst Kuper

eingereicht am 16.3.2007 


\section{Inhaltsverzeichnis}

Einleitung 4

1. Theorie $\quad 7$

1.1 Grundlegende Annahmen dieser Arbeit 8

1.1.1 Zustand des internationalen Systems: Anarchie 8

1.1.2 Unsicherheit und Instabilität 9

$\begin{array}{ll}\text { 1.1.3 Vielfalt der Akteure } & 10\end{array}$

1.1.3.1 Wichtigste Akteure: Staaten 10

1.1.3.1.1 Motivationen für staatliches Handeln 11

1.1.3.2 Subnationale Einheiten 12

1.1.3.3 Nichtstaatliche Akteure 13

1.1.4 Systembedingte (Unsicherheits-)Faktoren $\quad 14$

1.1.5 Abgrenzung zu anderen Referenzrahmen $\quad 15$

$\begin{array}{lll}1.2 & \text { Zivilisierung } & 16\end{array}$

1.2.1 Vielfalt und Dichte der Verbindungen $\quad 16$

1.2.2 Keine eindeutige Hierarchie der Themen 17

1.2.3 Undenkbarkeit des offen ausgetragenen Konflikts 18

1.2.4 Konsequenzen 18

$\begin{array}{ll}\text { 1.2.5 Macht } & 19\end{array}$

1.2.5.1 „Hard Power“ und „Soft Power“ 19

1.3 Einflussmöglichkeiten von IOs 20

1.3.1 Phasen der Einflussnahme 20

1.3.2 Möglichkeiten des Beitrags zur Zivilisierung 21

1.3.2.1 Geographische Ausdehnung und Mitgliederzahl 21

1.3.2.2 Bekanntheitsgrad in der Öffentlichkeit 22

1.3.2.3 Form der Administration 23

1.3.2.4 Umgang mit u. Bereitstellung von Informationen 23

1.3.2.5 Erzeugung personeller Bindungen 25

1.3.2.6 Wahrnehmung von Monitoring-Aufgaben 26

1.3.2.7 Formulierung internationaler Normen 27

1.3.2.8 Umsetzung konkreter Projekte 28

1.3.3 Überlagerung von CBSS und anderen Organisationen 28

2. CBSS-Gründung im Kontext von Kooperation und Spannungen 29

$\begin{array}{lll}2.1 & \text { Vorgeschichte } & 29\end{array}$

2.2 Nordische Kooperation 30

2.3 KSZE / OSZE 31

$\begin{array}{lll}2.4 & \text { Ostseeparlamentarierkonferenz } & 32\end{array}$

2.5 Russland, die baltischen Staaten und Polen 32

2.6 Vom Fall des Eisernen Vorhangs bis zur Gründung des CBSS 33

2.7 Militärische Bündnispolitik 34

2.8 Zwischenbetrachtung $\quad 35$

3. Der CBSS 36

3.1 Zielsetzung und Handlungsfelder 36

$\begin{array}{lll}3.2 & \text { Organisationsstruktur } & 39\end{array}$

3.2.1 Intergouvernementale Ebene $\quad 39$

3.2.2 Zusätzliche Arbeitsgruppen $\quad 40$

3.2.3 Sukzessive Ausweitung der Kooperation $\quad 42$

3.2.4 Das Sekretariat 43

3.2.5 Die Präsidentschaft 46 
3.2.6 Die Integration anderer Kooperationsformen der Region 48

3.3 Der geographische Einzugsbereich des CBSS 49

3.4 CBSS-Einbindung in die Gestaltung des Systems $\quad 52$

3.5 Zwischenbetrachtung 56

4. Ostsee-Kooperation in der Energiepolitik 57

$\begin{array}{lll}4.1 & \text { Faktoren des Systems } & 58\end{array}$

4.1.1 Position des CBSS $\quad 59$

4.1.2 Konkreter Anlass für dieses Thema 60

4.2 Energiepolitik im CBSS 61

4.2.1 Ebene des CSO 62

4.2.2 Ministerielle Ebene 62

4.2.3 Ebene der Regierungschefs 64

4.2.3.1 „Baltic 21“ 65

4.2.4 Parlamentarierkonferenz 67

4.2.5 BASREC 67

4.3 EU-Politik für die Region $\quad 69$

4.3.1 Die Nördliche Dimension $\quad 70$

4.3.2 Der 1. Aktionsplan $\quad 72$

4.3.2.1 Energie im 1. Aktionsplan 73

4.3.3 Der 2. Aktionsplan 74

4.3.3.1 Energie im 2. Aktionsplan 75

4.4 Politischer Prozess, der im Pipeline-Projekt mündet 76

4.5 Zwischenbetrachtung $\quad 78$

5. Schlussfolgerungen 80

Quellen- und Literaturverzeichnis 


\section{Einleitung}

Am 5. und 6. März 1992 wurde in Kopenhagen der Ostseerat von den Außenministern sämtlicher Ostseeanrainerstaaten und Norwegens sowie eines Vertreters der Europäischen Kommission gegründet. Island ist seit 1995 ebenfalls Mitglied, was trotz seiner räumlich recht großen Entfernung von der Ostsee nicht überrascht, da es in vielfältiger Weise mit seinen nordischen Partnern politisch eng verbunden ist. Der Ostseerat, offiziell „Council of the Baltic Sea States“ (CBSS), ist eine Organisation intergouvernementalen Typs; die Gremien der Organisation setzen sich aus den Ministern der Mitgliedsstaaten bzw. hochrangigen Repräsentanten ihrer Außenministerien und jeweils einem Vertreter der EU-Kommission zusammen. Seit 1996 finden sich im zweijährigen Abstand darüber hinaus die Regierungschefs zu einem Gipfeltreffen ein.

1998, d.h. nach sechsjähriger Tätigkeit, wurde die Organisationsstruktur wesentlich ergänzt, indem ein Sekretariat gegründet wurde, dem die Wahrnehmung administrativer Aufgaben und in Teilen die Umsetzung der Vorhaben obliegt. ${ }^{1} \mathrm{Zu}$ diesen Aufgaben zählt - damit wird ein für das Wesen des CBSS charakteristisches Moment deutlich - die Kontaktpflege zu NGOs und Vertretern anderer politisch-administrativer Einheiten der Ostseeregion.

Gegründet infolge der geopolitischen Veränderungen, die in der OstseeRegion mit dem Ende des Kalten Krieges unmittelbar gegenwärtig wurden, fungiert der CBSS als ,overall political forum for regional intergovernmental cooperation“2. Seine Aufgabe ist es, politische Ziele zu bestimmen, Aktionspläne zu entwerfen, Projekte zu initiieren und als Plattform $\mathrm{zu}$ dienen für den Ideenaustausch $\mathrm{zu}$ regionalen Themen von gemeinsamem Interesse. In seinen politischen Zielen stützt er sich auf Prinzipien, die in KSZE-Dokumenten sowie der Charta der Vereinten Nationen festgehalten sind.

Der seit dem Fall des „Eisernen Vorhangs“ beträchtlichen Verdichtung wirtschaftlicher, gesellschaftlicher und politischer Kooperation wie gesellschaftlicher Kontakte im Ostseeraum wird sowohl seitens der beteiligten Akteure als auch der wissenschaftlichen Literatur erheblicher Respekt gezollt. Die bis heute

\footnotetext{
${ }^{1}$ Siehe Establishment Agreement of a CBSS Secretariat (1998), auch Terms of Reference of the Secretariat of the CBSS (2004), Art. 2.

${ }^{2}$ Broschüre des CBSS-Sekretariats: Innovative Cooperation for a Dynamic Region“, Stockholm 2005, S. 4.
} 
nicht aufgehobene Machtkonfrontation zwischen Westeuropa, namentlich der EU, und Russland, die politischen Konflikte zwischen „dem Westen“ und „dem Osten“, die infolge der Rede Vladimir Putins auf der Münchner Sicherheitskonferenz dieses Jahres neu entfacht scheinen, spielen für den Ostseeraum selbst, eine Region zwischen den Einflusssphären, mittlerweile eine bemerkenswert kleine Rolle. Nicht nur geographisch - die Einflusssphäre des Ostseerats deckt den gesamten Küstenraum ab -, sondern auch inhaltlich wird dieser Organisation eine „Schlüsselrolle“ an dieser Entwicklung zugeschrieben, so beispielsweise vom ehemaligen Generalsekretär der Organisation der Vereinten Nationen, Kofi Annan. ${ }^{3}$

Gestützt auf die Vermutung, diese Institution habe einen wesentlichen Beitrag zur Zivilisierung der Konstellationen im Ostseeraum geleistet, soll mit dieser Arbeit untersucht werden, was Struktur und Arbeit des CBSS ausmacht und welches die entscheidenden Faktoren für das Wirken dieser Internationalen Organisation sind. Der mutmaßliche Erfolg des CBSS soll mit dieser Arbeit analysiert werden, motiviert gewissermaßen durch eine Aufforderung des Politikwissenschaftlers Robert Keohane: „Students of world politics could profitable spend more of their time asking how international institutions should be structured, both within Western and Central Europe and between Europe and other powerful states, in order to prevent the recurrence of a fear-driven slide toward military conflict that would be disastrous for our generation and those to follow. “4

Die Grundannahme dieser Arbeit ist in etwa mit dem Schlagwort ,institutions matter" beschrieben; sie geht über die Einschätzung hinaus, Institutionen seien grundsätzlich auf die Bedeutung eines außenpolitischen Instruments von Regierungen zu reduzieren; vielmehr sind in institutionellen Strukturen potentielle Handlungsrestriktionen sowie gleichermaßen -optionen zu sehen. Zudem wird davon ausgegangen, Kooperation im internationalen System könne durchaus ohne Zwang - Zwang einer übergeordneten Macht - initiiert werden und bestehen, d.h. aus freiwilliger Entscheidung der beteiligten Akteure. Damit orientiert sich diese Arbeit am Spektrum der institutionalistischen Theorien von den Internationalen Beziehungen (IB). ${ }^{5}$

\footnotetext{
${ }^{3}$ Zitiert im CBSS-Newsletter „Baltinfo“ Nr. 45, Februar 2002.

${ }^{4}$ Keohane, Robert O.: „Correspondence“, in: International Security, Nr. 15, Heft 2, 1990, S. $192-$ 194, hier S. 194.

${ }^{5}$ Für einen Überblick siehe z.B. Keck, Otto: „Der neue Institutionalismus in der Theorie der Internationalen Politik“, in: Politische Vierteljahresschrift, Nr. 4, 1991, S. 635-653, hier S. 637; Boehmer, Charles / Gartzke, Erik / Nordstrom, Timothy: „Do Intergovernmental Organizations
} 
Die Behauptung, Internationale Organisationen (IOs) begünstigten grundsätzlich friedliche Problemlösungen oder machten das gewaltsame Intervenieren von Antagonisten zwangläufig unwahrscheinlich, muss als zu pauschal verworfen werden. Da in der wissenschaftlichen Literatur gar auf Beispiele verwiesen wird, die diesem diametral widersprechen, ${ }^{6}$ ist jeder Fall für sich zu betrachten.

Ist in dieser Arbeit von IOs und insbesondere IGOs (Internationale Regierungsorganisationen), die Rede, sind diese als Teile eines Wortfelds zu verstehen, zu dem auch „Institution“ und „Regime“ zu zählen sind. Die entsprechenden Definitionen variieren je nach Autor und Zusammenhang und überschneiden sich bisweilen erheblich. Keohane - als Verfasser der für diese Arbeit maßgeblichen wissenschaftlichen Theorie - bezieht sich überwiegend auf den Begriff des Regimes als „,clusters of principles, norms, rules and decision-making procedures“ ${ }^{67}$ und als „transnational and interstate [...] governing arrangements“ ${ }^{*}$, womit sich durchaus der Rahmen an rechtlichen Abkommen beschreiben lässt, in den die IGO CBSS eingeordnet ist. ${ }^{9}$ Grundsätzlich sind IOs zu verstehen als ,auf Verträgen beruhende Zusammenschlüsse von Staaten; sie besitzen eigene Organe und Kompetenzen, die das Zusammenwirken nach innen und außen (Kooperation, Interdependenz) regeln“. ${ }^{10}$

Folgende Thesen seien untersuchungsleitend:

1. Als einzige Organisation, in der die Regierungen sämtlicher Anrainerstaaten des „Mare Baltikum“ wie die EU-Kommission gleichberechtigt vertreten sind, hat der CBSS einen maßgeblichen Beitrag zur Zivilisation des internationalen Systems in der Ostseeregion geleistet. Trotz relativ geringen Bekanntheitsgrads in der Öffentlichkeit die Zusammenarbeit nicht zurückzufahren, sondern sie auszubauen, spricht dafür, dass sie von allen Beteiligten als sinnvoll eingeschätzt wird, um länderübergreifend an Probleme heranzugehen und Lösungen $\mathrm{zu}$ erarbeiten, die im Interesse aller sind. Da nicht auf einem formalen Vertrag beruhend, somit ohnehin entscheidend von Kooperationsbereitschaft

Promote Peace?“, in: World Politics, Nr. 57, Heft 1, Okt. 2004, S. 1-38, gehen näher auf Formen der Institutionalisierung von IOs ein.

${ }^{6}$ Verweise finden sich bei Boehmer / Gartzke / Nordstrom, S. 3.

${ }^{7}$ Keohane, Robert O.: „Accountability in World Politics“, in: Scandinavian Political Studies, Bd. 29 (2), 2006, S. 75-87, hier S. 76.

${ }^{8}$ Keohane, Robert O. / Nye, Joseph S.: Power and Interdependence, New York u.a. $2001^{3}$, S. 5 , (1. Aufl. 1976).

${ }^{9}$ Dazu näher Kap. 3.2, „Organisationsstruktur des CBSS“, S. 39ff..

${ }^{10}$ Definition laut Pfetsch, Frank R.: Internationale Politik, Stuttgart u.a. 1994, S. 82. 
seiner Mitglieder abhängig, dürfte der CBSS auf Konflikte, die im Rahmen der intergouvernementalen Zusammenarbeit auftreten, einen schlichtenden Einfluss ausüben.

2. Die Dichte der Kontakte im geographischen Einzugsbereich des CBSS findet auch in der Struktur der Organisation ihren Ausdruck, da sie enge Verbindungen zu subnationalen und gesellschaftlichen Akteuren zu pflegen und ihnen Einfluss zuzugestehen verspricht. Dadurch begünstigt der CBSS in hohem Maß eine Identitätsbildung im Ostseeraum, womit er für die EU, der es an Rückhalt in den Bevölkerungen mangelt, eine Vorbildfunktion einnimmt, statt als Vehikel ihrer Politik für diese Region herhalten zu müssen.

\section{Theorie}

Einem schwer durchschaubaren Basar gleicht das Angebot an Theorien von den Internationalen Beziehungen. ${ }^{11}$ Davon zeugt nicht zuletzt die Literatur, die sich dem Unterfangen widmet, überblicksartige Darstellungen $\mathrm{zu}$ formulieren: Zum einen fällt die Vielzahl der Theorien ins Auge, zum anderen zeigt sich eine bemerkenswerte Vielfalt in der Art ihrer Wahrnehmung durch die Wissenschaft. Je nach Autor werden Realismus und Idealismus als Pole ausgegeben, zwischen denen die übrigen Theorien gewissermaßen oszillieren, ${ }^{12}$ oder es werden Realismus, Funktionalismus und Globalismus als die grundlegenden Denkschulen ausgemacht ${ }^{13}$, um nur die offensichtlichsten Unterschiede zu nennen. Da darüber hinaus weder die Etikettierungen der jeweiligen Lehrsätze übereinstimmen noch ihre Grenzen einheitlich gezogen werden, ist bei der Auseinandersetzung mit einem Gegenstand der IB die theoretische Verortung en detail darzulegen.

\footnotetext{
${ }^{11}$ Siehe Friedrichs, Jörg: European Approaches to International Relations Theory. A House with many Mansions, London 2004, schon im Titel die Breite des Spektrums aufgreifend.

${ }^{12}$ So bei Menzel, Ulrich: Zwischen Idealismus und Realismus. Die Lehre von den Internationalen Beziehungen, Frankfurt a. M. 2001.

${ }^{13}$ Siehe Keck, Otto: S. 640.
} 


\subsection{Grundlegende Annahmen dieser Arbeit}

Das internationale System, der funktionale Bezugsrahmen des CBSS, ist hinsichtlich seiner Elemente in den Blick zu nehmen, da von der Art, wie sich dieses darstellt, die Handlungs- und Wirkungsmöglichkeiten der Akteure abhängen, die in ihm auftreten. Wenn auch die Schlichtheit mancher Beschreibungs- und Analysemodelle für manchen attraktiv erscheinen mag, ${ }^{14}$ bieten sie doch für die Vielfalt politischer Entwicklungen der Gegenwart keine zufriedenstellende Erklärung; es ist im Einzelnen zu differenzieren zwischen unterschiedlichen Gegebenheiten und dementsprechend unterschiedlichen Erklärungsansätzen: Für die gegenwärtig engen und vielfältigen, auf Zusammenarbeit ausgerichteten Beziehungen der westeuropäischen Staaten untereinander können - soviel ist unbestreitbar - schwerlich dieselben Aussagen zutreffen wie beispielsweise für diejenigen zwischen den USA und dem Iran in den vergangenen Jahren. Mit dem Werk „Power and Interdependence“, bieten Robert Keohane und Joseph Nye ein umfangreiches inhaltliches und begriffliches Gerüst, um Komplexität und Befindlichkeiten des Geschehens auf internationaler Ebene zu erfassen, wobei sie explizit kooperative Beziehungen in den Blick nehmen und zu erklären versuchen, welches die Charakteristika von Politik sind, wenn internationale Interdependenz, d.h. wechselseitige Abhängigkeit, als umfassend einzustufen ist. ${ }^{15}$ Sie suchen nach den Bedingungen und Möglichkeiten von Kooperation, nicht nach den Gründen von Konflikt (wobei ein Zusammenhang dieser Aspekte nicht geleugnet werden soll).

In der Analyse kann eine Arbeit wie die vorliegende, die das Geschehen innerhalb einer Region in den Blick nimmt, sich nicht auf das internationale System als Ganzes beziehen; sie rückt ein Subsystem in den Mittelpunkt. Erkenntnisse über das Wirken des Ostseerats als Bestandteil eines solchen dürften einen konstruktiven Beitrag für die Gestaltung anderer Subsysteme oder auch des übergeordneten Referenzrahmens leisten können. ${ }^{16}$

\subsubsection{Zustand des internationalen Systems: Anarchie}

Trotz zahlreicher und vielfältiger Versuche ist es bis heute im Grunde nicht gelungen, ein globales System von Regeln zu entwerfen, dem sich alle Akteure

\footnotetext{
${ }^{14}$ Vgl. Mearsheimer, John J. im Interview mit „International Relations“, Nr. 20, Heft 1, 2006, S. 105-123, hier S. 107, der erklärt, sogar dann die Eleganz einfacher, teils vereinfachender Modelle zu bevorzugen, wenn sie starrköpfig seien.

${ }^{15}$ Vgl. Koehane / Nye S. 4.

${ }^{16}$ Zur Beschreibung des politischen Systems im Ostseeraum vgl. Kap. 3.4, S. 52.
} 
verpflichtet haben und das universal respektiert und befolgt wird; eine übergeordnete Macht im internationalen System existiert nicht. Ambitionierte Initiativen, diesem abzuhelfen, erweisen sich bislang als Stückwerk, wie der Internationale Strafgerichtshof, der im November 2006 zwar seine Arbeit aufnehmen konnte, allerdings bei weitem nicht von allen Regierungen anerkannt und nur bedingt zuständig ist. ${ }^{17}$ In diesem Sinne ist der Zustand des internationalen Systems als ursprünglich anarchisch zu verstehen. Keohane bezeichnet die Akteure im internationalen System als ,independent actors, the most of which are states, not subordinated to a worldwide governmental hierarchy", ${ }^{18}$ wobei implizit ist, dass als einzige Einschränkung, der ein souveräner Staat außerhalb seiner Grenzen verpflichtet ist, die Souveränität und Integrität der anderen Staaten zu sehen ist.

Anders gelagert ist dies mittlerweile in Westeuropa, wo das Regelwerk der Europäischen Gemeinschaften starke Bindungen vielfältiger Art und auch Sanktionsmöglichkeiten darstellt. Deren Wirkungsbereich ist sukzessive auch im Ostseeraum ausgedehnt worden, wo nunmehr nur Russland nicht von diesen Bindungen erfasst wird. - Allein in der Abwesenheit einer den Staaten übergeordneten Instanz läge allerdings kaum Grund zur Besorgnis, denn Gleichberechtigung der Akteure wäre um ihrer selbst willen zu begrüßen. Den Zustand der Anarchie als einen allgegenwärtigen Kriegszustand aufzufassen wäre irreführend; ein solcher existiert nicht. Der Bedarf an Verregelung und Kontrolle oder - um den Titel dieser Arbeit aufzugreifen - an einer Zivilisierung des System erklärt sich aufgrund der folgenden Erwägungen:

\subsubsection{Unsicherheit und Instabilität}

Das außenpolitische und militärische Verhalten einzelner Staaten bzw. ihrer Repräsentanten gegenüber ihrem Umfeld, d.h. sowohl gegenüber unmittelbaren Nachbarn als auch u.U. weit entfernten Regionen, wirkt - beabsichtigt oder nicht - nicht selten unterschwellig bedrohlich oder auch offen feindselig. Lediglich empfundene oder tatsächliche Bedrohung und darauf bezogene abschrekkende oder gar aggressivere Maßnahmen in einem wenig verbindlichen normativen Rahmen sind häufig als Ausdruck einer Unsicherheit zu verstehen, die die

\footnotetext{
${ }^{17}$ Vgl. Homepage des Internationalen Strafgerichtshofs, dortige Angaben zur Gründung und Zuständigkeit desselben, URL: http://www.icc-cpi.int/about/ataglance/establishment.html, 28.11.2006.

${ }^{18}$ Vgl. Keohane, Robert O.: After Hegemony. Cooperation and Discord in the World Poltical Economy, Princeton 1984, S. 18.
} 
Politik der Staaten im internationalen System maßgeblich prägt - Unsicherheit bezüglich der zu erwartenden Ereignisse. ${ }^{19}$ Exemplarisch kann hier die Diskussion über die Funktion des von den USA angestrebten Raketen-,,Abwehr“-Systems in Osteuropa angeführt werden, das von Russland als Bedrohung ausgelegt wird. Derartige Beziehungen der Staaten untereinander lassen sich dementsprechend als instabil bezeichnen. - Instabilität und Unsicherheit hinsichtlich der Intentionen der Akteure bedingen sich gegenseitig und bergen Ge-waltpotential, sofern nicht bewusste Maßnahmen ergriffen werden, friedliche Stabilität zu begünstigen.

\subsubsection{Vielfalt der Akteure}

Es ist mittlerweile unumstritten, dass außer den Staaten weitere Akteure das weltweite Geschehen beeinflussen und demzufolge auch in der Analyse zu berücksichtigen sind. Über welche Funktionen und welches Gewicht diese verfügen, besteht in den Theorien von den IB allerdings erheblicher Widerspruch. Demzufolge ist hier darzustellen, auf welchen Annahmen diese Untersuchung fußt.

\subsubsection{Wichtigste Akteure: Staaten}

Diese Arbeit geht von der grundsätzlichen Einschätzung aus, dass unter den Akteuren des internationalen Systems die Staaten nach wie vor die wichtigste, wenn auch nicht mehr die einzig entscheidende Rolle spielen, obwohl dies in Anbetracht einiger Entwicklungen in Frage zu stellen ist: Insbesondere IOs, in denen Regierungen kooperieren (also International Governmental Organizations bzw. IGOs), vermögen bisweilen eine erhebliche Eigendynamik zu entwickeln. Das Beispiel der EU mit ihrem z.T. gar supranationalen Charakter, mit EU-Bürgerschaft als Ergänzung zur Staatsbürgerschaft, mit Kompetenzen, die den nationalen Legislativen und Judikativen übergeordnet sind, oder mit (Ansätzen zu) einer gemeinsamen Verteidigungspolitik vermag jeglichen grundsätzlichen Einwand zu entkräften, dass ausschließlich Staaten in der Weltpolitik eigene Ziele durchsetzen könnten. Gleichzeitig liefert das Stichwort Bürger eine weitere Unterstützung für die Einschätzung, Staaten hätten eine Vorreiterrolle unter den Akteuren inne: Sie sind bislang die oberste Bezugsinstanz für Individuen, deren Rechte und Pflichten an Staatsbürgerschaften gebunden sind. Sogenannte failing states, in denen keine Staatsgewalt erkennbar zu regieren in der Lage ist und somit

\footnotetext{
${ }^{19}$ Vgl. Keohane (1984), S. 257.
} 
kaum eigene Interessen $\mathrm{zu}$ definieren und durchzusetzen vermag, ebenso wie Terrorismus, der nicht eindeutig in einzelnen Staaten wurzelt, sind prominente Erscheinungen, die diese Bedeutsamkeit anzweifeln lassen. Die exponierte Position der Staaten in der Weltordnung ist allerdings dennoch nach wie vor gegeben, da ihnen die bei weitem meisten Mittel zur Verfügung stehen, andere zu reglementieren. ${ }^{20}$ Satzung und Praxis der UNO bestätigen dies: Staaten - selbst failed states - sind Mitglieder und die ersten Ansprechpartner bei Versuchen, Frieden in Krisenregionen zu sichern oder in Kriegsgebieten wiederherzustellen, wobei nur unter besonderen Umständen in innere Angelegenheiten eingegriffen werden darf. ${ }^{21}$ Es ist somit berechtigt, trotz einschränkender Phänomene weiterhin von der Prädominanz der Staaten auszugehen.

\subsection{Motivationen für staatliches Handeln}

Gemeinhin werden für nach außen gerichtetes staatliches Handeln die Attribute egoistisch und altruistisch angeführt, was wahlweise mit vermeintlich realistischen bzw. idealistischen Weltbildern in Zusammenhang gestellt wird. Keohane entschärft diese Dichotomien, wodurch er ihnen eine andere Bedeutung verleiht. Auf die Gefahr der Verschleierung bestimmter Absichten durch Dieologien oder Rhetorik verweisend, schreibt er, altruistisches Verhalten könne immer auch als egoistisches (miss-)gedeutet werden:

[T]he 'altruistic' may be seen as preferring to sacrifice herself rather than to violate a principle or see someone else suffer. Thus it is often impossible to determine whether to classify a given action as one of farsighted egoism or altruism. $^{22}$

Demzufolge distanziert er sich von dem Gebrauch dieser Termini und fordert stattdessen Antworten darauf, inwieweit Interessen oder Ziele einzelner unabhängig von denen anderer Akteure und inwieweit sie mit dem Wohlergehen aller verflochten sind. ${ }^{23}$ Interessen interpretiert er als „not merely derived from material identities, but [...] also constituted by ideas and norms“. ${ }^{24}$ Für die vorliegende Arbeit ist dies insbesondere deshalb von Belang, da - nach dem

\footnotetext{
${ }^{20}$ Auf die zentrale Rolle der Staaten in der Weltgemeinschaft verweist Herdegen, Matthias: Völkerrecht, München $2004^{3}$, S. 3.

${ }^{21} \mathrm{Vgl}$. Satzung der UNO, Kap. I, in: Unser, Günther: Die UNO. Aufgaben und Strukturen der Vereinten Nationen, München $1997^{6}$, S. 360 f..

${ }^{22}$ Keohane (1984), S. 122.

${ }^{23}$ Vgl. Keohane / Nye, S. 122.

${ }^{24}$ Keohane (2006), S. 76.
} 
Interesse an Kooperation fragend - mit Keohane davon auszugehen ist, internationale Organisationen seien

rarely if ever instituted by disinterested idealists for the sake of the common good. Instead, they are constructed by governments whose officials seek to further the interests of their states (as they interpret them) or of themselves. ${ }^{25}$

Ungeachtet dessen, welches Interesse im konkreten Fall als ausschlaggebend ausgemacht wird, ist die freiwillige Kooperation in jedem Fall als Ausdruck rationalen, zielgerichteten Verhaltens der Akteure zu verstehen.

\subsubsection{Subnationale Einheiten}

Nicht nur nationale Regierungen formulieren Interessen in den Außenbeziehungen, sondern es bekunden auch andere staatliche Ebenen und Organe eigene Präferenzen und bemühen sich um deren Durchsetzung. Die Vertretungen der deutschen Länder und Kommunen sowie subnationaler Einheiten anderer Länder bei bzw. in der EU in Brüssel belegen dies; dieses wird überwiegend als subsidiäre Zuständigkeit interpretiert, so dass diesbezüglich weniger von außenpolitischem Engagement zu sprechen ist. Solchen Charakter hat allerdings das Auftreten der Länder auf weltweiter Bühne in eigener Sache; trotz der eigentlichen Zuständigkeit des Bundes in auswärtigen Angelegenheiten ${ }^{26}$ verfügen sie durchaus über den Spielraum, eine Politik zu betreiben, die sich nicht ohne weiteres mit den Prioritäten des Bundes deckt.

In diesem Zusammenhang lässt sich unter Berufung auf „Power and Interdependence" darauf verweisen, dass Staaten nicht als geschlossene Einheiten gesehen werden sollten, ${ }^{27}$ sondern dass transgouvernementale Beziehungen - d.h. Verbindungen der Regierungsorgane auf verschiedenen Ebenen über Staatsgrenzen hinweg ${ }^{28}$ - als einflussreiche Erscheinung des internationalen Systems zu berücksichtigen sind, denn

alongside the necessary but imperfect interstate institutional framework, there is developing an informal political process that supplements the formal process of cooperative relations among states. ${ }^{29}$

\footnotetext{
${ }^{25}$ Keohane (1984) S. 22; die Untersuchung gilt zwar eigentlich internationalen Regimen, doch definiert der Autor diesen Begriff ausreichend weit, um ihn als Äquivalent zu einem allgemeinen Begriff von Internationalen Organisationen aufzufassen.

${ }^{26}$ Vorgegeben durch das Grundgesetz, Art. 32, Satz 1.

${ }^{27}$ Vgl. Keohane / Nye, S. 261.

${ }^{28} \mathrm{Vgl}$. Keohane / Nye, S. 47.

${ }^{29}$ Keohane / Nye, S. 261.
} 
Die Autoren selbst verweisen auf die Beschränkung dieser Entwicklung in zeitlicher und räumlicher Hinsicht. ${ }^{30}$

\subsubsection{Nichtstaatliche Akteure}

Neben den Staaten sind als wesentliches Element des politischen Geschehens nicht nur auf nationaler, sondern auch auf globaler Ebene mittlerweile Akteure anderer Provenienz zu berücksichtigen. Von verschärfender Wirkung für die ohnehin gegebene Unsicherheit im internationalen System ist das Vorgehen verschiedener Protagonisten - genannt seien hier beispielsweise Terroristen, die kaum an nationale Grenzen gebunden sind, das organisierte Verbrechen, aber auch gesellschaftliche Gruppen, die aus ethnischen, religiösen oder anderen Gründen eine Minderheit darstellen oder Diskriminierungen beklagen und gewaltsam für eigene Belange kämpfen, wie es beispielsweise für die Auseinandersetzungen zwischen Tschetschenen und Russland von erheblicher Bedeutung ist. Erscheinungen dieser Art tragen erheblich zu Unsicherheit und Instabilität bei, da sie sich zumeist herkömmlichen Werkzeugen staatlicher Macht entziehen und da sie teilweise geradezu darauf ausgerichtet sind, säkulare, demokratische und nationalstaatliche Strukturen durch andere Ordnungen $\mathrm{zu}$ ersetzen. Letzteres ist zumindest bei fundamentalistisch religiösen Kämpfern anzunehmen. ${ }^{31}$

Die zunehmende Verwendung in Wissenschaft und Öffentlichkeit und steigender Bekanntheitsgrad einer Vielzahl von Akronymen wie NGO oder $\mathrm{BINGO}^{32}$ weist auf den - in seinem Ausmaß jedoch stark umstrittenen - Bedeutungszuwachs solcher Akteure für das internationale System hin, die nicht staatlicher Natur sind, sich jedoch weitgehend mit dem System arrangieren. Durch ihr Engagement, einzelne Themen in das Bewusstsein der Öffentlichkeit zu rükken, und durch gezielte Aktionen vermögen sie anerkanntermaßen bisweilen ausreichend Druck zu erzeugen, um einen Wandel in Zielsetzung und Ausrichtung bestimmter politischer Themenfelder einzuleiten. Die Initiativen solch unter-

\footnotetext{
${ }^{30}$ Vgl. Keohane / Nye, S. 245.

${ }^{31}$ Vgl. u.a. Tibi, Bassam: Die neue Weltunordnung, München 2001, S. 25 ff..

${ }^{32}$ Diese stehen für "International Governmental Organization", "Non-Governmental Org." bzw. "Buisiness International Non-Governmental Organization", wobei der letztgenannte Typ sich im Wesentlichen mit dem Begriff „Wirtschaftskonzern” deckt.
} 
schiedlicher Akteure wie „Amnesty International“ oder einzelner Stiftungen werden mittlerweile auf politischen Foren durchaus ernstgenommen. ${ }^{33}$

Des weiteren ergänzt „,die Wirtschaft“ als zunehmend einflussreich und mit einer - von Staaten weitgehend unabhängigen - Eigendynamik agierend das Mosaik der Akteure. Konzerne, Unternehmen, Handelskammern und andere vermögen Entscheidungen zu treffen und sich Handlungsfelder zu eröffnen, die von grenzüberschreitender Konsequenz sind und gegenüber denen legitimierten Entscheidungsträgern nicht selten anscheinend nur die Reaktion bleibt. ${ }^{34}$

\subsubsection{Systembedingte (Unsicherheits-)Faktoren}

Zunehmende Aufmerksamkeit - gegenüber historischen Erfahrungen wird seitens Politik und Wissenschaft mittlerweile Entwicklungen gewidmet, die als besorgniserregende Herausforderungen einzustufen sind. Ein Phänomen wie der Klimawandel, der eine Veränderung der Lebensgrundlagen bedingt und damit Migrationsströme zur Folge haben kann, steht hier stellvertretend für weitere ökologische Probleme, die sich in ihrer Auswirkung auf die Politik i.d.R. nicht auf einzelne Staaten beschränken. ${ }^{35} \mathrm{Da}$ sich zumeist auch Verantwortung und $\mathrm{Zu}$ ständigkeit nicht einzelnen Staaten zuordnen lassen und da sich ob deren Souveränität ohnehin nicht in sie hineinregieren ließe, sind solche Probleme als systembedingt einzustufen. Insbesondere weltweit zunehmender Mangel an Trinkwasser, dessen Dimension sich in manchen Regionen der Erde bereits zeigt, ${ }^{36}$ birgt erhebliches Konfliktpotential: In bereits betroffenen Regionen von jedem Individuum als essentiell wahrgenommen, verursacht der Wassermangel auf vielen Ebenen - zwischen Individuen, kleineren gesellschaftlichen Einheiten oder Staaten - Konfliktpotential. Solchem Herr zu werden stellt sich als internationale Herausforderung dar, die allerdings nicht mit kurzfristiger Befriedigung von Partiku-

\footnotetext{
${ }^{33}$ Nicht unumstritten zwar, dennoch wohlwollend respektiert engagiert sich z.B. die „Bill and Melinda Gates Foundation“ finanziell und programmatisch in Entwicklungshilfe.

${ }^{34}$ Vgl. Kell, Georg: „Über die Einhegung der Macht. Die Einbindung von Unternehmen und NGOs in globale Ordnungsstrukturen“, in: Herbert-Quandt-Stiftung (Hg.): ,Jenseits des Staates? ,Außenpolitik“ durch Unternehmen und NGOs“, 21. Sinclair-Haus-Gespräch, Bad Homburg v.d. Höhe, 2004, S. 58-64, hier S. 59.

${ }^{35}$ Siehe hierzu Welzer, Harald: „Schluss mit nutzlos! Die Geisteswissenschaften werden gebraucht, um die Welt neu zu denken. Doch dafür müssen sie mutiger werden“, in: DIE ZEIT, Nr. 5, 25.1.2007, S. 43.

${ }^{36}$ Siehe UNDP (Hg.): „Human Development Report 2006“, Vorwort S. vi, online-Dokument, URL: http://hdr.undp.org/hdr2006/pdfs/report/HDR06-complete.pdf, 5.12.2006; siehe auch Trittin, Jürgen: Rede am 27.04.2004, online-Dokument, URL: http://www.bmu.de/reden/doc/5820.php, 5.12.2006.
} 
larinteressen zu bewältigen, sondern langfristig im Konsens von den verschiedenen Akteuren zu meistern sein wird.

Zudem wirken sich verschiedene sozialpolitische, kulturelle oder andere Themen, die originär innenpolitischen Charakter haben, auf das internationale System aus, ${ }^{37}$ so dass sie bei dessen Analyse zu berücksichtigen sind. Dies kann beispielhaft - gelten für den Bereich Bildung und Forschung, mit dem Regierungen sich durch Abwerben von Fachkräften, höhere Investitionen oder andere Maßnahmen zu Kontrahenten im Streben nach gleichen Zielen entwickeln können - die Abwanderung Hochqualifizierter ins Ausland wird derzeit von Politik und Medien als für Deutschland fundamentales Problem dargestellt. ${ }^{38}$

Seit einigen Jahren wird zunehmend deutlich, welche Sprengkraft Auseinandersetzungen innewohnen kann, die religiös oder ideologisch motiviert sind. Z.T. stellen sie - z.B. nach einem Gottesstaat strebende Fundamentalisten bestehende Ordnungen grundsätzlich in Frage und durchsetzen die Struktur des internationalen Systems mit neuartigen Verhaltensmustern und Machtverhältnissen. Gleichzeitig lassen sie sich, da sie nicht notwendigerweise an Staatsgrenzen festzumachen sind und ggf. deren Legitimität nicht anerkennen, von den Hauptakteuren dieses Systems nur schwerlich in den Griff bekommen.

\subsubsection{Abgrenzung zu anderen Referenzrahmen}

Bezöge sich diese Untersuchung lediglich auf Prozesse zwischen Regierungen, wäre dies mit dem Terminus ,internationale Politik“ als Summe der Außenpolitiken zu erfassen. Die Begriffe „transnationale“ oder „,internationale Beziehungen“ (IB) werden zumeist gebraucht, um darüber hinaus - handlungsorientiert - auch individuelle oder gesellschaftliche Beziehungen in das Blickfeld einzuschließen, ${ }^{39}$ während IB auch den politikwissenschaftlichen Teilbereich selbst benennt. Da dieser Arbeit jedoch die Annahme zugrunde liegt, dass die Einflussmöglichkeiten einzelner Akteure in deren gesamtem Umfeld zu betrachten sind, dass also die Strukturen, in die sie eingebettet sind, die Prozesse zwischen den Akteuren mit bedingen, stellt das internationale System den entscheidenden Referenzrahmen dar.

\footnotetext{
${ }^{37}$ Vgl. Keohane / Nye S. 14.

${ }^{38}$ Siehe u.a. „Große Anfrage“ im Deutschen Bundestag: „Konsequenzen der Auswanderung Hochqualifizierter aus Deutschland“" am 30.10.2006, Drucksache 16/3210.

${ }^{39}$ Nicht ganz einheitlich werden diese Begriffe in der Forschungsliteratur wie auch in Lexikoneinträgen behandelt. Ein Konsens für diese Definitionen lässt sich jedoch ausmachen.
} 


\subsection{Zivilisierung}

Als Zivilisierung dieses Systems ist demzufolge eine ordnende, eine stabilisierende Gestaltung der Verhältnisse zu verstehen, durch die Frieden begünstigt und Gewaltpotential minimiert wird. Es wird also mit diesem Begriff bewusst darauf angespielt, die Bedeutung militärischer Fragen zu verringern - eine Aufwertung anderer, bisher international u.U. marginalisierter Themen eingeschlossen. Mit anderen Worten: Als zivilisiert kann eine Gruppe von Staaten und Gesellschaften gelten, die so tiefgreifend verflochten sind, dass ihnen militärische Gewalt untereinander nicht mehr als adäquates Mittel der Problemlösung zur Verfügung steht, sondern dass sie Dispute mit friedlichen Mitteln und kooperativ zu lösen versuchen. Zivilisierung sei also gewissermaßen als Zustand verstanden sowie als Prozess, der diesen Zustand anstrebt und weiterentwickelt. Es ist davon auszugehen, dass der Erfolg solcher Gestaltung zu einem erheblichen Teil von wohlwollender Zustimmung und aktiven Teilnahme nicht nur der verantwortlichen Politiker, sondern auch der Gesellschaften abhängt, da über derartige Richtungsentscheidungen auch in nationalen Wahlkämpfen befunden wird und mancher Beschluss von der Bevölkerung umgesetzt werden muss.

Unter Berücksichtigung der Tatsache, dass trotz ursprünglich gegebener Regellosigkeit des Systems nicht nur, aber besonders in Westeuropa willentlich wechselseitige Abhängigkeiten sowie intensive Kooperationsformen entstanden sind und bestehen und gegenseitige Bedrohungen hier zum gegenwärtigen Zeitpunkt schwer vorstellbar sind, ist die Einschätzung zu verwerfen, Zivilisierung des internationalen Systems sei eine Utopie. ${ }^{40}$ Angelehnt an das in „Power and Interdependence“ entwickelte Modell der komplexen Interdependenz ${ }^{41}$ lässt sich Zivilisierung folgendermaßen charakterisieren bzw. lässt sich ein System als zivilisiert beschreiben, wenn es sich wie folgt darstellt:

\subsubsection{Vielfalt und Dichte der Verbindungen}

Zum einen sind Staaten und Gesellschaften durch vielfältige Kanäle verbunden, die sowohl formeller als auch informeller Art sein können. Neben inter-

\footnotetext{
${ }^{40}$ So argumentiert z.B. Mearsheimer, der grundsätzlich davon ausgeht, Unsicherheit über Absichten und Strategien der Staaten untereinander lasse sich nicht überzeugend überwinden; vgl. Interview mit „International Relations“, Nr. 20, Heft 2, 2006, S. 231-243, hier S. 233 f..

${ }^{41}$ Vgl. Keohane / Nye, S. 21 ff..
} 
gouvernementalen gelten andere Kooperationsformen - informelle Treffen von Regierungsmitarbeitern, Zusammenarbeit von NGOs, und insbesondere ökonomische Verbindungen - als Konstituenten einer vielschichtigen, komplexen wechselseitigen Abhängigkeit. Hinsichtlich deren Wirkung oder Inhalts ist damit allerdings nichts festgelegt: Nicht nur beiderseitiger Vorteil, sondern auch Nachteile können entstehen, so dass in der Verflechtung unter Umständen sogar Konfliktpotential liegen kann, wie Haas, Keohane und Levy exemplarisch für Zusammenarbeit in umweltpolitischen Bereichen formulieren:

Whether a new world environmental order emerges or not, there is likely to be more international environmental cooperation in future years, and therefore more conflict over its terms. ${ }^{42}$

Überwiegend sind sie jedoch als positiv, weil stabilisierend einzuschätzen, da Unsicherheit und Instabilität um so mehr reduziert werden, je enger die Interessen sich gleichen.

\subsubsection{Keine eindeutige Hierarchie der Themen}

Zum zweiten ist bei komplexer Interdependenz eine klare Hierarchie der Themen nicht länger gegeben. Indem sie auf die wechselseitigen Abhängigkeiten verweisen, in denen sich die Staaten befinden, konstatieren die Autoren:

Many issues arise from what used to be considered domestic policy, and the distinction between domestic and foreign issues becomes blurred. ${ }^{43}$

Hiermit weisen Keohane und Nye, traditionelle Unterscheidungen zwischen „high“ und „low politics“44 revidierend, auf eine erkennbare Neugewichtung der Bedeutsamkeit einzelner Themen für das internationale System hin, da mittlerweile weitaus vielfältigere Themen zur „high politics agenda“ zu zählen sind. Infolgedessen kann die Betrachtung des internationalen Systems allein unter dem Aspekt militärischer und ökonomischer Macht nicht mehr zu brauchbaren Aus- und Vorhersagen führen. ${ }^{45}$ Mit der Neugewichtung einzelner Themenfelder wird im Übrigen ermöglicht, in unterschiedlichen Feldern unterschiedliche Ziele anzustreben, anstatt alle Politik an einem Ziel auszurichten.

\footnotetext{
${ }^{42}$ Haas / Keohane / Levy, S. 425, gleichermaßen Keohane / Nye, S. 7 ff..

${ }^{43}$ Keohane / Nye, S. 21.

${ }^{44}$ Vgl. Holm, Eric: High Politics and European Integration. From EMU to CSFP, London 2000, S. 1 .

${ }^{45}$ Vgl. Keohane / Nye, S. 196.
} 


\subsubsection{Undenkbarkeit des offen ausgetragenen Konflikts}

Schließlich wird als Charakteristikum beschrieben, dass ,,[m]ilitary force is not used by governments toward other governments within the region, or on the issues, when complex interdependence prevails. “46 Die Existenz der Vielzahl von grenzüberschreitenden Kontakten und vielfältiger Themen, durch die Gesellschaften verbunden sind, und das Bewusstsein hierüber begünstigen die Entwicklung zur „Undenkbarkeit“ des Kriegs als Mittel. ${ }^{47}$ Dabei ist davon auszugehen, bei Erfüllung der beiden anderen Kriterien Konflikte gar nicht ein solches Ausmaß erreichen, dass militärische Intervention überhaupt in Erwägung gezogen wird.

\subsubsection{Konsequenzen}

Wenn diese Art von Interdependenz für einen bestimmten geographischen Raum, mit anderen Worten: für ein internationales (Sub-) System, gegeben ist, dann sind Gefahren und Bedrohungen für international erstrebten wirtschaftlichen Wohlstand und Frieden damit zwar nicht als gänzlich überwunden anzusehen, doch sie haben eine andere Qualität: Sie sind weniger auf der Ebene der Staatenwelt zu verorten, sondern haben z.B. gesellschaftliche oder ökologische Ursachen. Die bewusste Zusammenarbeit mit anderen, ja unterschiedlichsten Akteuren, die sich zu ähnlichen Zielen bekennen, sollte den Hauptverantwortlichen umfangreichere Handlungsoptionen bereitstellen und es somit erleichtern, politische Vorhaben in Maßnahmen umzuwandeln. Inwiefern Kooperation im internationalen Rahmen, wie sie für den CBSS gegeben ist, solch einen Prozess und Zustand ursächlich begünstigt hat und $\mathrm{zu}$ verfestigen und $\mathrm{zu}$ verbessern vermag, soll diese Untersuchung erörtern.

Der Einschätzung, Akteure betrachteten einander nicht notwendigerweise als Widersacher im Kampf um Macht, sondern vornehmlich als „Mit-Streiter“ für gemeinsame Interessen auf internationaler Bühne, entspricht das in der politikwissenschaftlichen Literatur modellierte Plussummenspiel, das allen Beteiligten mehr oder weniger Gewinn in Aussicht stellt. ${ }^{48}$ Hierzu bedarf es, wie anhand der Darlegungen in „Power and Interdependence“ deutlich wird, keines

\footnotetext{
${ }^{46}$ Keohane / Nye, S. 26.

${ }^{47}$ So Keohane / Nye, S. 246.

${ }^{48}$ Über die wissenschaftliche Auseinandersetzung dazu gibt einen Überblick u.a. Menzel, Ulrich: Zwischen Idealismus und Realismus. Die Lehre von den Internationalen Beziehungen, Frankfurt a.M. 2001, v.a. S. 113 ff..
} 
Idealismus, der Kooperation als Allheilmittel zur Friedenssicherung und Wohlstandsmaximierung darstellen wollte. Keohane konstatiert, Kooperation werde kaum um ihrer selbst willen gesucht, sondern sei vielmehr Ausdruck der Suche rationaler Akteure nach einer Möglichkeit, ihre Interessen durchzusetzen. ${ }^{49}$ Welche Ziele hierbei Priorität genießen, hängt von der Institution ab, in der die Kooperation im einzelnen ihren Ausdruck findet. Welche politischen Ziele dem CBSS gegeben sind, auf welche Weise er die Aspekte von Zivilisierung zu erreichen verspricht und inwieweit er schließlich dieser Erwartung gerecht wird, ist auf dieser Grundlage zu beantworten.

\subsubsection{Macht}

Keohane und Nye gehen in diesem Werk vornehmlich der Frage nach, von welcher Bedeutung Macht bei komplexer Interdependenz sei. Dabei fassen sie Macht auf als Antwort auf die Frage, wer Regeln und das Geschehen zu bestimmen in der Lage ist, ${ }^{50}$ und liefern eine elementare Differenzierung des Begriffs.

\subsubsection{1 „Hard Power“" und ,Soft Power“6}

Sieht sich ein Akteur in der Lage, entgegen den Zielsetzungen der anderen die von ihm gewünschten Ergebnisse zu erzielen - unter Rückgriff auf entsprechende Ressourcen, wie wirtschaftliche oder militärische Unabhängigkeit oder auch nur glaubwürdige Androhung von Zwang ${ }^{51}$-, ist dies mit „,hard power“ zu benennen. Daneben fassen die Autoren die Möglichkeit ins Auge, mittels Überzeugung oder Anziehungskraft andere Akteure für eigene Ziele zu gewinnen. Mit dieser "soft power” meinen sie „the ability to get desired outcomes because others want what you want" und halten dafür ,,attraction rather than coercion“ für ausschlaggebend. “52

Da sie aufeinander basieren und sich wechselseitig verstärken können ${ }^{53}$, mag im Einzelfall unklar sein, welche der beiden Formen von Macht vorzufinden

\footnotetext{
${ }^{49}$ Keohane (1984), S. 10.

${ }^{50} \mathrm{Vgl}$. Keohane/Nye, S. 13.

${ }^{51}$ Keohane / Nye sprechen von resource power bzw. behavioral power, S. $219 \mathrm{ff}$..

${ }^{52}$ Keohane / Nye, S. 220; wiederholt und hinsichtlich ihrer unterschiedlichen Aspekte geht Nye auf diese Form von Macht ein in: Soft Power. The Means to Success in World Politics“, New York 2004, behält darin allerdings im wesentlichen die gleichen Einschätzungen bei wie in „Power and Interdependence" präsentiert.

${ }^{53}$ Vgl. Keohane / Nye, S. 222.
} 
ist; nichtsdestotrotz ist diese Herangehensweise hilfreich in der Untersuchung der Einflussmöglichkeiten einer IO: Die Autoren identifizieren eine Schwäche politischer Verhandlungsprozesse, in denen Machtpotential in Ergebnisse übersetzt werde. Ein Teil der notwendigen Informationen drohe stets verfälscht übermittelt zu werden, ,,and a lot is often lost in the translation““54.

Vor diesem Hintergrund lässt sich die Rolle von IOs einschätzen: Als Übersetzer und Vermittler zwischen einzelnen Standpunkten und als Norm-Stifter können sie umso gefragter und einflussreicher sein, je größer ihre Akzeptanz unter den federführenden Protagonisten ist. Welche Handlungsspielräume ihnen im Einzelnen zur Verfügung stehen, wird im folgenden Abschnitt näher erläutert.

\subsection{Einflussmöglichkeiten von IOs}

Die in der einschlägigen Literatur erörterten Einflussmöglichkeiten von IGOs sind zahlreich und können unterschiedlich kategorisiert werden. Vor dem Hintergrund der Aussage ,[i]nstitutions do not need enforcement powers to succeed“55 ist der Ostseerat zu bewerten, der im Gegensatz zur EU über kein legislatives oder exekutives Mandat gegenüber seinen Mitgliedern verfügt. Gesetzgebende Maßnahmen sind bei dieser Analyse nicht zu beachten; für diese Arbeit sind demzufolge andere Handlungsoptionen in den Blick zu nehmen.

\subsubsection{Phasen der Einflussnahme}

Ihren Einfluss vermögen IGOs in verschiedenen Phasen des politischen Prozesses zu entfalten, die analytisch zu differenzieren sind, sich zeitlich jedoch durchaus überschneiden können, ${ }^{56}$ weshalb eine entsprechend gegliederte Untersuchung als nicht sinnvoll erscheint. Zum einen ist dies die Phase des Agenda-Setting, in der Probleme identifiziert, bewertet und auf die gemeinsame Tagesordnung gesetzt werden. Ganze Themenfelder, denen zuvor keine Aufmerksamkeit geschenkt wurde, können somit ggf. erschlossen werden. Die zweite Phase ist der Prozess der Formulierung politischer Antworten auf die

\footnotetext{
${ }^{54}$ Keohane / Nye, S. 10.

${ }^{55}$ Haas, Peter M. / Keohane, Robert O. / Levy, Marc A.: Institutions for the Earth. Sources of Effective International Environmental Protection, Cambridge u.a., 1993, S. 24

${ }^{56}$ In dieser Form erläutert von Haas / Keohane / Levy, S. 11 ff..
} 
entsprechenden Probleme, in der versucht wird, Maßnahmen international aufeinander abzustimmen und zu koordinieren. Exemplarisch ist dies zu erkennen in den Versuchen, den weltweiten Ausstoß an $\mathrm{CO}_{2}$-Emissionen durch nationale Kontingentierungen $\mathrm{zu}$ regulieren, da - nicht vorhandene oder möglicherweise kontraproduktive - Strategien einzelner Staaten als nicht ausreichend eingeschätzt werden und daher durch übergreifende Programme zu ersetzen seien. ${ }^{57}$ Schließlich ist die Umsetzung der Maßnahmen in den Blick zu nehmen, die (in Abwesenheit einer supranationalen Exekutive) auf nationaler Ebene geschieht und dort juristisch und administrativ zu bewerkstelligen ist.

\subsubsection{Möglichkeiten des Beitrags zur Zivilisierung}

Da dem CBSS, der als die Summe seiner Mitglieder auftritt, keine Möglichkeiten zur Verfügung stehen, eigene Vorhaben gegen den Willen oder die Interessen seiner Mitglieder durchzusetzen, ist er auf Überzeugungsarbeit und die Attraktivität seiner Vorhaben für alle angewiesen. Solche „soft power“ dauerhaft überhaupt erlangen, dann aber auch ausspielen und behaupten zu können, ist von verschiedenen Faktoren abhängig.

\subsubsection{Geographische Ausdehnung und Mitgliederzahl}

Eine IO intergouvernementaler Natur, die sich als Meinungsforum versteht und über keinerlei Kompetenz-Kompetenz verfügt, kann - wie Pevehouse aufzeigt - ihren Einfluss in Form von „soft power“ aus der Größe des Einzugsbereichs und der Mitgliederzahl schöpfen; ${ }^{58}$ es ist davon auszugehen, eine verhältnismäßig kleine Mitgliederzahl begünstige die Intensität der Zusammenarbeit:

Because regional IOs tend to operate with small numbers and with higher levels of interaction than global organizations, processes such as political conditionality with monitoring and enforcement are much more likely in regional organizations. ${ }^{59}$

Dies ist vornehmlich deshalb von Interesse, da die EU mit ihrer Politik der „Nördlichen Dimension“ selbst eine Politik speziell für diesen Raum verfolgt.

\footnotetext{
${ }^{57}$ Vgl. z.B. Mangels-Voegt, Birgit: „Erneuerbare Energien - Erfolgsgaranten einer nachhaltigen Politik?“, in: Bundeszentrale für Politische Bildung (Hg.): Aus Politik und Zeitgeschichte, B37/2004, S. 12-17.

${ }^{58}$ Vgl. Pevehouse, Jon C.: "With a Little Help from my friends? Regional Organizations and the Consolidation of Democracy", in: American Journal of Political Science, Nr. 46, Heft 3, 2002, S. 611-626, hier S. 617.

${ }^{59}$ Pevehouse, S. 117.
} 
Damit orientiert sie sich an ähnlichen Zielen wie der CBSS und umfasst auch dessen Einzugsbereich, kann jedoch, da sie sich selbst über einen wesentlich größeren Raum erstreckt, nicht ihre volle Aufmerksamkeit auf diese Region richten. Die damit verbundenen Finanzhilfen auch Nicht-EU-Mitgliedern zur Verfügung zu stellen, setzt eine Zustimmung aller EU-Mitglieder voraus, kann jedoch durchaus auf Ablehnung stoßen bei Staaten, die hiervon nicht unmittelbar profitieren.

In der relativ kleinen Ostseeregion ist aber die Nähe zwischen den Staaten in mehrfacher Hinsicht größer und eine direkte Verbindung aller mit allen erkennbar, und Unterschiede zwischen Einzugsbereich und Wirkungsraum sind für den CBSS weitaus weniger von Bedeutung, was ihm zum Vorteil gegenüber der EU gereichen dürfte.

Ergänzend sei auf die Einschätzung von Pevehouse verwiesen, dass die Kosten für gemeinsame, langfristig orientierte politische Maßnahmen unter Verzicht auf kurzfristige Gewinne besonders dann gut getragen werden können, wenn der gemeinsame bzw. durchschnittliche Wohlstand der Mitglieder besonders hoch ist. ${ }^{60}$ Für den Einzugsbereich des CBSS wird dies sicherlich zu konstatieren sein, denn wenn auch die wirtschaftliche Kluft zwischen den Transformationsstaaten und den etablierten westlichen Wohlfahrtsstaaten und der EG bzw. EU beträchtlich war und ist, so zählten und zählen diese insgesamt doch zu den bestbegüterten weltweit.

\subsubsection{Bekanntheitsgrad in der Öffentlichkeit}

In dieser „Selbstreferenz“ der Arbeit des CBSS dürfte für die Mitglieder die Attraktivität liegen, sich aktiv $\mathrm{zu}$ beteiligen und ihr damit Zugkraft $\mathrm{zu}$ verleihen. Zwei Tendenzen halte ich für möglich: Werbung außerhalb der eigenen Organisationsstrukturen durch eine bewusste Promotion der zugrundeliegenden Ideen und Prinzipien sowie durch eine gezielte Präsentation eigener Erfolgsmeldungen könnte Interesse wecken und zu positiven Rückmeldungen in Medien und Politik führen. Dies ließe sich gegenüber den Mitgliedern wiederum in eigener Sache in die Waagschale werfen.

Im Gegenzug ist jedoch auch vorstellbar, dass gerade ein geringer Bekanntheitsgrad dazu beiträgt, dass der auf dieser Bühne stattfindende

\footnotetext{
${ }^{60}$ Vgl. Pevehouse, S. 616.
} 
Meinungsaustausch vertrauensvoll gehandhabt wird und die Arbeit sachorientiert und langfristig ausgeführt werden kann. Ist die Arbeit nicht ständiger Kritik und öffentlicher Aufmerksamkeit ausgesetzt, werden die Ausführenden nicht zu egozentrischer Selbstbeweihräucherung und kurzfristiger Profilierungssucht verleitet, Erscheinungen, die konzeptioneller Arbeit abträglich wären.

\subsubsection{Form der Administration}

Es ist auf die Überlegung einzugehen, inwieweit der Erfolg einer Organisation von der Größe ihres bürokratischen Unterbaus bzw. von der Art ihrer Entscheidungsfindungsprozesse abhängig ist. In „Institutions for the Earth“ erläutern die Autoren, aus den darin vorgelegten Untersuchungen schlussfolgernd, das Vorteilhafte eines kleinen organisatorischen Unterbaus und einer konsensualen Beschlussfassung unter rotierendem Vorsitz: Bei überschaubarer eigener Organisationsstruktur gelinge es in der Regel besser als bei einem großen Verwaltungsapparat, sich auf die inhaltlichen Ziele zu konzentrieren und Zeit und Geld in die anvisierten Maßnahmen statt in die Selbstorganisation zu investieren. ${ }^{61}$ Mit der Vorgabe, Beschlüsse im Konsens zu fassen und jedem Mitglied zuzugestehen, jederzeit eigene Vorschläge für die Agenda zu unterbreiten, werde die Wahrscheinlichkeit erhöht, auch den Interessen kleiner, schwacher Staaten ein Forum zu bieten. Von der Festlegung, die Präsidentschaft turnusgemäß und reihum wechseln zu lassen, könnten insbesondere junge Staaten ohne eigene internationale Lobby profitieren, da - ohne sich in Bewerbungen dafür aufreiben zu müssen - der Vorsitz ihr Selbstbewusstsein stärken dürfte. ${ }^{62}$

In der einvernehmlichen Beschlussfassung liegt jedoch ein weiteres anzunehmendes Plus des CBSS gegenüber der EU, da Russland in dieser Regionalorganisation als gleichberechtigter Partner behandelt wird, statt sich Bedingungen der Zusammenarbeit von der EU diktieren lassen zu müssen.

\subsubsection{Umgang mit und Bereitstellung von Informationen}

Konkret ist zu erwarten, dass IGOs, sofern ihre Regeln und Prozeduren von den in ihnen mitwirkenden Regierungen anerkannt und eingehalten werden, über umfangreichere Informationen als die Mitglieder im einzelnen und hiermit über

${ }^{61}$ Vgl. Haas / Keohane / Levy, S. 409.

${ }^{62}$ Vgl. Haas / Keohane / Levy, S. 400. 
ein Plus verfügen, das sie eigenständig einsetzen können. ${ }^{63}$ Das Mehr an Informationen kann dadurch zustande kommen, dass in partnerschaftlicher Atmosphäre einzelne Standpunkte ausgetauscht werden, wodurch sich neue Einsichten eröffnen. Hingegen könnten Zusammenkünfte von nur einigen der möglichen Partner von den jeweils anderen als Ausschluss empfunden werden und $\mathrm{zu}$ Protesthaltungen führen mit der Folge, wiederum Informationen zurückzuhalten. Hier sei gedacht an die Möglichkeit der EU-Mitglieder unter den Ostseeanrainern, sich in regionalen Belangen - unter Ausschluss des Nicht-EUMitglieds Russland - aufeinander abzustimmen, was von Russland als bewusste Ausgrenzung empfunden werden könnte. Darüber hinaus könnte die enge Verzahnung von CBSS und EU von Russland ein Grund sein, diese Regionalorganisation als Arm der Union zu betrachten und sich dementsprechend einer vollen Partizipation verweigern.

Die Möglichkeit, Information und Expertenwissen bereitzustellen, ist von unterschiedlicher Bedeutung: Derartige Initiativen können der politischen Bildung in sich neu findenden Gesellschaften, der Stärkung zivilgesellschaftlicher Institutionen oder auch der Stärkung länderübergreifenden Zusammengehörigkeitsgefühls gelten. Sie dienen jedoch auch einem technokratischen Ziel, worauf in „Institutions for the Earth“ verwiesen wird: Organisationen engagierten sich um der Vergrößerung politischer und administrativer Kapazitäten der begünstigten Staaten willen. ${ }^{64}$

IOs, insbesondere unter Beteiligung von Regierungen, wird in der Literatur gemeinhin die Funktion zugeschrieben, Informationen zu bündeln, aufzubereiten und weiterzugeben, die ohne diesen Vermittler nicht allen Beteiligten gleichermaßen und zu gleichen Bedingungen zur Verfügung stünden. Keohane und Nye halten fest, dass ,[i]nformation does not just exist; it is created“65 Organisatorische Strukturen, die insbesondere auf Informationsbeschaffung ausgerichtet sind, indem z.B. eigens Expertisen eingeholt werden, sind als begünstigend einzuschätzen, da hier eigene Informationen ermittelt werden können. ${ }^{66}$ Dies gilt, beispielhaft, für ökologische Probleme, derer sich einzelne Staaten aufgrund gefürchteter kurzfristiger Kosten u.U. nicht annehmen würden;

\footnotetext{
${ }^{63}$ Keohane (1984), S. 257.

${ }^{64}$ Vgl. Haas / Keohane / Levy, S. 23.

${ }^{65}$ Keohane / Nye, S. 219.

${ }^{66}$ Vgl. Boehmer u.a., S. 12, auch Haas / Keohane / Levy, S. 21.
} 
es ist anzunehmen, dass eine IO ohne Eigeninteresse in dieser Sache solche Punkte auf die gemeinschaftliche Tagesordnung setzen, überparteilich gemeinsame Präferenzen, Vorbehalte und Nutzen ausloten und vermittelnd $\mathrm{zu}$ einer Problemlösung beitragen kann.

Somit vermag eine IGO als Akteur, der sich aus souveränen Staaten zusammensetzt und doch ein hohes Maß an Unabhängigkeit hat, Problematiken in das Bewusstsein der Beteiligten zu rücken und auf die internationale Agenda zu setzen. Aus dieser Position heraus kann sie zugunsten grenzübergreifenden Problembewusstseins darüber hinaus gezielt Akteure ansprechen, die ihrerseits auf die Hauptakteure Einfluss haben - innerstaatliche oppositionelle oder andere zivilgesellschaftliche Gruppierungen -, was zur Schaffung einer grenzübergreifenden Öffentlichkeit und der Verflechtung von Gesellschaften beitragen und daher begünstigen kann, dass kooperationsunwillige Regierungen sich aufgrund innerstaatlichen Drucks für einen Kurswechsel entscheiden. ${ }^{67} \mathrm{Im}$ Gegenzug dürfte es für subnationale Akteure, bspw. die deutschen Länder, erheblich einfacher sein, sich über den CBSS in das Geschehen in der Ostseeregion einzubringen als über die die EU, der der Kontakt ein unmittelbarer ist.

Vor dem Hintergrund, dass Unsicherheit als eine treibende Kraft im internationalen System zu verstehen ist, auf die Staaten möglicherweise mit konfliktverschärfenden Strategien reagieren, gewinnt die Rolle des InformationsVermittlers besonders an Bedeutung. ${ }^{68}$ Es ist daher $\mathrm{zu}$ erwarten, dass der zwischenstaatliche Charakter dem CBSS in seiner Arbeit zugute kommt:

Indeed, intergovernmental organizations can be expected to be more effective as catalysts for transnational networks of nongovernmental organizations and transgovernmental linkages among sympathetic governmental bureaucracies, than as independent actors. [...] To be effective, [IOs] must create networks over, around, and within states that generate the means and the incentives for effective cooperation among those states. ${ }^{69}$

\subsubsection{Erzeugung personeller Bindungen}

Das Ziel, kooperativ an Herausforderungen heranzugehen und politische Maßnahmen aufeinander abzustimmen, erfordert ein ernsthaftes Bekenntnis der

\footnotetext{
${ }^{67}$ Vgl. Haas / Keohane / Levy, S. 21.

${ }^{68}$ Vgl. Boehmer u.a., S. 12.

${ }^{69}$ Haas / Keohane / Levy, S. 24.
} 
Beteiligten zum Einhalten von Abmachungen und zu konstruktiver Mitwirkung. Unter dieser Voraussetzung hätte der Aphorismus „Das Ganze ist mehr als die Summe seiner Teile“ Aussagekraft. Der Beitrag einer IO kann - ausgehend von der intergouvernementalen Ebene - darin liegen, Anreize für Gruppen oder Individuen $\mathrm{zu}$ bieten, die ein Bekenntnis zur Zusammenarbeit erleichtern und somit vertiefen können. ${ }^{70}$ Finanzielle Mittel können solche Anreize darstellen ${ }^{71}$ im Fall des CBSS zwar nicht aus eigenen Ressourcen, auf Beschluss der Mitglieder aber in seinem Namen. Auch ein Wissenstransfer durch Entsendung von Personal - von besonderer Bedeutung für den umsichtigen Aufbau administrativer Strukturen in Transformationsstaaten - oder die Einbindung in wissenschaftliche oder gesellschaftliche Partnerschafts- und Austauschprogramme können der Intention folgen, Animositäten und Skepsis abzubauen und den Willen zur Kooperation zu untermauern. ${ }^{72}$

Darüber hinaus sollte insbesondere vom Sekretariat einer IO, sofern es keine Partikularinteressen vertritt, mittels gezielter umfangreicher und unverfälschter Informationsvermittlung die Bereitschaft der Beteiligten zur Kooperation verstärkt werden können. Es ist in diesem Zusammenhang in Erwägung zu ziehen, dass die Nordische Kooperation aufgrund bewährter Zusammenarbeit im Lauf der Zeit bereits eine solche Bindungswirkung hat entfalten können, gegenüber der der CBSS zurückstehen könnte, und es ist außerdem zu bezweifeln, dass die Bindungswirkung in Bezug auf Politiker in Deutschland, Russland und eventuell auch Polen als erfolgreich einzustufen ist. Diese Überlegung rührt daher, dass zumindest die beiden erstgenannten aufgrund ihrer Geographie nicht hautsächlich als Ostseestaaten gelten können. Ihren Ausdruck finden solcherart gefestigte Strukturen darin, dass ihre räumliche Ausdehnung auf einen definierbaren Bereich, eine Region, konzentriert ist.

\subsubsection{Wahrnehmung von Monitoring-Aufgaben}

Des weiteren kann eine IGO durch beobachtende und überwachende Begleitung des Geschehens, durch sog. Monitoring, in ihrem Einzugsbereich eine Kontrollfunktion ausüben, mittels derer sie, der Gemeinschaft ihrer Mitglieder verpflichtet, „Betrugsversuche“ einzelner gegenüber den Vertragspartnern

\footnotetext{
${ }^{70}$ Vgl. Haas / Keohane / Levy, S. 7.

${ }^{71}$ Vgl. Haas / Keohane / Levy, S. 405.

${ }^{72}$ Vgl. Pevehouse, S. 615.
} 
aufzudecken und somit deren Glaubwürdigkeit zu überprüfen hat. „Wherever states have reason to fear the consequences of being cheated, monitoring can help reassure them that such cheating will be detected in time to make appropriate adjustments", konstatieren Haas, Keohane und Levy in "Institutions for the Earth". ${ }^{73}$ Es ist zudem auf eine zweite Bedeutung des Monitoring hinzuweisen: Hierdurch gewonnene Erkenntnisse ermöglichen der Organisation, Erfolgs- oder Misserfolgsmeldungen hinsichtlich des Erreichens eigener Ziele auszuarbeiten.

In Ermangelung der Kapazitäten, die Umsetzung der beschlossenen Maßnahmen selbst durchzuführen oder auch Strafen bei Wortbruch zu verhängen, ist der CBSS in seinen Möglichkeiten stark eingeschränkt, das Erreichen eigener Ziele zu erzwingen. Es obliegt ihm bestenfalls, Unterstützungen für einzelne Projekte zu reduzieren oder geplante Programme, die dem entsprechenden Mitglied hätten zugute kommen sollen, zu streichen ${ }^{74}$, falls dieses willentlich den Abmachungen zuwider handelt.

\subsubsection{Formulierung internationaler Normen}

Eine weitere Funktion ist schließlich zu bedenken, die IGOs zum Ziel der Zivilisierung des internationalen Systems wahrzunehmen in der Lage sein sollten, wie bei Haas, Keohane und Levy dargelegt: Ein elementarer Aspekt der Zivilisierung zielt auf die Formulierung und Etablierung gemeinsamer Normen ab. Solche können einerseits das Verhalten der Akteure untereinander adressieren und dabei dem Ziel dienen, eben diesem Verhalten Berechenbarkeit zugrunde zu legen und die ursprünglich dominierende Unsicherheit hinsichtlich des Kalküls der jeweils anderen zu minimieren. Andererseits können Normen sich auch in der Formulierung neuer politischer Ziele niederschlagen, die erst im Rahmen von zwischenstaatlicher Kooperation erarbeitet werden. Ginge es beispielsweise darum, negative Begleiterscheinungen der wirtschaftlichen Globalisierung ${ }^{75}$ abzufangen, z.B. eine durch Produktionsverlagerung bedingte steigende Arbeitslosigkeit, ließe sich hier eine internationale Abmachung erst formulieren, wenn die Problemlösung als internationale, gemeinschaftliche Aufgabe verstanden wird. Verhaltensmaßstäbe und Normen könnten hier unter anderem darauf

\footnotetext{
${ }^{73}$ Haas / Keohane / Levy, S. 22 f..

${ }^{74}$ Darauf verweisen Haas / Keohane / Levy, S. 21.

${ }^{75}$ Dies bedarf für diese Arbeit keiner näheren Definition, sondern sei im weiten Sinne als weltweit intensivierte wirtschaftliche Verflechtung verstanden.
} 
abzielen, sich untereinander in der Außenwirtschaftspolitik zu begünstigen. Haas, Keohane und Levy betonen diesbezüglich die Möglichkeit von IOs, solche Normen zu formulieren. Verfügten sie auch nicht über die Möglichkeit, bindende Gesetze zu erlassen, sei doch in dieser Funktion der IOs ein wesentlicher Beitrag $\mathrm{zu}$ sehen, das Feld für folgende Verträge $\mathrm{zu}$ ebnen. ${ }^{76}$ Mit zielgerichteter Informationspolitik auf die Gesellschaften der Staaten einzuwirken, um den Normen dort zur Akzeptanz zu verhelfen, ist in diesem Zusammenhang ebenfalls als möglicher Beitrag von IOs in Erwägung zu ziehen. ${ }^{77}$

Die beharrliche Befassung mit bestimmten Themenfeldern ohne supranationale Vorgabe - im CBSS sämtliche, die im Zusammenhang mit „weicher Sicherheit“ gesehen werden, sofern ein multilaterales Interesse ausgemacht wird - dürfte dazu führen, vorbehaltlos deren Dringlichkeit anzuerkennen. Gegenüber der EU, der besonders im „Norden“ erhebliche Skepsis entgegengebracht wird, liegt hierin ein Vorteil des CBSS.

\subsubsection{Umsetzung konkreter Projekte}

Zweifelsohne dient die - finanzielle wie intellektuelle - Investition in einzelne Projekte immer auch dem Erreichen konkreter Ziele. Zur Beantwortung der Frage, inwieweit der CBSS seinen Beitrag zu den politischen Entwicklungen im Ostseeraum geleistet hat und leistet, ist daher ein Blick darauf zu werfen, inwieweit Projekte oder Initiativen von Erfolg gekrönt sind. Die Bedeutung des CBSS - wie jeder anderen IO - als eigenständiger Akteur bemisst sich zudem daran, ob es ihr gelingt, die internationale Tagesordnung zu verändern.

\subsection{3 Überlagerung von CBSS und anderen Organisationen}

Konkret ist im Verlauf der Untersuchung - wie im einzelnen bereits angedeutet - darauf einzugehen, wie sich das Wirken des CBSS im Verhältnis zu dem anderer Organisationen ausnimmt, denen andere Handlungsmöglichkeiten zur Verfügung stehen. Da eine ausgesprochen dichte Verflechtung von CBSS und EU besteht, allerdings keine offizielle Eingliederung der regionalen in die supranationale Organisation gegeben ist, ist der Frage nachzugehen, wie sie sich in ihrer Funktion für das internationale Systeme der Ostseeregion unterscheiden. Am Beispiel der Energiepolitik soll dies später näher beleuchtet werden.

\footnotetext{
${ }^{76}$ Vgl. Haas / Keohane / Levy, S. 412 f..

${ }^{77}$ Vgl. Haas / Keohane / Levy, S. 20.
} 


\section{CBSS-Gründung im Kontext von Kooperation und Spannungen}

Die Gründungsphase des CBSS ist im historischen Kontext zu verorten, denn nur darin werden die Zustände der Zeit deutlich, und zukünftige Optionen sind besser zu erkennen. Auch der Beitrag des CBSS zur Veränderung des Systems kann nur dann angemessen beurteilt werden, wenn die Ausgangslage verdeutlicht ist. Die in der „Kopenhagener Erklärung“, dem Gründungsdokument der Organisation, begrüßte „Wiederbelebung“ enger Zusammenarbeit und die „Stärkung der Verbindungen“ lassen sich vor diesem Hintergrund verstehen. „Gemessen an den Jahrhunderten dieser stets lebendigen Tradition, ist der Kalte Krieg eine lächerliche Episode geblieben“, schreibt Jasper von Altenbockum im Juli 1998 in der Frankfurter Allgemeinen Zeitung, ${ }^{78}$ womit die Wortwahl des CBSS-Dokuments Bestätigung findet.

\subsection{Vorgeschichte}

Obwohl zeitlich hiermit sehr weit ausholend, ist an dieser Stelle unbedingt die mittelalterliche „Hanse“ zu erwähnen, deren Spuren vor allem im Städtebild in der Ostseeregion augenfällig sind. Als für ihre Zeit beispielloser Handelsbund mit politischer und kulturell nachhaltig prägender Dimension ${ }^{79}$ erfährt sie heute anerkennende Erwähnung und wird bisweilen als Vorbild für Zusammenarbeitsformen der Gegenwart angegeben ${ }^{80}$.

In ihrer Geschichtsschreibung des Ostseeraumes verweisen Gerner und Karlsson darauf, dass es Teil der sowjetischen Rhetorik gewesen sei, die Ostsee als ein „Meer des Friedens“ darzustellen. Sie vertreten jedoch glaubhaft die Einschätzung, bis zum Ende des Ost-West-Konflikts sei die Bezeichnung „Meer des Kriegs" weitaus eher zutreffend gewesen. Krieg umfasse auch Spannungen in struktureller, ideologischer und psychologischer Hinsicht, wie es im Ostseeraum eindeutig dominierend gewesen sei, ohne dass offene militärische

\footnotetext{
${ }^{78}$ von Altenbockum, Jasper: „Auf dem Weg zur modernen Hanse - Russlands Annäherung an Europa führt über eine ,Nördliche Dimension““, Frankfurter Allgemeine Zeitung, 7.7.1998, S. 16. ${ }^{79}$ Vgl., stellvertretend für viele, Brockhaus Enzyklopädie, 24 Bde, Mannheim 199019, Bd. 9, S. $469 \mathrm{ff}$. .

${ }^{80}$ Dass sich auch der heutige Städtebund im Ostseeraum diesen Namen gegeben hat, unterstreicht die Vorbildfunktion des frühen Bündnisses, siehe www.hanse.org; außerdem nennt sich eine deutsch-niederländische Grenzregion „Neue Hanse“, siehe www.nhi-online.de.
} 
Auseinandersetzungen als ausschlaggebendes Kriterium für Krieg gesehen werden müssten. ${ }^{81}$

\subsection{Nordische Kooperation}

In jüngerer Zeit, konkret in der zweiten Hälfte des 20. Jahrhunderts, können vor allem die nordischen Länder auf gutnachbarschaftliche Beziehungen verweisen, die sie auch in überregionalen Gremien in die Waagschale werfen. Ein tiefes Zusammengehörigkeitsgefühl, begünstigt durch enge sprachliche Verwandtschaft ${ }^{82}$ und kulturelle Gemeinsamkeiten, ist offiziell in den zwei Organisationen Nordischer Rat (NR) und Nordischer Ministerrat (NMR) institutionalisiert: Ersterer existiert seit 1952 und versteht sich als Zusammenarbeitsorgan der Parlamentarier der beteiligten Länder, ${ }^{83}$ das darauf ausgerichtet ist, „die politische, wirtschaftliche, ökologische, soziale u.a. Entwicklung im Norden und nördlichen Europa voranzutreiben“. ${ }^{84} 1971$ folgten die entsprechenden Regierungen mit der Gründung des Ministerrats, unter dessen Dach die Fachminister ihre Vorhaben und Projekte aufeinander abstimmen, was der parlamentarischen Kontrolle des Nordischen Rats unterliegt. Die Erfolgsgeschichte verweist z.B. auf die Öffnung der Arbeitsmärkte (1982), Passfreiheit zum Reisen in den beteiligten Ländern (1957) oder auf umfangreiche Koordinierung in der Finanzpolitik. Lediglich die Außen- und Sicherheitspolitik wird gänzlich von diesen Gremien ausgeklammert. (Eine Einigung auf eine einheitliche Bündnispolitik war lange Zeit unmöglich ob unterschiedlicher neutralitätspolitischer Grundsätze, und heute noch unterscheiden sich die nordischen Länder in ihrer Mitgliedschaft in IOs. ${ }^{85}$ ) Die nordische Kooperation, durch bürgerschaftliches Engagement und zivilgesellschaftliche Vernetzung gewachsen und vor allem zwischengesellschaftlicher Natur, ${ }^{86}$ stellt für den

\footnotetext{
${ }^{81}$ Vgl. Gerner, Kristian / Karlsson, Klas-Göran: Nordens Medelhav: östersjöområdet som historia, myt och projekt, Stockholm 2002, S. 246.

${ }^{82}$ Obwohl die finnische Sprache zu einem gänzlich anderen Zweig gehört als die indogermanischen, kann es auch in linguistischer Hinsicht zu diesem Raum gehörig gelten, da Schwedisch offizielle Landessprache ist und von einem kleinen Teil der Bevölkerung sogar als Muttersprache gelernt wird.

${ }^{83}$ Dänemark, Schweden, Norwegen, Island und Finnland sowie die unter Selbstverwaltung stehenden Regionen Färöer, Áland und Grönland.

${ }^{84} \mathrm{Vgl}$. Homepage www.norden.org, in meiner Übersetzung.

${ }^{85}$ Schweden und Finnland sind nicht Mitglied der NATO; Norwegen und Island gehören zwar nicht der EU, jedoch dem EWR an und sind somit eng mit der EU verbunden.

${ }^{86}$ Vgl. Schymik, Carsten: „Nordische Sonderwege nach Europa“, in: Aus Politik und

Zeitgeschichte, Nr. 47, 2004, S. 10-15, hier S. 10.
} 
Ostseeraum ein politisches Gewicht dar, dessen Reputation der des CBSS weit voraus ist.

Schon im Jahr 1991 wurden seitens der nordischen Kooperation zu den Ländern des Baltikum - noch vor deren Selbständigkeit - offizielle Kontakte aufgenommen, indem ihnen Beobachterstatus erteilt wurde, was durch die Öffnung von Büros der Räte in Estland, Lettland und Litauen und zahlreiche gemeinsame Aktivitäten in und mit den Ländern in der Folgezeit unterstrichen und ausgeweitet wurde. ${ }^{87}$ Illustriert wird die Intensivierung der Einbindung der baltischen Länder in die nordische Kooperation z.B. durch deren Aufnahme in die „Nordic Investmentbank“ im Jahr 2005, die als Ausdruck einer zumindest wirtschaftlich starken Verbindung der acht Staaten untereinander zu sehen ist. Der „Norden“ verstehe sich zwar als Teil der Ostseeregion und sehe sich in der Verantwortung für die Entwicklung dieser im Ganzen, doch folge er der Maxime, seine Aktivitäten komplementär zu denen des CBSS und in enger Abstimmung mit dieser Organisation zu gestalten, so Per Unckel, Generalsekretär des NMR. ${ }^{88}$

\subsection{KSZE / OSZE}

Besondere Aufmerksamkeit zollt die politikwissenschaftliche Literatur den Entwicklungen im Umfeld der Konferenz für Sicherheit und Zusammenarbeit in Europa (KSZE) und der daraus hervorgegangenen Organisation (OSZE), deren langjährige Arbeit, besiegelt mit der Unterzeichnung der Schlussakte unter maßgeblicher Vermittlung der nordischen Staaten 1975 in Helsinki, überwiegend in positivem Licht gesehen wird. ${ }^{89} \mathrm{Zu}$ einem gewichtigen Teil wurde damit das internationale System im Ostseeraum und darüber hinaus schon während des Kalten Krieges von der OSZE adressiert und zu zivilisieren versucht. Dass diese Organisation, die sich mit Nachdruck in zivilgesellschaftlichen Bereichen engagiert, als einflussreich und für das internationale System auch im Ostseeraum von prägendem Wert eingestuft wird, unterstreicht die Bedeutung, die den gemeinhin als „low politics“ titulierten Themenfeldern in Europa mittlerweile beigemessen wird. Thematisch lassen sich viele Parallelen zwischen den Agenden

\footnotetext{
${ }^{87}$ Siehe Informationen zur internationalen Zusammenarbeit des „Norden“ auf dessen Website, URL: http://www.norden.org/internationellt/sk/baltikum.asp?lang=1\&p_id=677, 3.3.2007.

${ }^{88}$ Vgl. Interview mit Per Unckel, Generalsekretär des NMR, im Mitteilungsblatt des CBSS, Baltinfo, Nr. 72, Mai 2005, S. 1 ff..

${ }^{89}$ Formulierungen allgemeiner Lexika verdeutlichen die allseits positive Bewertung; siehe z.B. Brockhaus Enzyklopädie, 24 Bde, Mannheim 1990 ${ }^{19}$, Bd. 12, S. 244 f..
} 
der OSZE und des CBSS ausmachen, und dementsprechend bezieht sich das Gründungsabkommen des Ostseerats hinsichtlich der eigenen Handlungsprinzipien expressis verbis v.a. auf OSZE-Dokumente..$^{90}$

\subsection{Ostseeparlamentarierkonferenz}

Erwähnung finden soll an dieser Stelle zudem die OstseeParlamentarierkonferenz, in der seit Januar 1991 jährlich Delegierte der nationalen und regionalen Parlamente der Ostseeregion zum Meinungs- und Informationsaustausch zusammenfinden. Die Institution der Parlamentarier ist somit älter als die der intergouvernementalen Organisation der Anrainerstaaten und genießt im CBSS den Status eines ,special participant“, womit seit Ende der '90er Jahre eine kontinuierliche Einbindung und regelmäßige aktive Teilnahme an den CBSS-Sitzungen (auf Ebene des Ausschusses hoher Beamter) verbunden ist. ${ }^{91}$

\subsection{Russland, die baltischen Staaten und Polen}

Des weiteren spielt für die jüngste Geschichte vor der Gründung des CBSS das Verhältnis derer eine entscheidende Rolle, die sich aus der Sowjetunion in die Souveränität verabschiedet hatten: In vielerlei Hinsicht scheint die Orientierung der baltischen Staaten an westlichen Standards unmissverständlich gewesen $\mathrm{zu}$ sein, und „mindestens ebenso wichtig war, eine entsprechende NichtZugehörigkeit zu Moskau, zum Sowjetstaat und dessen dominierender russischorthodoxer Kultur zu unterstreichen.“ “92 Erstrebt zu einem erheblichen Anteil „,von unten“ - die polnische Solidarnosc in den '80ern und „Volksfronten“ in den Ländern des Baltikum zu Beginn der '90er -, konnten gesellschaftliche Tatsachen geschaffen werden, die unter den meisten Beteiligten weitgehend auf Akzeptanz stießen. Sowohl seitens der Regierungen als auch der Bevölkerungen wurde die Neuordnung nicht grundsätzlich in Frage gestellt. ${ }^{93}$

Auch auf russischer Seite wurde seinerzeit in dieser Region eine Hinwendung zum Westen erkennbar: Die Rückbenennung der Küstenstadt Leningrad in das ursprüngliche Petersburg wurde 1991 in einer Volksabstimmung be-

\footnotetext{
${ }^{90}$ Siehe Copenhagen Declaration, Einleitung, 5./6. März 1992.

${ }^{91}$ Neben der Parlamentarierkonferenz wurde u.a. der OECD dieser Status erteilt; siehe Website des CBSS, URL: http://www.cbss.st/specialparticipants/specialparticipants/, 3.3.2007.

${ }^{92}$ Gerner / Karlsson, S. 23.

${ }^{93}$ Vgl. Gerner / Karlsson, S. 256.
} 
schlossen. ${ }^{94}$ Dies dürfte als Ausdruck des Wunsches verstanden werden, an die Glanzzeit der Stadt anzuknüpfen, in der sie russische Hauptstadt und „Fenster nach Europa" war.

\subsection{Vom Fall des Eisernen Vorhangs bis zur Gründung des CBSS}

Der Fall des Eisernen Vorhangs führte zu erheblichen politischen Neuordnungen, in denen die staatlichen Emanzipationsprozesse an der Ostküste des Mare Baltikum eine positive Entwicklung nahmen: Es gelang ein friedlicher Wandel der neu konstituierten Staaten auf dem Weg zu westeuropäischen Standards trotz anfänglicher Drohgebärden aus Moskau. Dabei kann von einer dreifach erforderlichen Systemtransformation gesprochen werden: politisch hin $\mathrm{zu}$ liberaler Demokratie und Rechtsstaatlichkeit, wirtschaftlich hin zu Marktwirtschaft und Privateigentum sowie staatlich hin zum Nationalstaat. ${ }^{95}$ Darin orientierte man sich von Beginn an unmissverständlich an dem Ziel, westlichen Organisationen beitreten zu können, einhergehend mit bewusst gewählter Distanz zu den ehedem dominierenden umfangreichen Abhängigkeiten von Moskau. Die konkrete Ausgestaltung blieb damit zwar noch offen, doch eine grundsätzliche Bereitschaft zur Kooperation im einen oder anderen Rahmen war damit offengelegt.

Begleitet wurden diese Veränderungen in den baltischen Staaten sowie in Polen von Beginn an von einem Wandel in der prägenden Ideologie, der sich in Ablehnung des Kommunismus und Hinwendung zum kapitalistischen Wirtschaftssystem zeigte, was in den Bevölkerungen grundsätzlich bereitwillig aufgenommen wurde. ${ }^{96}$ Verlockungen des Wohlstands dürften einen erheblich Anteil an dieser neuen Ausrichtung gehabt, und wirtschaftliche Anreize der westlichen Staaten werden manch humanistisches Argument für Kooperation übertrumpft haben. ${ }^{97}$ Es zeigt sich in dieser Region gewissermaßen exemplarisch der Zusammenbruch des kommunistischen gegenüber dem kapitalistischen Wirtschaftssystem, das es fortan unter Berücksichtigung der Bedürfnisse der Bevölkerung zu gestalten galt. Auch Expansionsdrang des Raums freier Marktwirtschaft zur Erschließung neuer Märkte ist als Motivation für Initiativen aus dem

\footnotetext{
${ }^{94}$ Vgl. Gerner / Karlsson, S. 209

${ }^{95}$ Vgl. Schimmelpfenning, Frank: „Starke Anreize, ambivalente Wirkungen: Die Europäisierung Mittel- und Osteuropas“, in: Buchstein, Hubertus u.a. (Hg.): Leviathan. Berliner Zeitschrift für Sozialwissenschaft, Bd. 2, Berlin 2004, S. 250-268, hier S. 252.

${ }^{96}$ Vgl. Gerner / Karlsson, S. 256.

${ }^{97}$ Vgl. Krohn, Axel: Eine neue Sicherheitspolitik für den Ostseeraum. Perspektiven regionaler Rüstungskontrolle und Zusammenarbeit, Opladen 1993, S. 12.
} 
Westen nicht zu verkennen. Nun galt es, Grundlagen für Investitionen zu schaffen, Modernisierungen einzuleiten und Anpassungen an westeuropäische Normen durchzuführen. Damit sollte ein Aufschwung angestoßen und begleitet werden, der nicht nur im Inneren wirken, sondern auch zu einem Abbau der selbst heute noch erkennbaren Disparitäten beitragen soll.

Trotz euphorischer Gesellschaftsdebatten $\mathrm{zu}$ Fragen nationaler Selbstbestimmung oder Einführung der Marktwirtschaft sei, wie von Gerner und Karlsson erläutert, zahlreichen elementaren Herausforderungen nicht genügend Aufmerksamkeit gewidmet worden. „Fragen dazu, wie ein Rechtsstaat aus der sowjetischen Rechtlosigkeit [und] wie eine Bürgergesellschaft aus einer Sowjetgesellschaft, die von Mangel an Vertrauen in zwischenmenschliche Beziehungen und in nicht offiziell kommunistische Netzwerke geprägt worden war, [...] erlangten keine unmittelbare Aktualität.“98

\subsection{Militärische Bündnispolitik}

Mit der Debatte um den NATO-Beitritt der ehemaligen Warschauer PaktMitglieder unter den Ostsee-Anrainerstaaten stand in den '90er Jahren ein Thema der „hard security“ auf der politischen Agenda, das große Aufmerksamkeit in Wissenschaft und Öffentlichkeit fand. ${ }^{99}$ Vor allem in dieser Frage nach militärischer Bündniszugehörigkeit und Optionen in der Verteidigungspolitik hatte „hard security“ nach wie vor einen exponierten Stellenwert auf der europäischen politischen Agenda. Auch die wissenschaftliche Diskussion der Sicherheitspolitik im Ostseeraum der '90er Jahre spiegelt das Gewicht dieser Diskussionen wieder. Einen maßgeblichen Einfluss der USA auf den Ostseeraum verdeutlicht der Prozess der zweiten NATO-Erweiterung, die 2002 beschlossen wurde und mit der die baltischen Staaten dem Bündnis beitraten ${ }^{100}$, was naturgemäß in erster Linie „klassischen“ Sicherheitskonzepten entsprach. Militärische Bündnispolitik und strategisches Kalkül der Großmächte - bzw. Russland als Relikt der sowjetischen Großmachtzeit - ist bis heute relevant und wird von einem beträchtlichen Teil der wissenschaftlichen Literatur auch für den Ostseeraum nach wie vor thematisiert. Ohne allerdings tatsächlich einen kausalen Zusammenhang zwischen zunehmender

\footnotetext{
${ }^{98}$ Gerner / Karlsson, S. 261.

${ }^{99}$ Diesen Eindruck bestätigt Vitkus, Gediminas: Changing Security Regime in the Baltic Sea Region, Vilnius 2002, S. 21.

${ }^{100}$ Vgl. Hubel, Helmut: „The Baltic Sea Subregion after dual Enlargement“, in: Cooperation and Conflict, Nr. 39 (3), 2004, S. 283-298, hier S. 285 f..
} 
Bedeutung zivilgesellschaftlicher Verflechtung und Bedeutungsverlust von „hard security“-Themen zu untersuchen, werden zwar beide Phänomene wahrgenommen, letzteres aber im Grunde isoliert analysiert. ${ }^{101}$

Auch die im Lauf der Jahre steigende EU-Präsenz im Ostseeraum kann nicht gänzlich losgelöst von militärischen Fragen begriffen werden, das einer ihrer Arbeitsbereiche die Europäische Sicherheits- und Verteidigungspolitik umfasst. Allerdings sollte dieses Themenspektrum gänzlich außerhalb der Reichweite des CBSS verbleiben, so dass eine unmittelbare Einwirkung auf klassische Sicherheitsbelange von dieser Organisation nicht zu erwarten ist.

\subsection{Zwischenbetrachtung}

Während also auf westlicher Seite der Ostsee, insbesondere im „Norden“, die politische und gesellschaftliche Verflechtung bereits eine verhältnismäßig hohe Dichte erreicht hatte und man sich auf eine eindeutige Tradition in kooperativer Politikgestaltung berufen konnte, fand man zur Gründungszeit des CBSS am östlichen Ufer diesbezüglich weitgehend Brachland vor. Die Staatengründung war abgeschlossen, doch im Innern wie gegenüber dem Umfeld waren die Strukturen noch nicht gefestigt. Um diesem Wandel Impulse zu geben und Kräfte freizusetzen, aber auch eine politische Ordnung zu gewährleisten, gründeten die Außenminister den CBSS. ${ }^{102}$

Themen der ,hard security“ wurde allenthalben weiterhin große Aufmerksamkeit beigemessen, während andere Problemfelder nunmehr ebenfalls als dringend wahrgenommen wurden: u.a. die Frage des staatlichen Schutzes der Rechte von Minderheiten, die Neugestaltung des Rechts- und Polizeiwesens der Transformationsstaaten sowie eine untragbare Verbreitung von Krankheiten und Korruption. Die Einschätzungen zur Sicherheit im Ostseeraum waren seinerzeit kontrovers, bisweilen auch komplementär, wie Joenniemi zuspitzend formuliert:

Obviously the security landscape in Northern Europe does not hinge on the substitution of one logic by another, at least not in the short run. It rather reflects a mixture of various departures and a contest between different understandings. ${ }^{103}$

\footnotetext{
${ }^{101}$ Dies bestätigt Vitkus, S. 5 .

${ }^{102}$ Vgl. von Altenbockum, Jasper: „Meer der Möglichkeiten“, in: Frankfurter Allgemeine Zeitung, 4.11.1998, S. 1.

${ }^{103}$ Joenniemi, Pertti: „Security in Northern Europe: The contest between different understandings“, in: Österreichische Zeitschrift für Politikwissenschaft, Nr. 25, Heft 4, 1996, S. 431-441, hier S. 433.
} 
Ein Ansatz für die Hebelwirkung des CBSS, einen zivilisierenden Einfluss auf das System im Ostseeraum zu nehmen, ist auch darin zu sehen, einem neuen Sicherheitsverständnis mit einer geringeren Bedeutung militärischer Themen zur Geltung zu verhelfen.

\section{Der CBSS}

\subsection{Zielsetzung und Handlungsfelder}

Die Zusammenarbeit im CBSS beruht nicht auf einem bindenden Vertrag, sondern auf einer einfachen Abmachung der Außenminister. Einleitend wird in dieser „Kopenhagener Erklärung“ auf Prinzipien verwiesen, die der Zusammenarbeit in dieser Organisation zu Grunde liegen. Zur Verdeutlichung verweisen die Autoren des Textes auf Dokumente anderer Organisationen:

The Ministers viewed this new, emerging cooperation on the basis of the principles laid down in the UN Charter as well as in the Helsinki Final Act, the Charter of Paris and other OSCE documents. ${ }^{104}$

Allerdings werden die entsprechenden Grundsätze weder in diesem noch in anderen CBSS-Dokumenten expressis verbis genannt, sondern es sind explizit nur die darauf basierenden Handlungsfelder ausgewiesen. Es ist von einem Selbstverständnis des CBSS als beratende, Kooperationsmöglichkeiten auslotende Organisation auszugehen, die Probleme kaum als solche benennt, sondern vielmehr Handlungsoptionen aufzeigen will. In erster Linie soll ein Diskussionsforum geboten werden, auf dem während entsprechender Beratungen Gemeinsamkeiten der Teilnehmer auszuloten sind. Dies fasst der Jahresbericht '93/'94 des „Committee of Senior Officials“ in folgende Worte:

The [...]main task is to identify those fields of regional economic cooperation where the CBSS can play a "value-added" role either by mobilizing the necessary political will to foster concrete projects or by contributing to a better utilization of resources by assisting in the coordination of national and regional inputs. ${ }^{105}$

Vor dem Hintergrund des Falls der vormaligen Trennlinie wird eine ausgeweitete und verstärkte Zusammenarbeit im Ostseeraum als „,natürliche und logische Konsequenz" dargestellt; sie führe, so die Erklärung der Außenminister,

\footnotetext{
1041992 CBSS 1st Ministerial Session - Copenhagen Declaration, Einleitung.
}

${ }^{105}$ CSO Annual Report 1993/1994, Abs. 4. 
zu größerer politischer und wirtschaftlicher Stabilität und regionaler Identität. ${ }^{106}$ Die in diesem Dokument skizzierten Aufgabenbereiche künftiger Zusammenarbeit adressieren allesamt Themen, die auch in der Zusammenarbeit durch die OSZE als eminent für Frieden und Sicherheit in Europa aufgefasst werden. Die Programmatik erhält ihr Gewicht dadurch, dass sie das Vorhaben der Zusammenarbeit ausschließlich in einen regionalen Kontext stellt und dabei häufig die Gegenüberstellung von Ost und West an der Ostsee deutlich macht. Geht es beispielsweise um den Bereich „Unterstützung für neue demokratische Institutionen“, weisen die Formulierungen der „Kopenhagener Erklärung“ eine erhebliche Ähnlichkeit mit denen der „Charta von Paris“ auf, beziehen sich jedoch eindeutig auf die Gegebenheiten des Ostseeraums. Auch in den anvisierten Bereichen „Wirtschaftliche und technologische Unterstützung und Zusammenarbeit" und „Humanitäre Angelegenheiten und Gesundheit" sind Disparitäten zwischen den Staaten des ehemaligen Ostblocks einerseits und denen des Westens andererseits angesprochen. Entsprechend heißt es, die CBSS-Mitglieder seien ,prepared to protect, support and develop democratic institutions, especially in the new democracies” und sie seien sich der Notwendigkeit bewusst, „the transition from planned to market economies“ zu unterstützen.

Auch die weiteren Felder der Zusammenarbeit lassen eindeutig eine regionsbezogene Intention erkennen: Die Erläuterungen zu „Umweltschutz und Energie“, „Zusammenarbeit in Kultur, Bildung, Tourismus und Information“, „Transport und Kommunikation“ sowie - schon im Titel - „Zusammenarbeit zwischen Regionen des Ostseeraums“"107 erwähnen die für den Ostseeraum integrative Funktion entsprechender Vorhaben. Die Formulierung „[The Ministers] noted that a shared basis cultural heritage - but with different expressions - binds the countries surrounding the Baltic Sea together" spielt auf die Bedeutung gesellschaftlicher Einflüsse an.

Die in der Kopenhagener Erklärung aufgezeigten Felder der Zusammenarbeit lassen die Absicht erkennen, sich all dem $\mathrm{zu}$ widmen, was nicht militärischer Natur ist. Indem sich dieses Dokument auf die o.g. Verträge stützt, folgt es einer Logik, die Sicherheit im internationalen System auf „harte“ und „weiche“ Faktoren zurückführt und sich der letztgenannten widmet:

\footnotetext{
${ }^{106}$ Siehe „Copenhagen Declaration“, Einleitung.

${ }^{107}$ Zum Begriff der Region siehe Kap. 3.3, S. 49.
} 
Die Politikfelder zwischenstaatlicher Zusammenarbeit im Rahmen des Ostseerats liegen vor allem im Bereich der sogenannten, weichen Sicherheit' (soft security). [...] Sie gefährden weniger die staatliche Souveränität, als vielmehr die Identität und Wertvorstellungen der jeweiligen Gesellschaft. ${ }^{108}$

Da der Text allerdings den Begriff „Sicherheit“ selbst nicht nennt und ebenso wenig von „Risiken“ oder „Gefahren“, nicht einmal wohlwollend von „Herausforderungen“ spricht, kommt er in einem bemerkenswert optimistischen Duktus daher. Es klingt nach einer Tatsachenfeststellung, wenn es heißt, „the confrontation and division of the past is replaced by partnership and cooperation. An enhanced and strengthened Baltic cooperation is a natural and logical consequence of these events. “109 Indem die Kopenhagener Erklärung Themen der „hard security“ außer Acht lässt, zeichnet sie eine Realität, die den militärischen Aspekt im Ostseeraum eindeutig unerwähnt lässt, obwohl militärische und verteidigungspolitische Fragen seinerzeit eindeutig auf der Tagesordnung standen. Als Beschreibung des status quo muss dies überraschen, da zu Beginn der '90er Jahre der Abzug russischer Truppen aus den baltischen Republiken heiß diskutiert wurde:

Negotiations with Russia over troop withdrawal were difficult, to say the least. The Baltic States were effectively hostages of Russian military units. ${ }^{110}$

Daraus folgernd, ist es als hochgestecktes Ziel des CBSS zu sehen, in seinen Handlungsfeldern konkrete Aktionen erfolgreich durchzuführen und die Politiken seiner Mitglieder zu beeinflussen und sogar ,,hard security“-Themen für den Ostseeraum tatsächlich gänzlich irrelevant werden $\mathrm{zu}$ lassen. Die grundsätzliche Ausrichtung des CBSS charakterisiert ein Mitarbeiter des estnischen Außenministeriums mit folgenden Worten:

The founding fathers of the CBSS consciously excluded "hard security" items from the agenda of regional co-operation. But issues within the sphere of "soft security" have always - at least implicitly - been central to the agenda of the Council. It is pertinent to ask if "soft", civil security issues ought to form the core agenda of the CBSS today. ${ }^{111}$

\footnotetext{
${ }^{108}$ Hubel, Helmut / Gänzle, Stefan: „Der Ostseerat: Neue Funktionen subregionaler Zusammenarbeit im Kontext der EU-Osterweiterung“, in: Aus Politik und Zeitgeschichte, Nr. 1920, 2002, 3-11, hier S. 8.

109 „Copenhagen Declaration“, Einleitung, Kursivierung für diese Arbeit.

${ }^{110}$ Knudsen, Olaf F.: 'Institutions“ vs 'Power': Baltic Perspectives on Regional Security, Gdansk / Berlin, 2004, S. 44.

${ }^{111}$ Olljum, Alar: „Reflections On Baltic Sea Co-operation“, in: Baltinfo, Nr. 35, Februar 2001.
} 


\subsection{Organisationsstruktur}

\subsubsection{Intergouvernementale Ebene}

Auf der zwischenstaatlichen Ebene versteht sich der CBSS als Koordinations-Plattform für die Politiken seiner Mitgliedstaaten. Die Satzung, die zeitlich nicht in ihrer Gültigkeit eingeschränkt ist, legt hierzu fest, der „CBSS emcompasses all multilateral intergovernmental regional co-operation and serves as a forum for political dialogue among the group of CBSS members“. ${ }^{112}$ Die grundsätzlichen Richtungsvorgaben werden auf den seit 1996 stattfindenden und zweijährig abgehaltenen Gipfeltreffen der Regierungschefs und eines Kommissions-Mitglieds erarbeitet, ${ }^{113}$ die somit das höchste Gremium des CBSS bilden.

Dem eigentlichen Rat, dem der Außenminister, ist ein Ausschuss Hoher Beamter der Außenministerien und der Kommission, das Committee of Senior Officials (CSO), zugeordnet, das für die Zeit zwischen den Rats-Treffen für die Fortsetzung der Zusammenarbeit auf den beschlossenen Feldern verantwortlich zeichnet ${ }^{114}$ und somit gewissermaßen das ausführende Organ des CBSS darstellt.

Die Ratstreffen werden seit 2003 ebenfalls im zweijährigen Abstand abgehalten, wobei dies im Wechsel mit den Ostsee-Gipfeltreffen stattfindet. ${ }^{115}$ Der Vorsitz des CBSS, den in jährlicher Rotation eines der Mitglieder - mit Ausnahme der EU-Kommission - übernimmt und der zur Jahresmitte wechselt, gilt für all diese Gremien. Die zentrale Stellung des Rats in der Struktur der Organisation wird in der vom Sekretariat herausgegebenen Informationsbroschüre „Innovative Cooperation for a Dynamic Region“ betont, in der es heißt, die übergreifend koordinierende Rolle des CBSS liege in der Verantwortung der Außenminister. ${ }^{116}$

In den einzelnen Ressorts sind die Entscheidungen auf Treffen der Fachminister aufeinander abzustimmen, wovon in ansteigender Frequenz Gebrauch gemacht wird. Mit der revidierten Satzung erhalten auch die $\mathrm{Zu}$ sammenkünfte der Fachminister den Status von CBSS-Treffen, wohingegen sie anfänglich lediglich um Berichterstattung gebeten worden waren, jedoch nicht

\footnotetext{
112 Terms of Reference of the Council of the Baltic Sea States (revised 2005), Art. 5, Satz 2; mit der Revision der Satzung, engl. Terms of Reference, wurde sie im Wortlaut z.T. geringfügig abgewandelt, und sie ist nun umfangreicher; im folgenden sei auf die Satzung von 1992 als alte Fassung (ToR a.F.), auf die von 2005 als neue Fassung (ToR n.F.) verwiesen.

${ }^{113}$ ToR n.F., Art. 6; die Gipfeltreffen waren 1992 noch nicht vorgesehen und finden erst seit 1996 statt.

${ }^{114}$ ToR n.F., Art. 10 ff.; in der a.F. war dem CSO wesentlich weniger Raum gewidmet worden.

${ }^{115}$ Festgehalten in 2004 CBSS 12th Ministerial Session, Pori Communiqué.

${ }^{116}$ CBSS-Informationsbroschüre: „Innovative Cooperation for a Dynamic Region“, Stockholm, August 2005, publiziert in englischer Sprache, hier S. 13.
} 
formal in die Organisationsstruktur eingegliedert waren. Auf dem Gipfeltreffen des Jahres 2000 in Kolding in Dänemark wurde der entsprechende Vorschlag um einer Verbesserung der Koordination willen formuliert:

[T]he CBSS shall hereafter encompass all regional intergovernmental, multilateral co-operation among the group of CBSS Member countries. All meetings of field ministers of the group of CBSS member countries shall thus also be CBSS meetings." 117

Seither wird somit ,jegliche intergouvernementale Zusammenarbeit der Ostseeregion offiziell unter dem CBSS-Schirm betrachtet" ${ }^{118}$ und diese Organisation hat somit eine „Koordinierungsfunktion für die gesamte Regierungszusammenarbeit seiner Mitglieder“119, trägt also demnach zumindest formal zu einer fortschreitenden politischen Verflechtung im Ostseeraum auf Staatsebene bei.

\subsubsection{Zusätzliche Arbeitsgruppen}

Allen Gremien des CBSS steht es seit Gründung der Organisation frei, Experten und Vertreter anderer Staaten wie Organisationen als Berater, Beobachter oder Diskussionspartner zu Rate zu ziehen, ${ }^{120}$ wozu nähere Richtlinien 1999 vom Rat verabschiedet und vom CSO 2002 weiter ausgearbeitet wurden. ${ }^{121}$ In ihrer Form hat sich die Zusammenarbeit mit anderen Organisationen und Staaten durch diese neuen Dokumente dahingehend verändert, dass ihnen nicht mehr nur beobachtende Funktion, sondern sachbezogene Mitspracherechte offiziell eingeräumt werden. ${ }^{122}$ Außerdem können die CBSS-Organe - die Gipfelkonferenz, der Rat, die Ministerräte sowie das CSO - nach eigenem Befinden und ad hoc Arbeitsgruppen einrichten und andere handlungsorientierte Vereinbarungen treffen, um hiermit einzelne Vorhaben der zwischenstaatlichen Zusammenarbeit umzusetzen. ${ }^{123} \mathrm{Zu}$ einigen als besonders dringlich eingeschätzten

\footnotetext{
117 Baltic Sea States Summit, Kolding (2000): Review of structure and working methods of the CBSS, Vorschlag 1.

${ }^{118}$ CBSS-Informationsbroschüre, S. 14.

${ }^{119}$ Hubel / Gänzle, S. 7.

${ }^{120}$ ToR a.F., Art. 16; n.F. Art. 4 u. 16; obwohl die alte Fassung der Satzung über einen wesentlich längeren Zeitraum als die neue im juristischen Sinne ihre Gültigkeit hatte, ist hier dennoch häufig auf die neue zu verweisen, weil mit dieser vielfach Veränderungen festgehalten wurden, die sich in der politischen Praxis zuvor schon durchgesetzt hatten.

121 „Principles and Guidelines for Third Party Participation“, 1999, bzw. „Note to Observers and Special Participants“, Svetlogorsk, 4.3.2002.

${ }^{122}$ Begründet v.a. im Jahresbericht des CSO, 2001-2002.

${ }^{123}$ ToR n.F., Art. 11.
} 
Herausforderungen sind Task-Forces eingerichtet worden, nämlich „Organisiertes Verbrechen“ sowie „Übertragbare Krankheiten“. Auch ein Kommissariat für demokratische Entwicklung wurde bereits 1994 errichtet, das sein Hauptaugenmerk auf die im Umbruch befindlichen Gesellschaften an der Ostküste der Ostsee richtete. Insbesondere die Situation der russischen Minderheiten im Baltikum wurde damit ins Auge gefasst, so dass es nicht zu verwundern vermag, dass gerade diese auf die Wahrung der Menschen- und der Minderheitenrechte ausgerichtete Institution auf russischen Antrieb ins Leben gerufen worden war. ${ }^{124}$ Niedergelegt wurde dieser Posten 2003, da die Aufgaben als erfüllt angesehen wurden. Mit der Task Force on Organised Crime, deren Mandat mehrfach ausgeweitet und verlängert wurde, etablierten die Anrainerstaaten eine spezifisch für den Ostseeraum zuständige Institution, die in die innenpolitischen Hoheitsbereiche der Mitglieder hineinreicht und in der sich eindeutig die Einschätzung manifestiert, die Sicherheit des internationalen Systems bedrohende Herausforderungen seien lediglich grenzübergreifend $\mathrm{zu}$ meistern. ${ }^{125}$ Es arbeiten hierin Regierungsvertreter wie Polizeibehörden nicht nur der Region eng zusammen, sondern es sind z.B. auch US-amerikanische Institutionen eingebunden. ${ }^{126}$ Dies vermag $\mathrm{zu}$ verdeutlichen, dass in der Ostseeregion systembedingte Herausforderungen sehr ernst genommen und kooperativ angegangen werden.

Mit Befugnissen, eine Umsetzung der Initiativen zwingend durchzusetzen, ist der CBSS selbst nicht ausgestattet, sondern hierzu bedarf es des Einsatzes der Mitgliedstaaten. Laut Satzung sind Entscheidungen der CBSS-Organe im Konsens von den Mitgliedern zu treffen, ${ }^{127}$ so dass die Organisation nicht gegen einen ihrer Teile befinden kann, weshalb sie formal zumindest auf der intergouvernementalen Ebene als Instrument ihrer Mitglieder einzuordnen ist. Ungeachtet der implizit erklärten Gleichheit aller Mitglieder - allen kommen nach Rotationsprinzip dieselben Aufgaben $\mathrm{zu}^{128}$ - hat die EU-Kommission einen gewissen Sonderstatus

\footnotetext{
${ }^{124}$ So berichtet bei Hubel / Gänzle, S. 8.

${ }^{125}$ Siehe Baltic Sea States Summit, Visby (1996): Presidency Declaration.

${ }^{126}$ Siehe Website der Task Force on Organised Crime, URL: http.//www.balticseataskforce.fi.

127 Terms of Reference 1992, Art. 13; deutlicher noch Terms of Reference 2005, Art. 19.

${ }^{128}$ Nach Rotationsprinzip festgelegt sind die jährlich wechselnde Präsidentschaft des CBSS und damit verbundene Verpflichtungen wie Ausrichtung der Council-Treffen.
} 
inne, indem sie von der Funktion des Vorsitzes ausgenommen ${ }^{129}$ und auch an der Finanzierung des Sekretariats nicht beteiligt ist. ${ }^{130}$

Mit dem abschließenden Artikel der Satzung in ihrer alten wie neuen, umfangreicheren Fassung wird das schwache juristische Gewicht dieser Organisation im internationalen Beziehungsgeflecht deutlich:

Participation in the CBSS will not in any way infringe on any international obligation, be it of legal or political nature, of any of the participating states.

Auch die Verpflichtung der Mitglieder gegenüber den im CBSS getroffenen Vereinbarungen ist nur politischer, nicht aber juristischer Natur, da die Satzung keinen völkerrechtlichen Status hat. Somit sind, worauf Hubel und Gänzle in einem Aufsatz über den CBSS hinweisen, eine langwierige Ratifizierung durch die nationalen Parlamente verhindert und die Gründung der Organisation innerhalb nur knapp eines halben Jahres ermöglicht worden. ${ }^{131}$

\subsubsection{Sukzessive Ausweitung der Kooperation}

Die von Beginn an erfolgte sukzessive Ausweitung und Intensivierung der Zusammenarbeit drückt sich nicht nur in der anno 2000 erfolgten Integration der Fachminister-Treffen wie der Gipfeltreffen in die CBSS-Struktur aus, sondern findet sich auch in der Verwendung gewichtigerer Begriffe wieder. So hat sich schon im zweiten Jahr seines Bestehens im CBSS eine „Troika“ herausgebildet, mit der eine Kontinuität in der Arbeit von vergangener, amtierender und kommender Präsidentschaft durch entsprechende CSO-Vertreter gewährleistet werden soll. Mit der Satzung von 2005 wird der Troika die Repräsentation des CBSS auf dem internationalen Parkett aufgetragen. ${ }^{132}$ Die auf schwedische Initiative einberufenen Gipfeltreffen, ebenfalls vom vorsitzenden CBSS-Mitglied vorzubereiten $^{133}$, illustrieren das Gewicht, das die Mitgliedstaaten ihrer OstseeKooperation beimessen, indem sie zumindest auf dem Papier die Zusammenarbeit auch auf höchster Ebene institutionalisieren. Die Bedeutung äußert sich zudem darin, dass EU-Rats- wie Kommissionspräsidenten zu den Gipfeltreffen geladen sind, worin sich überdies der enge Zusammenhang von CBSS- und EU-Politik

\footnotetext{
${ }^{129}$ Entsprechend unterscheidet die Satzung je nach Belang zwischen Mitgliedern bzw. Mitgliedsstaaten.

${ }^{130}$ Der Finanzierungsschlüssel verlangt den drei baltischen Ländern und Island je $4 \%$ des Etats ab, allen übrigen Staaten je 12 \%; siehe Establishment Agreement of a CBSS Secretariat (1998).

${ }^{131}$ Hubel / Gänzle, S. 3.

132 ToR n.F., Art. 17.

${ }^{133}$ ToR n.F., Art. 7.
} 
zeigt. ${ }^{134}$ Die formale Gestalt des CBSS ist zu keiner Zeit grundsätzlich verworfen, sondern mit der nach rund dreizehnjährigem Bestehen, d.h. im Jahr 2005 vorgenommenen Satzungsänderung sogar betont worden.

Tatsächlich aber deckt sich dieser in den CBSS-Dokumenten formulierte Anspruch an die Ostseekooperation auf Ebene der Regierungschefs offensichtlich nicht uneingeschränkt mit der politischen Wirklichkeit. Zumindest wurden die Möglichkeiten zu Beginn zu optimistisch eingeschätzt: In der Schlusserklärung des ersten Gipfeltreffens ist die Absicht formuliert, sich bereits nach einem Jahr erneut zusammenzufinden - ,to the next Baltic Sea States Summit in 1997“. ${ }^{135}$ In der internationalen Presse wurde seinerzeit darauf verwiesen, der Wunsch nach jährlichen - wenn auch informellen - Zusammenkünften sei namentlich vom damaligen Kanzler Kohl geäußert worden, der somit die Ostseepolitik zu einem „Pendant“" zur „Mittelmeerlastigkeit“ der EU habe aufwerten wollen. ${ }^{136}$

Mit der Etablierung der Gipfeltreffen intendierte Schweden im Übrigen, ein Forum zu schaffen, auf dem sich auch Russlands Staats- und Regierungschef im Kreis seiner Nachbarn auf Augenhöhe einbringen kann. ${ }^{137}$ Damit unterscheidet sich der CBSS im positiven Sinne von anderen Organisationen wie EU und NATO, in denen Russland keine volle Mitgliedschaft ausfüllt und infolgedessen in der Rolle dessen verbleiben muss, dem die Bedingungen diktiert werden. Gewissermaßen wirkt die Einbeziehung Russlands als „vertrauensbildende Maßnahme“, die im CBSS unternommen wird, jedoch auch darüber hinaus Bedeutung haben könnte.

\subsubsection{Das Sekretariat}

Ursprünglich war in der Satzung festgehalten worden, der CBSS ,should not be seen as a new formalized institutional framework with a permanent secretariat"“ ${ }^{138}$ doch die Praxis der ersten Jahre führte zu einem geänderten Anspruch. Da entsprechende Aufgaben bis dato jeweils von dem Land wahrzunehmen waren, das den Vorsitz des CBSS innehatte und damit i.d.R. auch

\footnotetext{
${ }^{134}$ Vgl. Hubel / Gänzle, S. 6.

${ }^{135}$ Baltic Sea States Summit, Visby (1996): Presidency Declaration.

${ }^{136}$ Vgl. Rietig, Thomas: „Der sanfte Riese und Klaus Stoertebeker - Ostseegipfel diente Deutschland zum Austarieren politischer und geographischer Unwuchten in Europa“, in: Associated Press Worldstream, Visby, 5.5.1996.

${ }^{137}$ Siehe Rietig, Thomas: „Ein Mare Nostrum für die EU“, in: Associated Press Worldstream, Visby/Bonn, 1.5.1996.

${ }^{138}$ ToR, a.F., Art. 3.
} 
Gastgeber der Treffen war, war eine kontinuierliche Öffentlichkeitsarbeit erschwert. Nichtsdestotrotz wurde zusätzlich zu den üblichen Pressekonferenzen der CBSS-Gremien schon im zweiten Jahr des Bestehens unter der damaligen estnischen Präsidentschaft damit begonnen, ein Mitteilungsblatt herauszugeben, das in der Folgezeit als „The Baltic Newsletter“ regelmäßig über die CSOVertreter der Staaten an die Adressaten verteilt wurde. ${ }^{139}$ Nach dem VisbyGipfeltreffen hatte Schweden dem CBSS eine Arbeitsgruppe zur Verfügung gestellt, mit der für Kontinuität in der Sekretariats-Tätigkeit gesorgt werden sollte.

Da Schweden bis heute besonderen Anteil am Geschehen im Ostseeraum wie im CBSS selbst nimmt und sich als Zentrum dieser Region sieht, liegt es nahe, diese schwedische Initiative als Ausdruck eines Führungsanspruchs zu deuten. ${ }^{140}$ In geographischer Hinsicht ließe sich Schweden als Zentrum der Region schwerlich verkennen, denn der längste Teil der Ostseeküste ist schwedisches Territorium und die Nachbarstaaten des Landes sind allesamt CBSS-Mitglieder. Die politische Hinwendung zu den östlichen Anrainern des Gewässers seit Beginn der '90er Jahre hat offenkundig zugenommen; sie zeigt sich z.B. in der Dichte des schwedischen Partnerortprogramms auf kommunaler Ebene mit den östlichen Nachbarn, in dem beinahe alle administrativen Einheiten des Landes mitwirken. Dennoch stellen EU und Nordische Kooperation eindeutig die maßgeblichen Bezugsrahmen dar. ${ }^{141}$

Trotz dieser Fortschritte wurde die Forderung nach einer intensivierten Öffentlichkeitsarbeit und einer Koordinierung der Verwaltung aufrechterhalten, wie v.a. die Jahresberichte des CSO dokumentieren. ${ }^{142}$ Dementsprechend nahm das Sekretariat im Oktober '98 seine Arbeit auf und erfüllt in Person seines Direktors die Funktion des CBSS-Sprachrohrs nach außen. Unter dem Stichwort Öffentlichkeitsarbeit ist ihm expressis verbis die Umsetzung einer „Information and Communication Strategy“ auferlegt. Die Publikation des Mitteilungsblatts „Baltinfo“, die Betreuung der CBSS-Website, Kontaktpflege zu den diploma-

\footnotetext{
${ }^{139}$ Siehe „Information and Communication Strategy“ (2005), S. 3 f..

140 Über die Umstände der Sekretariats-Gründung siehe Bericht der Frankfurter Allgemeinen Zeitung: (N.N.): „Ostsee-Sekretariat in Stockholm eröffnet“, 21.10.1998, S. 8.

${ }^{141}$ Siehe die detaillierte Darstellung der Ostsee-Politik Schwedens, von der Regierung dem Reichstag vorgelegt: Ekonomisk utveckling och samarbete i Östersjöregionen, Skr. 1999/2000:7, 30.9.1999.

${ }^{142}$ Der „CSO Annual Reportt 1995/1996“ verweist unter Punkt 9 auf entsprechende Diskussionen; ebenso wird im „CSO Annual Report 1996/1997“ mehrfach auf die entsprechenden Diskussionen der vergangenen zwölf Monate verwiesen; das „1997 CBSS 6th Ministerial Session, Riga Communiqué" verweist in Punkt 27 auf den Entschluss, ein ständiges Sekretariat einzurichten.
} 
tischen Vertretungen in Stockholm oder auch die Veranstaltung von Seminaren oder Pressekonferenzen zählen zu den Möglichkeiten, die dem Sekretariat gegeben sind. ${ }^{143}$ Untergeordnet ist dies in jedem Fall dem ,overall goal [...] to make the CBSS better known to the public". ${ }^{144}$

Die Einrichtung des ständigen Sekretariats mit Sitz in Stockholm im Januar 1998 geschah ebenfalls mit der Intention, die bestehenden Strukturen zu festigen und sämtliche im Namen des CBSS stattfindenden Prozesse besser verwalten, dokumentieren und an die Öffentlichkeit tragen zu können. Die Hauptaufgabe des Sekretariats ist es, die CBSS-Präsidentschaft in technischen Belangen $\mathrm{zu}$ unterstützen. Darüber hinaus hat es das Archiv des CBSS zu betreuen und - gleich einer Informationszentrale - die öffentliche Aufmerksamkeit auf die Arbeit des CBSS zu lenken und gegenüber Medien und anderen Organisationen als Ansprechpartner zu fungieren. Dieser Verwaltungsapparat, d.h. das Sekretariat und die im Rahmen der CBSS-Kooperation gegründeten Arbeitsgruppen, ist neben den gleichberechtigten Mitgliedern als zweiter wichtiger Pfeiler des CBSS zu sehen. ${ }^{145}$ Damit wurde die mit der alten Satzung gegebene gänzlich informelle, intergouvernementale Natur abgewandelt und der CBSS zu einer formal eigenständigen Organisation ausgeweitet.

Von der Möglichkeit, Seminare und ähnliche Treffen zu organisieren, wird durch das Sekretariat durchaus Gebrauch gemacht. Ebenso wie für zahlreiche Machbarkeitsstudien zu unterschiedlichen Sachbereichen zeichnen der CBSS im allgemeinen oder dessen Sekretariat im besonderen Häufig für Workshops und Konferenzen verantwortlich, z.T. gemeinschaftlich mit anderen Auftraggebern wie dem NMR, worüber die Jahresberichte des Sekretariats Aufschluss geben. ${ }^{146}$ Überdies fungieren die Mitarbeiter als Repräsentanten des CBSS auf internationaler Bühne.

Erfolg zeitigt diese Intensivierung der Öffentlichkeitsarbeit allerdings nur bedingt, wie 2005 seitens des Sekretariats selbst eingeräumt wird:

It is probably fair to say that Baltic Sea Cooperation in general, and the [CBSS] in particular, is not very well known to the public. [...] Apparently, stable regional cooperation with decision-making based on consensus is not „sexy“ for the media. [...] Another question is whether increased visibility and awareness would

\footnotetext{
${ }^{143}$ Diese Mittel sind genannt in der „Information and Communication Strategy“, darin S. 4 f..

144 "Information and Communication Strategy", S. 5.

${ }^{145}$ Entsprechend der methodischen Vorgehensweise von Reinalda, Bob u. Verbeek, Bertjan: „The issue of decision making within international organizations“, in: dies. (Hg.): Decision Making Within International Organizations, London u.a. 2004, S. 9-42, hier S. 11.

${ }^{146}$ Siehe Website des CBSS, URL: http://www.cbss.org/structure/secretariat/annualreports/.
} 
enhance the impact of the CBSS in the region? The answer is, presumably, that it would. ${ }^{147}$

Die Vermutung, der CBSS scheue das Rampenlicht, um ungestört arbeiten zu können, ist somit zu verwerfen. Es ist anzunehmen, dass ein höherer Bekanntheitsgrad und vor allem eine größere Aufmerksamkeit dazu beitragen könnten, einen gewissen moralischen Druck auf einzelne Akteure auszuüben und infolgedessen zügiger in der Arbeit voranzukommen. - Letztlich sei an dieser Stelle jedoch darauf verwiesen, dass mit der „Information and Communication Strategy“ dem Sekretariat zwar gewichtige Aufgaben übertragen werden, in diesem Dokument selbst jedoch betont wird, die Hauptverantwortung für ein positives Erscheinungsbild des CBSS liege bei den Mitgliedern, also den Staaten selbst, und es kann als Ermahnung an die Unterzeichner verstanden werden kann, dass ,the key to success in raising the visibility and profile of Baltic Sea cooperation lies primarily in the Member states.“

\subsubsection{Die Präsidentschaft}

In der ursprünglichen Fassung der Satzung fand der Terminus „Präsidentschaft“" noch keine Erwähnung, sondern es wurde lediglich dem - nach Rotationsprinzip wechselnden - Gastgeber des kommenden Ratstreffens die Verantwortung zugeteilt, diese vorzubereiten und die mit dem CBSS verbundenen Angelegenheiten zu koordinieren. Recht unprätentiös wurde vom Amt des Vorsitzenden gesprochen, das der jeweilige Außenminister bekleidet. ${ }^{148}$ Von der Präsidentschaft ist erstmals 1998 im Gründungsabkommen des Sekretariats und im Jahresbericht des CSO explizit die Rede, verfasst unter dänischem Vorsitz, und wird schließlich in die revidierte Fassung der Satzung aufgenommen.

Die Satzung bedingt, dass der Vorsitz genutzt werden kann, um der Arbeit der Organisation eigene Schwerpunkte zu verleihen. Beispielsweise will Schweden gegenwärtig das Hauptaugenmerk auf die drei Bereiche „Zivile Sicherheit“, „Energie und Umwelt“ sowie „Handel und Investitionen“ richten, der Vorgänger Island hatte sich eine Themenliste mit neun Prioritäten gegeben, und Deutschland hatte in den Jahren 2000 / 2001 neben wirtschaftlicher Kooperation auch die aktive Mitarbeit an der „Nördlichen Dimension“ der EU, Umweltschutz sowie den

\footnotetext{
${ }^{147}$ Bøtcher, Bjarke W.: „Is the CBSS sufficiently well known to the public?““, in: Baltinfo Nr. 71, März 2005, S. 8; der Autor ist Öffentlichkeitsreferent des Sekretariats.

${ }^{148}$ ToR, a.F., Art. 10 f..
} 
Ausbau zivilgesellschaftlicher Aktivitäten in der Region auf seine Prioritätenliste gesetzt. Zwar ist damit den anderen Mitgliedern keineswegs die Möglichkeit genommen, in den zahlreichen Gremien und Arbeitsgruppen jederzeit ihre Interessen zu artikulieren, doch die offizielle Agenda wird vom Rat gesetzt „upon the proposal of the host country of each session“ bzw. ,upon the proposal from the CBSS Presidency“. 149

Von bundesdeutscher Seite gestaltet sich die Mitarbeit recht passiv. Aus den Dokumenten des CBSS sind nennenswerte Anstöße nicht zu entnehmen - ein Eindruck, der Bestätigungen unterschiedlicher Art findet: Informationen des Auswärtigen Amtes erwähnen den CBSS unter „ferner liefen“, ${ }^{150}$ und die Aufmerksamkeit für die gesamte Ostseeregion steht beträchtlich hinter der für die bilateralen Beziehungen mit Russland zurück. Entsprechend attestiert der Politologe Bernd Henningsen Deutschland während seiner CBSS-Präsidentschaft eine „Mitläuferrolle“ in der Ostseekooperation ${ }^{151}$, und Bundestagsdebatten sowie Stellungnahmen der Regierung zur Ostseepolitik weisen keinerlei Impulse auf, die sich programmatisch in den CBSS hätten einbringen lassen. ${ }^{152}$ In diese Kerbe schlägt auch der Vorwurf des schleswig-holsteinischen Europa-Ministers Gerd Walter, geäußert 1999:

Die norddeutschen Bundesländer, allen voran Schleswig-Holstein, fühlen sich häufig genug wie Rufer in der Wüste. Die politische und wirtschaftliche Bedeutung der Ostseeregion nehmen die Amerikaner eher wahr als viele hier in Deutschland. ${ }^{153}$

Desinteresse der Regierung Kohl gegenüber der Region als solcher spricht außerdem aus der Tatsache, dass der Kanzler seinen ersten Aufenthalt in Lettland anlässlich des CBSS-Gipfels 1998 in Riga nutzte, bilaterale Gespräche mit dem russischen Vertreter zu suchen. ${ }^{154}$ Dies kann auch als Ausdruck einer grundsätzlichen Geringschätzung gegenüber der Zusammenarbeit im CBSS verstanden

\footnotetext{
149 ToR, a.F. Art 17 bzw. n.F. Art.8.

${ }^{150}$ Siehe Erläuterung des Organigramms auf der Website des Auswärtigen Amts, URL: http://www.auswaertiges-amt.de/diplo/de/AAmt/Abteilungen/Europaabteilung.html, 1.3.2007.

${ }^{151}$ Vgl. Henningsen, Bernd: „Glänzende Perspektiven der Ostsee-Region nutzen. Deutschland muss aus seiner Mitläuferrolle herausfinden“, in: Focus, Nr. 28, 10.7.2000, S. 54.

${ }^{152}$ Für die SPD-Fraktion watete am 9.2.2001 in der Aussprache zur Ostseepolitik die Abgeordnete Wetzel mit dem amüsanten Fazit auf: „Regierung und Koalitionsfraktion sagen Ja zur Wachstumsregion Ostsee." Von einer inhaltlichen Programmatik für den Vorsitz im CBSS scheint dies weit entfernt. Vgl. Deutscher Bundestag: Plenarprotokoll 14/150, S. 14708; andere Debatten sind ähnlich verlaufen.

${ }^{153}$ Walter, Gerd: „Der Ostseeregion gehört die Zukunft“, in: Focus Nr. 32, 9.8.99, S. 50.

${ }^{154}$ So berichtet Donath, Klaus-Helge: „Die Balten als Statisten“, in: taz - die tageszeitung, 24.1.1998, S. 2.
} 
werden. Vor dem Hintergrund dieser recht uninspirierten Teilnahme Deutschlands im CBSS ist die o.g. Begeisterung für diese Organisation gegenüber der „Mittelmeerlastigkeit“ der EU allerdings sehr fadenscheinig.

Russland allerdings hat einen durchaus pikanten Versuch unternommen, die Arbeit des CBSS auszuweiten: Es war beabsichtigt, Fragen militärischer Kooperation auf die Agenda dieser Organisation zu setzen und auch die Auseinandersetzung über das geplante amerikanische Raketenabwehrsystem in den CBSS-Gremien zu führen, ${ }^{155}$ was jedoch auf Ablehnung der übrigen Staaten stieß. In der Prioritätenliste für die Präsidentschaft 2001-2002 ist angeführt, Russland wolle solche Kooperationsfelder erschließen, ,that are formally not on the CBSS agenda but are becoming an essential element of the Baltic Sea co-operation. In particular, this concerns developing contacts among military authorities““156.

\subsubsection{Die Integration anderer Kooperationsformen der Region}

In der Aufgabe des Sekretariats, Kontakte zu anderen nicht-staatlichen Akteuren im Ostseeraum $\mathrm{zu}$ knüpfen und $\mathrm{zu}$ pflegen, findet ein wesentliches Merkmal des CBSS seinen Ausdruck: Er versteht sich expressis verbis auch als wiederum lockeres - Forum für sämtliche transnationale Zusammenarbeit im Ostseeraum, womit sowohl Gruppierungen nationalstaatlicher Akteure und substaatlicher Ebenen als auch nicht-staatlicher Akteure unterschiedlicher Art angesprochen sind. Zusammenschlüsse wie die der Nicht-RegierungsOrganisationen, der Handelskammern oder der Einheiten der sub-nationalen Ebenen sind in die Strukturen des CBSS fest eingebunden, doch sind sie ihrerseits weder von der Existenz des CBSS abhängig noch an seine Entscheidungen gebunden:

A successful cooperation around the Baltic Sea area needs active participation of political decisionmakers at all levels. There are many ways to realize regional cooperation, depending on the various issues and the partners involved. The [CBSS] will encourage regional initiatives, public or private, as long as they contribute to the general aim of this cooperation. ${ }^{157}$

\footnotetext{
${ }^{155}$ Siehe Nienhuysen, Frank: „Ein Meer verschiedener Interessen“, in: Süddeutsche Zeitung, 1.7.2000, S. 8.

${ }^{156}$ Siehe „Priorities of the Russian Presidency of the CBSS in 2001-2002“.

157 „Copenhagen Decleration“, Abschnitt III.
} 
Durch das vom CBSS-Sekretariat betreute Internetportal der Ostseeregion $^{158}$ sind gegenwärtig 24 Initiativen, Organisationen oder Netzwerke verbunden - Union of the Baltic Cities, Baltic Sea Chambers of Commerce Association, The Baltic University Programme u.a. -, wofür der CBSS gewissermaßen einen Knotenpunkt darstellt. Um bei dem von Hubel und Gänzle gewählten Bild des Ostseeraums als „Experimentierfeld differenzierter Integration“"159 zu bleiben, ist der Ostseerat als Laboratorium der Koordination und Richtungsweisung zu bezeichnen, der qua Satzung die Verbindungen gesellschaftlicher Akteure forcieren und dadurch Grenzen nivellieren und eine Identifikation mit der Region begünstigen kann und will.

Indem Dokumente wie die Kopenhagener Erklärung oder die Strategie für das Sekretariat wiederholt den Vorrang der horizontalen gegenüber den vertikalen Verbindungen betonen, die der CBSS zu pflegen hat, wird CBSS-intern die intergouvernementale Zusammenarbeit allerdings über die Beziehungen zu substaatlichen oder privaten Gruppierungen gestellt.

\subsection{Der geographische Einzugsbereich des CBSS}

Ist für diese Analyse das politische System des Ostseeraums der entscheidende Referenzrahmen, orientiert die Wahrnehmung der beteiligten - wie außenstehenden - Akteure vielmehr an dessen geographischem Raum, der sich als Region bezeichnen lässt. Vom System sollte als politischer Ausgestaltung einer Region gesprochen werden können, da beide um der Definition willen auf Grenzziehungen nach außen sowie auf charakteristische Merkmale im Innern angewiesen sind. An zahlreichen Stellen wird in Schriften des CBSS auf die „Ostseeregion“ als Wirkungsfeld und Einzugsbereich Bezug genommen, ohne jedoch deren Grenzen explizit zu definieren. Es ergibt sich aus der Summe unterschiedlicher Aspekte allerdings ein recht klares Bild:

Zwar setzt der CBSS sich aus den Regierungen der Anrainerstaaten zusammen, doch ist sein Einzugsbereich nicht als deckungsgleich mit deren Territorien zu verstehen - weit entfernte Gebiete des Mitglieds Russland sprechen für sich. Vielmehr wird - Norwegen und insbesondere Island bilden gewissermaßen kuriose Ausnahmen - Bezug genommen auf die „unmittelbar“ angrenzenden Gebiete. Deutlich wird die Zugehörigkeit einzelner subnationaler

\footnotetext{
${ }^{158}$ URL: www.balticsea.net

${ }^{159}$ Hubel / Gänzle, S. 5.
} 
Einheiten zur Ostseeregion in ihrer Vertretung in der 1993 gegründeten „Baltic Sea States Subregional Cooperation“ (BSSSC), der Versammlung der Körperschaften direkt unterhalb des Nationalstaats, auf der die entsprechenden Regierungsvertreter zusammenkommen. Die BSSSC zählt aus Deutschland Mecklenburg-Vorpommern, Schleswig-Holstein und Hamburg, nicht aber Bremen, zu den Ostseeanrainern; aus Russland sind die Oblaste (Gebiete) Kaliningrad, Leningrad, Novgorod und Pskov sowie die Stadt St. Petersburg im BSSSC vertreten.

Ein ähnliches Bild zeichnet die seit 1991 einberufene OstseeParlamentarier-Konferenz (BSPC) - neben den entsandten Abgeordneten der nationalen Parlamente kommen hier Delegierte der Volksvertretungen der subnationalen Einheiten zusammen: Von deutscher Seite sind dies die Länder Mecklenburg-Vorpommern, Hamburg, Bremen und Schleswig-Holstein, von russischer Seite die Republik Karelien, die Regionen Leningrad und Kaliningrad sowie die Stadt St. Petersburg; zudem ist die „Nordwestliche Parlamentarische Versammlung Russlands“" Mitglied. ${ }^{160}$

Sowohl BSSSC als auch BSPC zählen zur Gruppe der „Special Participants“ des Ostseerats, werden also zu unterschiedlichen Themen in beratender Funktion regelmäßig zu den Sitzungen seiner Gremien eingeladen. Da der CBSS selbst Teilnehmer der Parlamentarier-Konferenz ist, kann sein Wirkungsbereich auf dieser Grundlage definiert werden; die Frage, ob bspw. Bremen zur Ostseeregion zu rechnen ist oder nicht, scheint eher akademischer Natur zu sein, in der Praxis aber keine Rolle zu spielen. Auf solch exakte Grenzziehungen wird im CBSS verzichtet.

Der Versuch, unter wirtschaftlichen Gesichtspunkten eine Ostseeregion zu definieren, stößt sich an den nach wie vor bestehenden Disparitäten zwischen den Anrainern des Binnenmeeres. ${ }^{161}$ Zwar können die ehemals planwirtschaftlich geführten Staaten grundsätzlich auf einen Aufschwung seit Beginn der '90er Jahre zurückblicken, doch kann dies nicht darüber hinwegtäuschen, dass bspw. Polen mit gänzlich anderen Voraussetzungen konfrontiert ist als z.B. Norwegen. Insofern ist schwerlich von einem einheitlichen Raum zu sprechen. Mit der Einbindung der

\footnotetext{
${ }^{160}$ Siehe Auflistung der Teilnehmer der Ostsee-Parlamentarier-Konferenz, online-Dokument, URL: http://www.norden.org/bspcnet/seiten/lin_bspc.htm, abgerufen am 1.2.2007.

${ }^{161}$ Vgl. z.B. Amt für Veröffentlichungen der Europäischen Gemeinschaften (Hg.): „Regionen: Statistisches Jahrbuch 2006“, Luxemburg 2006.
} 
EFTA-Staaten Norwegen und Island in den europäischen Binnenmarkt mit Inkrafttreten des Europäischen Wirtschaftsraums (EWR) im Jahr 1994 und mit dem EU- und damit gleichzeitig EWR-Beitritt der baltischen Staaten ist eine weitere Trennlinie nivelliert bzw. verschoben worden, da nunmehr lediglich Russland diesem Raum nicht angehört.

Dies kann jedoch nicht darüber hinwegtäuschen, dass dennoch die wirtschaftlichen Verbindungen innerhalb dieses Raumes in den vergangenen gut anderthalb Jahrzehnten erheblich ausgebaut wurden. Entsprechend wird der Ostseeraum als einheitliche Wirtschaftsregion verstanden: Die EU trägt diesem von Beginn an in ihrer Regionalpolitik Rechnung, und auch seitens der USA adressiert man „Northern Europe“ als Region, allerdings vornehmlich die nordischen und Baltischen Staaten. ${ }^{162}$ Die „Baltic Sea Chambers of Commerce Association“ (BCCA), die ebenfalls mit dem Kontaktnetz des CBSS verknüpft ist, verweist darauf und zeigt sich gar überrascht von der Wirtschaftskraft dieser Region:

The Baltic Sea Region is forming a surprisingly clear economic area of its own, a kind of economic sub-region of the European Economic Area. ${ }^{163}$

Der Begriff der „Subregion Ostseeraum“ findet gelegentlich Verwendung in Bezug auf den EWR, häufig auf die EU, bisweilen auf den Kontinent Europa. Damit wird ,die - auf Kriterien der Funktionalität bzw. Homogenität eines politischen, geographischen, kulturellen oder sozioökonomischen Raumes beruhende - Zuordnung dieser Ebene zu einem übergeordneten ,Ganzen““164 verdeutlicht, und es wird überdies hervorgehoben, dass sich diese Einheit in ihren Strukturen von ihrem Umfeld absetzt. Sicherlich lässt sich spätestens mit dem Beitritt der östlichen Ostseeanrainer zur EU dieser Teil Europas als Subregion der EU bezeichnen, doch hebt sich dieser Raum durch seine spezifischen Strukturen mittlerweile deutlich genug vom Umfeld ab, um als eigenständige Einheit gelten zu können. Durch das In-Beziehung-Setzen zu größeren Einheiten entstünde außerdem ein Zerlegspiel ähnlich einer „Russischen Puppe“, und es ließen sich immer weitere Einheiten als Sub-Region benennen, womit jedoch in keiner Weise

\footnotetext{
${ }^{162}$ Siehe allgemeine Informationen des US-Außenministeriums: „The Enhenced Partnership in Northern Europe (e-PINE)“, Website desselben, URL: http://www.state.gov/p/eur/rt/epine/, 2.2.2007.

${ }^{163}$ Siehe die allgemeine Einschätzung der BCCA der aktuellen Handelsstatistiken, Homepage der BCCA, URL: http://www.bcca.ws/cm2f/default.asp?id=19, 4.2.2007.

${ }^{164}$ Hubel / Gänzle, S. 4.
} 
Klarheit geschaffen würde. Dementsprechend ist sowohl für die innere Beschaffenheit als auch in der Abgrenzung nach außen von einer Einheit als Region zu sprechen.

\subsection{CBSS-Einbindung in die Gestaltung des Systems}

Unmittelbar nach dem Wiedererlangen der Souveränität der baltischen Staaten hatte sich die Einheit der Region nicht eindeutig abgezeichnet, obwohl die Hinwendung dieser Länder und Polens zum Westen nicht strittig war. Priorität hatte seit deren Unabhängigkeit, wie Aussagen von Politikern der baltischen Staaten in Interviews aus dem Jahr 2000 deutlich machen, ${ }^{165}$ aus vornehmlich sicherheitspolitischen Erwägungen die Aufnahme bzw. Mitgliedschaft in EU und NATO. Dass der Weg dahin über eine regionale Integration führen könnte, schien anfangs keine ernsthafte Option zu sein, sondern stattdessen war befürchtet worden, Engagement in Projekten regionaler Kooperation sei als einer Annäherung an EU und NATO abträglich, so Browning und Joenniemi. ${ }^{166}$ Diese Einschätzung wurde jedoch offensichtlich alsbald revidiert oder zumindest wesentlich durch eine andere überlagert, und ,engaging in regional cooperation became seen as a route to Western security organizations, and a training ground for transition process“. ${ }^{167}$ Indem sich die Interpretation durchsetzte, Sicherheit auch um der Wahrung der Souveränität willen - sei in Form von „soft security“ durch Kooperation zu erlangen, wurden die Weichen für gemeinsame, regionale Strategien gestellt. ${ }^{168}$ Mit der Adaption einer „,soft security agenda“, also der Betonung des Sicherheitsaspekts von ökologischen Themen, von Konzepten wie Demokratie und Gesellschaft wie von zivilen Elementen, habe sich ein regionaler Rahmen für Kooperation herausbilden und an Bedeutung gewinnen können, ${ }^{169}$ was mit der Gründung des CBSS unterstrichen wurde. Auf dem Außenministertreffen 1999 wurde die Bedeutung betont, die der CBSS für die Normsetzung in östlichen Mitgliedstaaten habe:

The Council stressed the high political relevance for the Baltic Sea Region of three interrelated political processes of the European Union - EU enlargement, the

\footnotetext{
${ }^{165}$ Vgl. Knudsen, ebd..

${ }^{166}$ Vgl. Browning / Joenniemi: ,Regionality beyond Security? The Baltic Sea Region after Enlargement", in: Cooperation and Conflict, Nr. 39, Heft 3, 2004, S. 233-253, hier S. 237.

${ }^{167}$ Browning / Joenniemi, S. 237.

${ }^{168}$ So Joenniemi, Pertti: ,Security in Northern Europe: The contest between different unterstandings“, in: Östereichische Zeitschrift für Politikwissenschaft, S. 431-441, hier S. 436.

${ }^{169}$ So Browning / Joenniemi, S. 234, ebenso Joenniemi (1996), hier insbes. S. 433.
} 
Common Strategy towards Russia and the Northern Dimension. The similarity of aims and close links between EU and CBSS countries offer a unique opportunity for the Council to bring added value in key sectors of economic and social life of the Region. ${ }^{170}$

In ihrer historischen Darstellung des Ostseeraums benennen Gerner und Karlsson einen wesentlichen Aspekt zur Wahrnehmung einer Region als solcher, indem sie von einer ,,aktiven Konstruktionsarbeit ${ }^{\text {“171 }}$ sprechen, die sie im Ostseeraum zu erkennen meinen:

Es gibt einen offensichtlichen Willen bei exponierten gesellschaftlichen Gruppen, solche regionalen Räume $\mathrm{zu}$ identifizieren und durch Erscheinungen zu untermauern, die einigend wirken. ${ }^{172}$

Schon in den Gründungsdokumenten des CBSS wird dessen Wirkungsraum dezidiert als Region benannt, und wenn dies seinerzeit auch eher einer Absichtserklärung oder einer Wunschvorstellung und weniger den Tatsachen entsprochen haben sollte, hat es doch als Wort gelten können, an dem sich die Vertragspartner orientieren konnten. Die ,aktive Konstruktionsarbeit“ mag im Fall des CBSS den Charakter einer „,self-fulfilling prophecy“ haben; sie ist zumindest als begünstigend für die wechselseitige Verflechtung der Akteure und für eine Identifikation mit der Region zu bewerten. Eine Abgrenzung nach außen geht damit unausgesprochen einher, was sowohl für die Sondierung gemeinsamer Probleme - z.B. Verschmutzung der Ostsee - als auch für die Darstellung gemeinsamer Chancen - wie Rohstoffreichtum der Region - zutrifft.

Das politische System dieser Region ist mittlerweile von einer auffällig komplexen Struktur, denn es zeichnet sich aus durch eine große Vielfalt horizontaler und vertikaler Kontakte verschiedener gesellschaftlicher Gruppen, für die die Ostsee eine Binnenmeerfunktion hat. War dies zur Zeit der Gründung des CBSS nur in Ansätzen gegeben, hat es sich seither deutlich verstärkt: Neben den in zahlreichen Feldern institutionalisierten Beziehungen der nationalen Regierungen, die sich über größere Räume erstrecken - z.B. OSZE, NATO oder EU -, und neben den zahlreichen bilateralen Kontakten, die auf noch längere Traditionen verweisen können, sind eine geradezu unüberschaubare Zahl von Institutionen entstanden, die sich explizit auf den Ostseeraum beschränken, häufig nicht-

\footnotetext{
170 „1999 CBSS 6th Ministerial Session, Palanga Communiqué“.

171 Gerner / Karlsson, S. 284.

${ }^{172}$ Gerner / Karlsson, S. 288.
} 
gouvernementaler Natur und in vielen Fällen miteinander verbunden sind. ${ }^{173}$ Die „Union der baltischen Städte“ (UBC), die „Helsinki Commission“ (HELCOM), die sich dem Schutz der Ostsee unter ökologischen Gesichtspunkten widmet, das Gewerkschafts-Netzwerk BASTUN, das „Baltic University Programme“ (BUP), ein Netzwerk von mehr als 180 Universitäten und höheren Ausbildungsstätten, das „Baltic Sea NGO Forum“, ein Prozess jährlich stattfindender Treffen von NGOs, oder das „Baltic Media Forum“ zur Stärkung der Kontakte von Journalisten im Ostseeraum sind einige Beispiele, die die Vielschichtigkeit der Beziehungen andeuten, wie sie von Henningsen beschrieben wird:

Wohl nirgends in Europa gibt es eine so blühende Flora nichtstaatlicher Zusammenarbeit: Städtepartnerschaften, Wirtschaftskooperationen, Universitätszusammenarbeiten, übernationale Kunstveranstaltungen und viele weitere, nicht mehr zählbare institutionelle und nichtinstitutionelle Vereinigungen stellen eine solide Basis für politisches Handeln dar. ${ }^{174}$

Der CBSS selbst versteht sich und gilt als Triebkraft für die Entstehung und Unterstützung solcher Kooperationsformen:

There are many ways to realize regional cooperation, depending on the various issues and the partners involved. The [CBSS] will encourage regional initiatives, public or private, as long as they contribute to the general aim of this cooperation.

So legt es die Kopenhagener Erklärung fest, ${ }^{175}$ und in der Tat nimmt der CBSS eine zentrale Position in diesem Geflecht ein, da er als Knotenpunkt vieler solcher Institutionen fungiert und ihm seit Bestehen des Sekretariats durch dessen Personal die notwendige Koordination obliegt.

Zur Kenntnis zu nehmen sind bezüglich der Koordinationsaufgabe allerdings im Lauf der Zeit wiederholt erhobene Forderungen nach deutlicherer Koordinierung des politischen Geschehens im Ostseeraum: „Die in den letzten Jahren entstandene weit verzweigte Kooperation im Ostseeraum hat teilweise zu Unübersichtlichkeit und unnötiger Doppelung von Aktivitäten geführt. “176 Für die Aktivitäten auf Regierungsebene war die Ausweiterung der Koordinierung per Beschluss des Gipfels anno 2000 durchgeführt worden, demzufolge sämtliche

\footnotetext{
${ }^{173}$ Ein Teil dieser ist aufgelistet auf dem Internet-Portal www.balticsea.net.

${ }^{174}$ Henningsen, Bernd: „Glänzende Perspektiven der Ostsee-Region nutzen. Deutschland muss aus seiner Mitläuferrolle herausfinden“, in: Focus, Nr. 28, 10.7.2000, S. 54.

175 „Copenhagen Declaration“, Abs. III.

${ }^{176}$ Deutsche Bundesregierung am 30.8.2000 in einer Antwort auf die Große Anfrage aus der FDPFraktion, DS 14/4026, S. 6
} 
zwischenstaatliche, multilaterale Zusammenarbeit der CBSS-Mitglieder von der Organisation erfasst wird. ${ }^{177}$

Es ist an dieser Stelle ausdrücklich zweierlei Einschränkung anzuführen: Zum einen stellt der CBSS zwar hinsichtlich der Gesamtheit der Anrainerstaaten einen Knotenpunkt der intergouvernementalen Zusammenarbeit dar, doch damit führt er gewissermaßen ein Paralleldasein $\mathrm{zu}$ NMR und EU, deren Handlungsräume, Tätigkeiten und Zuständigkeiten sich in dieser Region teilweise überschneiden. Somit sind die Kanäle des Systems nicht einzig auf den CBSS ausgerichtet, sondern sie überlagern und überschneiden sich, was unübersehbar ist, da die EU durch ihre Kommission selbst Mitglied dieser regionalen Organisation ist. Mit Blick auf Überschneidungen dieser Art stellt der CBSS nicht notwendigerweise das Gravitationszentrum dieses Systems dar. ${ }^{178}$ Zum anderen ist der CBSS ebensowenig als einzige Organisation mit der Koordinierung staatlicher Kooperation betraut: Für die Ostsee-Parlamentarier-Konferenz z.B. bildet der NR in technischer Hinsicht die erste Bezugsinstanz, da das Sekretariat der BSPC seinen Sitz beim Sekretariat des NR hat. ${ }^{179}$ Auch in der US-Amerikanischen Strategie für eine Zusammenarbeit mit den Staaten des Ostseeraums scheint der Fokus in erster Linie auf die nordischen und baltischen Staaten gerichtet. Entsprechend ist in einem allgemeinen Hinweis des Außenministeriums auf diese Kooperation formuliert, die USA seien "introducing the Enhanced Partnership in Northern Europe [...] as its framework for U.S. activity within and in cooperation with the eight Nordic and Baltic States. “180

Neben der „Universalität“ der Mitglieder - insbesondere die Einbindung Russlands als vollwertiger Partner sticht hier hervor -, aufgrund derer dem CBSS trotz der genannten Einwände zumindest formal eine Schlüsselrolle im vielschichtigen politischen System der Region zuzugestehen ist, dürfte darüber hinaus die Tatsache, dass das Sekretariat dieser Organisation nahezu im geographischen Zentrum der Region seinen Sitz hat, in der Wahrnehmung seiner Mitglieder (seit 1998) zum Vorteil gereichen.

\footnotetext{
${ }^{177}$ Vgl. Kap. 3.2, Organisationsstruktur.

${ }^{178}$ Weitere Überlegungen dazu in den folgenden Kapiteln.

${ }^{179}$ Siehe insbesondere Informationen auf Website der Nordischen Zusammenarbeit zum Stichwort „Nordischer Rat und Ostseeregion“, URL: http://www.norden.org/internationellt/sk/nr_osterso.asp?lang=1\&p_id=678, abgerufen am 4.2.2007.

${ }^{180}$ Siehe Information auf der Homepage des US-Außenministeriums, URL: http://www.state.gov/p/eur/rt/epine/, abgerufen am 2.2.2007.
} 


\subsection{Zwischenbetrachtung}

Mag angesichts des stetigen Wandels der Organisationsstruktur der negative Eindruck entstehen, der Arbeit des CBSS mangele es an einer Konzeption oder an Zielstrebigkeit, wird dieses Prozesshafte von den beteiligten Akteuren jedoch positiv herausgestellt. Das Schlusskommuniqué des Ratstreffens 1999 gibt die Einschätzung der Außenminister wie folgt wieder:

The Council welcomed the dynamic character and widening scope of multilateral regional co-operation in the Baltic Sea area, which contributes to the continued interaction between the societies of the member countries, broadens the network of contacts across the Baltic Sea, promoting economic, social and democratic development of the Region. ${ }^{181}$

Gerade der informelle Charakter der Organisation, die sich mit der Satzung zahlreiche Ausformungen der Zusammenarbeit offenhält, wird von den Akteuren begrüßt. Eine kritische Äußerung über die Wirkungskraft der Ostseekooperation unter dem Dach des CBSS ist dahingegen von Uffe Ellemann-Jensen zu vernehmen, der gemeinsam mit Hans-Dietrich Genscher als Gründungsvater des CBSS geführt wird. Auf die günstigen wirtschaftlichen Bedingungen wie die weit vorangeschrittene Integration verweisend, fordert er im Jahr 2001 stärkeres Engagement der Regierungen, um die Region wirtschaftlich weiter voranzubringen. So schreibt er im Mitteilungsblatt des CBSS, auf Worte müssten endlich Taten folgen. ${ }^{182}$

Auf den Erfolg in einzelnen Vorhaben sei später eingegangen, doch an dieser Stelle ist bereits festzuhalten, dass Militärisches, z.B. in Form von Bündnispolitik, auch in dieser Region keineswegs aus dem Blickfeld gestrichen werden kann. Nicht nur, dass die Diskussionen über einen Beitritt der baltischen Staaten und Polens zu EU und NATO von Russland seinerzeit argwöhnisch verfolgt wurden - auch der Abzug russischer Truppen aus den nun unabhängigen Staaten war mit Spannungen verbunden. Mittlerweile wird Sicherheit von den meisten Ostseeanrainern zwar keineswegs mehr ausschließlich in ihrer militärischen Dimension verstanden, und insbesondere die gutnachbarschaftlichen und partnerschaftlichen Beziehungen werden einhellig betont, doch die Russische Föderation, Litauen und Estland bedienen sich weiterhin herkömmlicher

\footnotetext{
181 „1999 CBSS 6th Ministerial Session, Palanga Communiqué“.

182 Ellemann-Jensen, Uffe, in Baltinfo Nr. 41, Oktober 2001.
} 
Denkmuster. ${ }^{183}$ Im Fall der baltischen Staaten geschieht dies unter eindeutiger Berufung auf die EU sowie auf das Sicherheitsbündnis NATO, in deren politischem Selbstverständnis „,soft security“ allerdings ein zunehmend stärkeres Gewicht erhält. In Russland wird jedoch nach wie vor von bedingungsloser Notwendigkeit gesprochen, in jedwedem Streitfall militärisch bestehen zu können. Es wird auch von den Ostseeanrainerstaaten nicht ignoriert werden können, dass die russische Regierung die Modernisierung der Streitkräfte als eines ihrer Hauptanliegen bezeichnet und schreibt, das Land brauche ,armed forces able to simultaneously fight in global, regional and - if necessary - also in several local conflicts“. ${ }^{184}$ Von der Zusammenarbeit im Ostseerat bleiben solche Themen jedoch ausgeklammert.

Letztlich ist jedoch zu konstatieren, dass militärische Auseinandersetzungen für die politische Tagesordnung innerhalb dieser Region de facto keine Rolle mehr spielen. Das Verhalten der Akteure ist berechenbar geworden, und Kooperation wird allenthalben als unumgänglich auch für den eigenen Vorteil angesehen, so dass ein Ausscheren unwahrscheinlich geworden ist. Außerdem unterstreicht die große Dichte gesellschaftlicher Kooperationsformen, in die auch die russische Seite eingebunden ist, dass nicht mehr einzig die offizielle Politik der nationalen Regierungen als wichtig für das internationale System eingestuft wird.

\section{Ostsee-Kooperation in der Energiepolitik}

Ein zentraler Arbeitsbereich der Organisation der Ostseeanrainerstaaten ist - um größerer politischer und wirtschaftlicher Stabilität sowie um Stärkung einer regionalen Identität willen - erklärtermaßen von Beginn an die Kooperation in der Energiepolitik, von der Kopenhagener Erklärung festgehalten im Absatz „Umweltschutz und Energie“:

The Ministers recognized that cooperation in the field of energy is an integral part of the efforts to improve the environment in the region and to ensure sustainable economic growth. They noted that improved cooperation in the field of energy is essential to ensure the best and most efficient production and use of limited energy resources. They also underlined the high priority of intensified cooperation in energy saving measures. The Ministers recognized the role of the European

\footnotetext{
${ }^{183}$ Die jeweiligen Erläuterungen zum Stichwort Sicherheitspolitik auf den Homepages der Staaten weisen in den Formulierungen klare Unterschiede zu denen der anderen Staaten auf.

${ }^{184}$ Statement Vladimir Putins auf der Website der russischen Regierung, URL:

http://www.president.kremlin.ru/eng/priorities/21817.shtml, 9.2.2007.
} 
Energy Charter in making the fundamental link between energy, environment and economic development. ${ }^{185}$

Zum Erreichen der verschiedenen Ziele gilt es, Entscheidungen zwischen unterschiedlichen Maßnahmen und Strategien zu fällen; dies bedeutet nicht nur, für die Stromerzeugung zu wählen zwischen verschiedenen Energieträgern bspw. Atomkraft, Windkraft, nachwachsende oder fossile Brennstoffe -, sondern es müssen auch die Netze darauf ausgerichtet sein bzw. werden.

\subsection{Faktoren des Systems}

Akteure und Adressaten in energiepolitischen Fragen sind im internationalen System zahlreich. Für industriell produzierende Volkswirtschaften hat die Gewährleistung der Energieversorgung eine entscheidende Bedeutung, und insbesondere angesichts naturgegebener Knappheit vorhandener Rohstoffe macht die Zielsetzung, die entsprechenden Ressourcen möglichst rationell und umweltschonend zu nutzen, eine Energiepolitik erforderlich, die eng mit Umweltpolitik verknüpft ist. ${ }^{186}$ Unterschiedliche Modelle der Energieversorgung zeigen, dass zwischen den wichtigsten Akteuren des internationalen Systems, den Staaten, erhebliche Interessenkonflikte bestehen können. Offenkundig ist die Unvereinbarkeit nationaler Positionen im Ostseeraum z.B. im Umgang mit Kernkraft, da Litauen sich einer Schließung eines Atomreaktors hartnäckig widersetzte, um sich nicht in Abhängigkeit von russischen Rohstofflieferungen begeben zu müssen, sich mit dieser Position jedoch gegenüber den Sicherheitsbedenken der Nachbarstaaten nicht durchsetzen konnte. ${ }^{187}$

Innenpolitisch wiederum ist Einigkeit über die $\mathrm{zu}$ beschließenden Maßnahmen nicht nur unter den Parteien herzustellen, sondern es vertreten auch die subnationalen Einheiten u.U. durchaus eigene Interessen. Aus einer Äußerung des schleswig-holsteinischen Wirtschaftsministers Austermann während einer

\footnotetext{
${ }^{185}$ Copenhagen Declaration, Auszug aus Art. II.4.

${ }^{186}$ Siehe Rede des Wirtschaftsministers Wolfgang Clement vom 18.1.2005, dokumentiert auf der Website des Bundesministeriums für Wirtschaft und Technologie, URL: http://www.bmwi.de/Navigation/Presse/reden-und-statements,did=57152.html, 19.2.2007; gegenwärtig weist das Bundesministerium für Wirtschaft und Technologie die Ziele Wirtschaftlichkeit, Versorgungssicherheit und Umweltverträglichkeit als leitend für ihre Energiepolitik aus, siehe Website des BMWI, URL: http://www.bmwi.de/BMWi/Navigation/Energie/ziele-der-energiepolitik,did=9170.html, 19.2.2007.

${ }^{187}$ Vgl. Johannsmeier, Birgit: ,Zündstoff im Baltikum. Streit um die geplante deutsch-russische Gasleitung“, in: Deutscher Bundestag (Hg.): Wochenzeitung „Das Parlament“, Nr. 49-50, 5.12.2005.
} 
Landtagsdebatte zur Energiepolitik im vergangenen Jahr ist dies deutlich herauszuhören, da er feststellt, „dass die wesentlichen Entscheidungen - wie so oft nicht hier, sondern auf Bundesebene getroffen werden. Damit ist klar, dass der Spielraum der Landesregierung eingeengt ist.“"188

Die Marktteilnehmer dieses Sektors, teilbar in Produzenten und Anbieter, agieren nicht selten international und sind z.T. auch grenzübergreifend miteinander verflochten. So ist der schwedische Konzern „Vattenfall“ einer der Hauptanbieter auf dem deutschen Strommarkt, während „e.on-Ruhrgas“ sich zunehmend in Norwegen etabliert, wobei die Konzerne bisweilen auch mehrheitlich in staatlicher Hand sein können, wie „Gazprom“, dessen Hauptaktionär die Russische Föderation mit einem Anteil von gut $50 \%$ ist. Der „Gasstreit“ Russlands mit der Ukraine und auch mit Weißrussland war nicht nur wirtschaftlicher Natur, sondern offenbart politische Machtfragen, die das internationale System prägen. Von großer Bedeutung für die inhaltliche Positionierung der Staaten ist deren Disposition über Energieträger, seien dies fossile Brennstoffe oder ,alternative“ Energiequellen wie Wind oder Sonne, Faktoren, die sich nicht notwendigerweise in der Machtverteilung im internationalen System widerspiegeln, dennoch über dessen Entwicklung mitentscheiden.

\subsubsection{Position des CBSS}

Für den CBSS-Rat stellt sich die Vielfalt der Akteure positiv dar, da sie zu einer Vielfalt an fachlichen Kompetenzen und zu einem breiten Spektrum an Handlungsoptionen beiträgt:

The Council noted the activities by competent international institutions and agencies as well as contributions by member states within the framework of regional energy transmission networks coupled with activities of private enterprise to create conditions for improvement and coordination of energy supply in the Baltic Sea region, including the study of the possibility to complete the "Baltic Ring" of interconnected electricity grids. ${ }^{189}$

Hinsichtlich der in der Region vorhandenen natürlichen Ressourcen gehen die Verantwortlichen im CBSS von einer komplexen Ausgangslage für die Zusammenarbeit aus, denn ,the Baltic Sea States have varying preconditions and that they differ considerably with regard to energy policies and infrastructure.“190

\footnotetext{
${ }^{188}$ Siehe Schleswig-Holsteinischer Landtag, Plenarprotokoll 16/24, Sitzung am 24.2.06.

189 „1994 CBSS 3rd Ministerial Session, Tallinn Communiqué“, Abs. II.4.

190 Schlusserklärung des 2. Treffens der CBSS-Energieminister, 24./25. Okt. 1999 in Helsinki.
} 
Die anerkanntermaßen günstigen Konditionen der Region mit relativ vielversprechenden Vorräten an natürlichen Ressourcen in Norwegen und Russland werden nicht in den Vordergrund geschoben, sondern man hat sich auf die effizientere Nutzung und auf Möglichkeiten umweltfreundlicherer Produktion ausgerichtet. ${ }^{191}$

\subsubsection{Konkreter Anlass für dieses Thema}

Aus heutiger Perspektive ist die Region in der nunmehr 15-jährigen Tätigkeit des CBSS im Kontext der Energiepolitik durch eine Debatte besonders in den Mittelpunkt der medialen Aufmerksamkeit gerückt: das umstrittene Projekt einer Gaspipeline von Russland nach Deutschland durch die Ostsee. Der mittlerweile begonnene Bau wurde zwischen Deutschland und Russland vereinbart, an der bisweilen hitzigen Auseinandersetzung darüber waren jedoch zahlreiche Staaten und andere Akteure beteiligt. Es ist zu erwarten, dass die Frage der Zusammenarbeit - die Partizipation anderer Staaten war ebenfalls diskutiert worden - auch im CBSS auf der Tagesordnung gestanden hat.

Als zeitlicher Rahmen, auf den die Untersuchung ausgerichtet ist, ist die Spanne von der Gründung bis ins Jahr 2005 ins Auge gefasst, da damit die Entwicklung bis zur Entscheidung zugunsten der entsprechenden Gasleitung gefallen und auch der zweite Aktionsplan der EU zu dieser Region aufgenommen war. Mit diesem und dem Vorgänger waren die EU-Intentionen zur Region als solcher, aber auch zum Thema Energie-Kooperation dargelegt, so dass in Bezug auf diesen Zeitrahmen der Frage nachgegangen werden kann, inwiefern CBSSund EU-Politiken interferieren. Auch die Satzungsänderung des CBSS fällt in dieses Jahr, von der Rückschlüsse auf das Wirken der Organisation zu ziehen sind. Indem außerdem die vier vormaligen Kandidaten zu dieser Zeit zu Mitgliedern der EU geworden waren, ist lediglich Russland gänzlich außerhalb der an die EU gebundenen Vertragswerke verblieben, womit für die meisten der Anrainer viele Entscheidungen nicht mehr internationaler Natur sind, sondern einen supranationalen Anklang haben.

Im folgenden wird untersucht, welche Rolle der CBSS an der Entwicklung in der Region gespielt hat.

\footnotetext{
${ }^{191}$ Siehe „Copenhagen Declaration“, Abs. 4 „Protection of the environment and energy“.
} 


\subsection{Energiepolitik im CBSS}

Die Formulierung der Kopenhagener Erklärung, „,cooperation in the field of energy is an integral part of the efforts to improve the environment in the region and to ensure sustainable economic growth“, beschreibt recht vage eher eine Herausforderung und Chance als eine Hürde, die zu überwinden wäre. Nur indirekt und lediglich im Kontext des gesamten Dokuments sind Probleme skizziert, die sich zu Beginn der '90er Jahre im Ostseeraum stellten. Basierend auf der Einschätzung, dass wirtschaftlicher Wohlstand und politische Sicherheit sich gegenseitig bedingen - ausgeführt in den für den CBSS maßgeblichen Dokumenten von OSZE und UNO wie in CBSS-Texten selbst -, stellte die volkswirtschaftliche Situation der postsozialistischen Staaten für die Staatengemeinschaft des Ostseeraums einen Risikofaktor dar. Vor diesem Hintergrund wird also auch dieses Politikfeld gesehen, da Kooperation im Energiebereich ein zukunftsfähiges Wachstum mit sich bringen könne. Auf die „European Energy Charter" Bezug nehmend, mit der 1991 die Dringlichkeit von Energiefragen für die gesamt-europäische Tagesordnung herausgestellt wurde, deuten die CBSSAußenminister in der Kopenhagener Erklärung die immense Bedeutung an, die der Energiepolitik in der Folgezeit beizumessen sei. Programmatisch heißt es in einer Einleitung zum „Energy Charter“-Vertragswerk:

Nowhere were the prospects for mutually beneficial cooperation between East and West clearer than in the energy sector. Russia and many of its neighbours were rich in energy resources but needed major investments to ensure their development, whilst the states of western Europe had a strategic interest in diversifying their sources of energy supplies. ${ }^{192}$

Exemplarisch wurde dies im CBSS-Gründungsdokument für diesen geographischen Raum betont. Sowohl unter dem ökologischen als auch unter dem ökonomischen Gesichtspunkt wird die Bedeutung des Energiesektors für die Entwicklung der Region herausgestellt, auf die expressis verbis verwiesen wird. „Umweltschutz und Energie“ sind als zusammenhängender Arbeitsbereich ausgewiesen, und aus dem geographischen Mittelpunkt wird ein thematischer Schwerpunkt abgeleitet.

\footnotetext{
${ }^{192}$ Energy Charter Secretariat (Hg.): The Energy Charter Treaty and Related Docouments, Brüssel 2004, S. 15. Der Energy Charter Treaty ist bisher von Russland nicht ratifiziert worden.
} 


\subsubsection{Ebene des CSO}

Hinweise darauf, welche operativen Probleme sich im Energiesektor in der Region konkret stellten, finden sich in den Dokumenten der ersten Jahre der CBSS-Tätigkeit nur spärlich. Als wesentliche Aufgabe des CSO, des „ausführenden“ Gremiums der Organisation, das die Kontakte zu den nationalen Verwaltungen $\mathrm{zu}$ pflegen hat, wurde es in den Anfangsjahren verstanden, Möglichkeiten der Zusammenarbeit überhaupt erst $\mathrm{zu}$ sondieren und damit einhergehend auch nach Interessen der Mitglieder zu fragen. In diesem Sinne heißt es im CSO-Jahresbericht '93/'94, es seien die Felder regionaler Kooperation zu identifizieren, auf denen ,the CBSS can play a 'value-added' role either by mobilizing the necessary political will to foster concrete projects or by contributing to a better utilization of resources by assisting in the coordination of national and regional inputs“193. Die 1993 gegründete „Working Group on Economic Cooperation“ (WGEC), zusammengesetzt aus Mitarbeitern der nationalen für Energie zuständigen Ministerien, befürwortete von Beginn an den Ausbau der Energie-Infrastrukturnetze, da dies ein mittel- bis langfristig fruchtbares Feld der Kooperation darstelle. In engem Kontakt mit den nationalen Behörden, liegt es in der Hand dieser Arbeitsgruppe, konkrete Projekte voranzutreiben und somit Erfolgsmeldungen ans Revers des CBSS zu heften. Entsprechend kann schon der genannte CSO-Jahresbericht auf den Einfluss der WGEC auf die Stilllegung der Kernenergieanlage im estischen Paldiski verweisen. $^{194}$

\subsubsection{Ministerielle Ebene}

Konkret äußert sich hinsichtlich zukünftiger Projekte der Rat 1996 in Norwegen, das „Kalmar Action Programme“ präsentierend, in dem zu den CBSSTätigkeitsfeldern konkrete Ziele ausgegeben sind, so auch zur EnergieKooperation. Nachdem vom Ministertreffen in den vorangegangen Jahren lediglich vage die Entwicklung regionaler Transport- und Energie-Netze als Priorität für Koordination durch den CBSS ausgewiesen worden war und man überdies der Energieversorgung in der Region in Form des „Baltic Ring“ eine elementare Bedeutung beigemessen hatte, ${ }^{195}$ stellt das Kalmar-Programm einen

\footnotetext{
${ }^{193}$ CSO-Jahresbericht 1993-1994, Abs. 3.

${ }^{194}$ Siehe CSO-Jahresbericht 1993/1994, Abs. 4.

195 „Tallin Communiqué“, Mai 1994.
} 
ersten Eckpunkt dar. - Der „Baltic Ring“, ein von der privaten Energiewirtschaft ausgearbeitetes Konzept untereinander verbundener Versorgungsnetze, sollte allerdings erst von 1996 bis '98 in einer hauptsächlich von der Privatwirtschaft durchgeführten Studie detailliert erörtert werden, sodass eine frühere Bezugnahme nichts Konkretes hätte bieten können. ${ }^{196}$

Das Kalmar-Programm, das nach vierjährigem Bestehen auf dem Treffen der Außenminister in der südschwedischen Küstenstadt entworfen wurde, diente für die Position des CBSS vorerst als Richtlinie in der Energiepolitik. Es heißt darin zu diesem Sachbereich, dem programmatisch „Supply, Environment and Safety“ vorangestellt ist, es seien alle zweckdienlichen Maßnahmen auf nationaler und multilateraler Ebene sowie durch die EU zu ergreifen, um folgendes zu erreichen: eine effiziente Energienutzung im Sinne der „Energy Charter“, die zunehmende Anwendung „erneuerbarer“ Energien sowie eine umweltschonende Energieerzeugung und -verteilung. Gleichermaßen wird ein regionales Elektrizitätsnetz, der „Baltic Ring“, in Aussicht gestellt, hinsichtlich seiner Finanzierung und technischer Ausführung jedoch noch nicht näher bestimmt, da diese erst zu evaluieren seien; des weiteren seien die Möglichkeiten eines Ausbaus eines regionalen Gasnetzes in einer entsprechenden Studie auszuloten. Kernenergie wird aufgrund technischer Sicherheitsbedenken und wegen unerwünschter Umweltbelastung v.a. bei der Entsorgung des atomaren Abfalls kritisch wahrgenommen, und es wird eine kritische Kontrolle der in der Region vorhandenen kerntechnischen Anlagen samt der Entsorgung des atomaren Abfalls angemahnt, wobei auch eine möglicherweise als notwendig erachtete Schließung entsprechender in Russland bzw. Litauen gelegener Anlagen ausdrücklich in Betracht gezogen wird. ${ }^{197}$ Eindeutig wird damit als Schwerpunkt der CBSSTätigkeit hervorgehoben, Studien anzuregen und gemeinsame Ziele auszuloten. An der Realisierung der Vision eines gemeinsamen Elektrizitätsmarktes wird nach wie vor gearbeitet, wofür das 1998 eingerichtete Beratungsgremium BALTREL ${ }^{198}$ verantwortlich zeichnet, das sich aus Vertretern von Unternehmen und Staaten zusammensetzt, so dass hier eine enge Vernetzung der Akteure erwirkt wurde.

\footnotetext{
${ }^{196}$ Siehe Abschlussbericht der „Baltic Ring Study“, online dokumentiert, URL: http://www.lps.lv/nozares/energy/elektr/parsk/balticring.htm, 15.2.2007.

${ }^{197}$ Siehe „Kalmar Action Programme“, 1996.

${ }^{198}$ BALTREL: „Baltic Ring Electricity Co-operation Committee“.
} 
Skizziert worden war in Kalmar somit die programmatische Zielsetzung des CBSS, sich künftig unter umsichtiger ökologischer Berücksichtigung neuer Technologien dem Ausbau von Energienetzen widmen $\mathrm{zu}$ wollen, da wirtschaftliche Interessen der Staaten dies nahelegten. Im Kalmar-Kommuniqué desselben Jahres, dem turnusgemäßen Abschlussdokument des Rats-Treffens, findet sich eine Aussage, die zwar nicht ausschließlich auf den Sachbereich Energie bezogen ist, sich jedoch auf diesen anwenden lässt, da sie von grundsätzlicher Natur ist: Der anzunehmende Beitritt der baltischen Staaten und Polens zur EU wecke die Aussicht auf größere Möglichkeiten der Zusammenarbeit. ${ }^{199}$ Die damaligen Gegebenheiten wurden demzufolge von den Hauptverantwortlichen selbst als nicht zufriedenstellend empfunden. Gewissermaßen als Bestätigung für Erwartungshaltungen dieser Art liest sich die Stellungnahme eines dänischen Diplomaten im Jahr 2001:

[...] the sheer intensity of the enlargement process and the entry into force of the EU-Russia Partnership and Co-operation Agreement turned the EU into a highly dominating agent in the region. The CBSS has made a considerable contribution, but is no longer the main agent for overall economic and political integration. ${ }^{200}$

Auf der Umweltminister-Konferenz im Stockholmer Vorort Saltsjöbaden im Oktober '96 (während lettischer CBSS-Präsidentschaft) sind Stellungnahmen zum künftigen Rahmen von umweltpolitischen Vorhaben verfasst worden, die gleichermaßen als Finanzinstrumente der Energiepolitik verstanden werden können. Sie verbleiben jedoch konturlos. ${ }^{201}$ Der Verweis auf die Abhängigkeit von Geldern, die von internationalen Finanzinstitutionen, z.B. der Europäischen Investititionsbank, oder aus nationalen Töpfen bereitgestellt werden, wird in der Erklärung der Umweltminister betont.

\subsubsection{Ebene der Regierungschefs}

Nachdem auf dem ersten Gipfeltreffen des CBSS 1996 zwar die Notwendigkeit einer Kooperation im Umweltschutzbereich betont, jedoch noch keine nennenswerten Verlautbarungen zum Sachbereich Energie gemacht worden waren, wurde im Jahr darauf mit der „Bergen-Declaration“ der - laut BASREC ${ }^{202}$ - eigentliche Auftakt gegeben zu einem langfristigen Kooperationsprozess hin-

\footnotetext{
${ }^{199}$ Siehe 1996 CBSS 4th Ministerial Session, Kalmar Communiqué.

${ }^{200}$ Nielsen, Dan, in: Baltinfo, Nr. 41, Oktober 2001.

${ }^{201}$ Siehe „1st CBSS Ministers of Environment meeting (Saltsjöbaden, 1996).

${ }^{202}$ Siehe Kap. 4.2.5, S. 67 ff.
} 
sichtlich „Sustainable Energy Supply around the Baltic Sea“, so der Titel des Dokuments. Allerdings zeichnet nicht der CBSS hierfür verantwortlich, sondern es ist im Rahmen der nordischen Kooperation entstanden und von den fünf Premiers an die Energieminister gerichtet. Auf dem zweiten Treffen der CBSS-Regierungschefs, 1998 in Riga, wurde Energiepolitik eine Schlüsselrolle für die wirtschaftliche Prosperität der Region attestiert: In seinem „Energy Fact Sheet“ beruft sich der Gipfel auf die „Bergen-Declaration“ und spricht sich grundsätzlich für eine umfangreiche Verknüpfung der Energienetze und eine klimafreundliche Nutzung aus, wobei auch hier die Bedürfnisse und Charakteristika der Region für sich genommen werden, ohne sie in einen größeren europäischen Kontext zu stellen. ${ }^{203}$ Einer auf die Ostseeregion bezogenen Energiepolitik war damit auf allen Ebenen in den - intergouvernemental zusammengesetzten - Gremien des CBSS ein hoher Status zugeschrieben, da die Versorgungssicherheit als entscheidender Faktor für Wachstum und Wohlstand wahrgenommen wurde. Die Verankerung dieses Themas auf der regionalen Agenda ist allerdings nicht auf die Initiative des CBSS, sondern die der Nordischen Kooperation zurückzuführen. Diese setzt auch gegenwärtig auf eine explizit nordische Energiepolitik, hat jedoch ihr Selbstverständnis gewandelt hin zu einer deutlichen Einbindung in den CBSS, wie aus dem gegenwärtig gültigen Handlungsplan des NMR hervorgeht, in dem es im Kapitel „Der Norden in der Energie-Zusammenarbeit in der Ostseeregion“ heißt:

Das nordische Engagement in der Energie-Zusammenarbeit des Ostseerats, das zuvor den Charakter einer nordischen Unterstützung zur Entwicklung eines Energiesektors in der Ostseeregion hatte [...], ist nun eine Zusammenarbeit unter gleichwertigen EU-/EWR-Ländern auf der einen Seite und auf der anderen Seite zwischen diesen und dem großen Energie-Exporteur - Russland. ${ }^{204}$

\subsubsection{1 „Baltic 21“6}

Auf dem Visby-Gipfel wurde die Idee lanciert, in Anlehnung an die UNOKonferenz des Jahres 1992 in Rio de Janeiro, eine „Agenda 21“ für die Ostseeregion aufzustellen. Als „Baltic 21“ wurde sie 1998 auf dem Ratstreffen angenommen und auf drei Jahrzehnte ausgerichtet, und es arbeiten in dieser Institution Repräsentanten der CBSS-Mitglieder sowie gesellschaftliche und privatwirtschaftliche Organisationen zusammen. Die umweltverträgliche, zu-

\footnotetext{
${ }^{203}$ Siehe „2nd Baltic Sea States Summit, Riga, 22-23 January 1998“, „Energy Fact Sheet“.

${ }^{204}$ Nordischer Ministerrat (Hg.): Handlingsplan for det nordiske energisamarbejde 2006-2009, Kopenhagen 2005, hier S. 28.
} 
kunftsfähige Entwicklung war somit durch die Regierungschefs und Außenminister in die Verantwortung einer Vielzahl von Akteuren gelegt worden, sollte allerdings für den Bereich Energie bereits im Jahr darauf der institutionalisierten Zusammenarbeit der Energie-Minister (BASREC) unterstellt werden. $^{205}$

In die Zeit um 1997 fallen erste konkrete Fortschritte hinsichtlich der regionalen Kooperation im Energiesektor. Die WG-EC kann über die bereits bestehende Beteiligung internationaler Finanzinstitutionen hinaus vermelden, dass zusätzliche Gelder, in erster Linie durch die Europäische Investitionsbank, in Aussicht gestellt sind. Außerdem sind - eine wesentliches Entgegenkommen für künftige Investitionen des privaten Sektors - erste erkennbare Angleichungen der nationalen rechtlichen Rahmenbedingungen umgesetzt worden, wie der Jahresbericht der WG-EC im Mai '97 unterstreicht, wobei er dies für die mit der EU assoziierten oder über einen Beitritt verhandelnden Staaten betont und bezüglich Russlands dementsprechend von einem Nachholbedarf spricht. ${ }^{206}$ Die bereits erwähnte Erwartungshaltung der Außenminister, zum Ausdruck gebracht in Kalmar, der EU-Beitritt der postsozialistischen Staaten werde die Kooperationsmöglichkeiten der Staaten untereinander erheblich verbessern, findet hierin Bestätigung, da die Harmonisierung der Gesetzgebung auf die Beitrittsverhandlungen mit der Union zurückgeführt wird. Die Ostsee-Kooperation selbst scheint hier als Zugpferd nicht kräftig genug für eine tiefere Verflechtung, wenn auch für die dringende Problemstellung - Sicherstellung der Energieversorgung - eine regionale Lösung gesucht wird. Auf Anregung Lettlands als CBSS-Vorsitzendem, so der Bericht außerdem, habe sich die EU-Kommission bereiterklärt, an der Entwicklung einer makro-ökonomischen Identität der Region konstruktiv mitzuwirken, deren Ziel es sein solle, „to form an idea of the economic potential of the Region as a whole, in which radical changes in economic development in the coming decades will take place. “207 In diesem Sinne ist es auch $\mathrm{zu}$ interpretieren, dass in zahlreichen Fällen die CBSS-Gremien den voranschreitenden Abbau der wirtschaftlichen Kluft in der Region auf den erfolgreichen Einsatz der EU-Struktur- und Regionalfonds zurückführen.

\footnotetext{
205 Über „Baltic 21“ und BASREC informieren umfangreich die entsprechenden Websites: www.baltic21.org bzw. http://www.cbss.st/basrec; zu BASREC siehe Kap. 4.2.5, S. 67 ff.. ${ }^{206}$ Vgl. WG-EC-Jahresbericht 1996/1997, Abs. 2.3.ff., bei CSO-Jahresbericht

${ }^{207}$ WG-EC-Jahresbericht, Abs. 2.13.
} 


\subsubsection{Parlamentarierkonferenz}

Von der Ostseeparlamentarierkonferenz wurde bereits 1995 die Aufforderung an die Regierungen gerichtet, kurzfristig den Aufbau eines Netzes für die Erdgasversorgung zu ermöglichen; über lange Sicht solle außerdem die kommerzielle Nutzung erneuerbarer Energiequellen gefördert werden. ${ }^{208}$ Darüber hinaus wird in der Resolution der Konferenz ein freier Markt für u.a. Energie und Rohstoffe sowie eine Erleichterung privatwirtschaftlichen Engagements in diesem Sektor gefordert. Dass dieser Aufruf in der Resolution des Folgejahrs gar wortwörtlich wiederholt wurde, ${ }^{209}$ deutet auf eine nur schleppende Entwicklung auf diesem Gebiet hin. Es kann jedoch auch als Hinweis darauf verstanden werden, dass seitens der Parlamentarier die Wahrnehmung der eigenen Arbeit durch die Regierenden als unbefriedigend bewertet wird. Es ist allerdings fragwürdig, ob dies als Ausdruck einer mangelhaften Wertschätzung durch die Regierungen $\mathrm{zu}$ verstehen ist. Denkbar ist auch ein $\mathrm{zu}$ wenig nachdrückliches Engagement der parlamentarischen Delegierten, eigene Konzepte vorzulegen oder Beiträge einzubringen.

\subsubsection{BASREC}

Unter dem Namen BASREC, „Baltic Sea Region Energy Co-operation“, institutionalisierten die für Energie zuständigen Minister der Ostseeanrainerstaaten Ende 1999 anlässlich ihrer Zusammenkunft in Helsinki ihre intergouvernementale Zusammenarbeit, in der die EU-Kommission durch die Generaldirektion Transport und Energie repräsentiert ist und die die grundsätzlichen Zielsetzungen des CBSS wie des NMR gleichermaßen einbindet. Dabei ist die BASREC-Struktur eng an die des CBSS gebunden: Eine „Group of Senior Energy Officials“ (GSEO) ist von den Ministern eingesetzt, steht für die Koordination der Arbeit ein und kann für administrative Zwecke auf ein Sekretariat zugreifen, das im CBSS-Sekretariat separat geführt ist, allerdings vom NMR finanziert wird. Auf der Basis der gegenwärtigen Marktsituation sowie in Orientierung an EU-Vorgaben sind Vorhaben hinsichtlich eines künftigen regionalen Energiemarkts zu erarbeiten, wozu auch von der Privatwirtschaft ausgehende operative Beiträge, formuliert z.B. über die „Baltic Ring Energie Cooperation“, dezidiert einzubinden sind. Der BASREC-Vorsitz entspricht jeweils dem des CBSS.

\footnotetext{
${ }^{208}$ Siehe „4th Parliamentary Conferences on Co-operation in the Baltic Sea Area (Sept. 95)“.

${ }^{209}$ Siehe ,,5th Parliamentary Conference on Co-operation in the Baltic Sea Area (Sept. 96)““.
} 
Für Detailfragen, auch für die Kontaktpflege mit den nationalen Behörden zeichnen fest etablierte Arbeitsgruppen verantwortlich, doch trotz der handlungsorientierten Ausrichtung ist BASREC ebenso wie die Dachorganisation CBSS mitnichten als ausführendes Organ, sondern als „Forum zum Aufbau einer regionalen Perspektive der [nationalen] energiepolitischen Strategien““210 zu verstehen. Eine zentrale Rolle kommt BASREC nunmehr in der Umsetzung der Aktionspläne der ND zu.

Einer der Arbeitsgruppen obliegt es, die Situation der Gasmärkte in der Region zu analysieren mit der Aufgabe, die Bedingungen und Hindernisse für den Bau von Offshore-Gasleitungen auszuloten und dabei die Bedürfnisse der gesamten Region in Betracht zu ziehen. Darüber informiert detailliert der Bericht der GSEO zur Vorlage auf dem Treffen der Energieminister 2002 in Vilnius. ${ }^{211}$ Den Vorsitz dieser Gruppe haben Deutschland und Russland inne. Für den möglichen Bau von Offshore-Pipelines seien, so der Bericht des GSEO, in einer Studie die Komplexität der behördlichen, institutionellen und technischen Rahmenbedingungen und Regeln als Hindernisse benannt worden. - Der Eindruck drängt sich auf, als wäre hier ein Grundstein zu einer bilateralen Lösung gelegt worden, findet jedoch in keinerlei Stellungnahme des CBSS eine Entsprechung.

Vorausgegangen war der Konferenz in Helsinki im Vorjahr ein Treffen der Energie-Minister im norwegischen Stavanger, auf dem diese „Materie“ im Rahmen des CBSS erstmals auf Ministerebene beraten wurde. Hier zeigt sich, dass die Organisation somit fraglos einen Rahmen für Beratungen auf allen politischen Ebenen bietet, dass jedoch die Initiative für die sektorale Zusammenarbeit durchaus nicht immer vom vorsitzenden Mitglied ausgeht: Norwegen hatte während litauischer Präsidentschaft nach Stavanger geladen, und bereits dort war die Entscheidung gefallen, das folgende Treffen in Finnland durchzuführen ${ }^{212}$, während der Vorsitz bei Norwegen liegen sollte. Die dritte Zusammenkunft fand zur Zeit der finnischen Präsidentschaft 2002 in Vilnius statt; 2005 kamen die Energieminister in Reykjavik zusammen, während Island auch den CBSS-Vorsitz innehatte. Durch den zwanglosen Charakter der Organisation ist diese unregelmäßige Frequenz durchaus ermöglicht und nicht per se ein Ausdruck von

\footnotetext{
${ }^{210}$ Grundlegende Informationen der BASREC selbst, dokumentiert auf der Website des CBSS, URL: http://www.cbss.st/basrec/dbaFile2000.html, 28.2.2007.

211 Report by the Group of Senior Energy Officials (GSEO) for the Meeting of the Energy Ministers of the CBSS Member Countries and the European Commission, Vilnius, 20.11.2002.

${ }^{212}$ Siehe „1st Meeting of the CBSS Energy Ministers (Stavanger, 30 Nov. - 1 Dec. 1998)“.
} 
Desinteresse an der Kooperation, doch es lässt sich hierin allerdings auch eine Vorreiterrolle einzelner Staaten in der Ostsee-Kooperation erahnen. Dieser Eindruck wird insbesondere durch die finnische Initiative zur ND innerhalb der EU bestärkt.

Ähnlich profitiert die Einbindung nicht-gouvernementaler Akteure durch den CBSS von dessen flexiblen Möglichkeiten der Zusammenarbeit, wie sich in der umfangreichen Mitwirkung an der Entwicklung der Energie-Infrastruktur zeigt. Privatwirtschaftliche Akteure, deren Handlungsspielräume mit der Öffnung und Liberalisierung der nationalen Märkte gewachsen sind, werden bei der konzeptionellen Arbeit einbezogen und somit zumindest politisch in die Verantwortung genommen, wodurch ein Ignorieren wechselseitiger Bindungen und ein Ausbrechen aus diesen erschwert wird.

Der Gruppierung um BASREC und „Baltic 21“ obliegt es nunmehr eingegliedert in die ND -, die Ostseeregion als Experimentierfeld zur Umsetzung des Kyotoprotokolls zu gestalten. In der hiermit skizzierten Situation findet sich ein deutlicher Hinweis darauf, dass sich in dieser Region das Bewusstsein verfestigt, Bedrohungen weniger im militärischen und vielmehr in anderen Bereichen verorten zu müssen und ihrer zudem nur in konzertierten Aktionen Herr werden zu können.

Mit diesen Gremien hat die Zusammenarbeit in der Energiepolitik im CBSS ihre heutige Form angenommen, die in multilateralem Format zur Koordination einzelner Maßnahmen geführt hat. Die Entwicklung wird bereits im Jahr 2000 als stark beinflusst von der ND wahrgenommen:

The salience of the field is also due to the role of Energy in the Northern Dimension. ${ }^{213}$

\subsection{EU-Politik für die Region}

Nicht nur die - erfolgreichen - Beitrittsverhandlungen mit weiteren Staaten, sondern auch eine inhaltliche Ausrichtung der Unions-Politiken auf diese Region macht das politische System des Ostseeraums zusätzlich komplex. Erste zögerliche Schritte zu einer Annäherung der EU an die Region sind zu Beginn der '90 Jahre unternommen worden, doch reichten diese in herkömmlich als „low

\footnotetext{
${ }^{213}$ Stålvant, Carl-Einar: „Baltic Sea co-operation: Moving forward?“, in: Baltinfo, Nr. 28, März
} 2000 . 
politics“ betitelten Bereichen nicht sehr weit. Zwar befanden sich die Systeme im ehemals sowjetischen Raum noch im Übergang zu demokratischen, rechtsstaatlichen und marktwirtschaftlichen Strukturen, so dass Unterstützung für möglich, wenn nicht nötig gehalten wurde, doch in erster Linie beschränkte sich dies auf bilaterale Verträge. Die „Baltic Sea Region Initiative“ der EU, im Juni 1996 vom Europäischen Rat angenommen, fasst erstmals die bisherigen EUBeiträge ideeller und finanzieller Art zusammen, unterscheidet sich in den Zielsetzungen jedoch unwesentlich von den bis dato vorliegenden CBSSDokumenten. In Orientierung an dem Ziel ,to strengthen political stability and economic development in the Baltic Sea region“ ${ }^{214}$ werden verschiedene Bereiche skizziert, denen Aufmerksamkeit geschenkt werden solle, doch das Papier betont die Absicht der Union, über die vorhandenen und bereits angewendeten Finanzinstrumente hinaus keine zusätzlichen Mittel zur Verfügung zu stellen. Parallelen zur Prioritätensetzung in der Kopenhagener Erklärung sind nicht nur augenfällig, sondern es wird abschließend die Sonderrolle des CBSS für die Kooperation in dieser Region bestätigt:

[T] he Commission suggests that measures for enhancement of democracy and stability be promoted by the CBSS on the basis of an action plan to be agreed upon by the Member States of the CBSS at ministerial level [...] [and] proposes to develop the CBSS as a forum for assessing regional needs and priorities and to strengthen in particular its Working Group on Economic Co-operation [...]. ${ }^{215}$

Obwohl sich in dieser Region gerade aus EU-Perspektive mit dem unlängst erfolgten Beitritt Schwedens und Finnlands und den sich intensivierenden bilateralen Kontakten mit den Nicht-Mitgliedern ein nennenswerter Wandel vollzog, war dem Ostseeraum kein eigenes politisches Konzept gewidmet. Mit dieser weitgehenden Konservierung der bestehenden Kooperation wurde die EU offensichtlich nicht den Vorstellungen der Adressaten gerecht, denn Finnland lancierte kurze Zeit später die Initiative zur ND der Union, die sich sukzessive zu einem Programm für die Region entwickeln sollte.

\subsubsection{Die Nördliche Dimension}

„Wahrgenommen“ (recognised) wurde die nördliche Dimension Europas, wie es in den Informationen der EU-Kommission heißt, erstmalig Ende 1997. Sukzessive wurde die dahinter stehende Idee von der Kommission zu einem

${ }^{214}$ EU-Kommission: „Baltic Sea Region Initiative“, Einleitung, Website des CBSS.

215 „Baltic Sea Region Initiative“, Abs. 5, „Reinforcing the Role of the CBSS“. 
eigenen Programm ausgearbeitet, das von Ratstreffen $\mathrm{zu}$ Ratstreffen vorangetrieben werden konnte und bestehenden Kooperationsformen einen Mehrwert geben soll. Dieser wird darin gesehen, unter Verzicht auf die Formulierung gänzlich neuer Vorhaben eine Koordination der verschiedenen Programme der EU und anderer Akteure $\mathrm{zu}$ erreichen, $\mathrm{zu}$ welchem Zweck grenzübergreifende Zusammenarbeitsmöglichkeiten zu sondieren und zu nutzen seien. ${ }^{216}$

Im wesentlichen wird mit der ND der Absicht Ausdruck gegeben, sich seitens der EU bewusst dieser Region - als Wirtschaftsraum sowie als Grenzbereich zu Russland - zuzuwenden, wobei die Erschließung russischer Energievorräte für den europäischen Markt von Anfang an ein wesentliches Motiv der ND war. Die ND ist geographisch wesentlich weiter gefasst als die Ostseeregion, indem sie über diese hinaus bis in die Arktis und nach Grönland gespannt ist, damit aber den Einzugsbereich des CBSS gänzlich einbezieht. Im Jahr 2000 fand der erste Aktionsplan der ND (1. AP) die Zustimmung des Rates, so dass damit acht Jahre nach Beginn der zwischenstaatlichen Kooperation im CBSS auch in der EU diese Region als solche etabliert war. ${ }^{217}$ Vorgeschlagen von Finnland, stieß die Idee ursprünglich offenbar nicht auf ungeteilte Euphorie unter allen Ostsee-Anrainerstaaten. Im Kommuniqué der Ostsee-Außenminister heißt es Mitte 1998 zwar lapidar, der Rat begrüße die Initiative, da sie zu einer Stärkung der Ostseerats-Aktivitäten beitragen werde. $^{218}$ Skepsis war nichtsdestotrotz gegeben, wenn auch anscheinend unterschiedlich motiviert: Während im Baltikum bereits Befürchtungen gehegt wurden, v.a. beim Bau neuer Gasnetze könnte es geographisch umgangen und somit um Einnahmen gebracht werden, die andernfalls mit dem Rohstoff-Transit zu verbuchen wären, seien die skandinavischen EU-Mitglieder über die Art des finnischen Alleingangs wenig erbaut gewesen. $^{219}$

\footnotetext{
${ }^{216}$ Siehe NDAP, Abs. 25, S. 8.

${ }^{217}$ Zur Geschichte der ND siehe ND-Informationssystem der Website der EU-Kommission, URL: http://ec.europa.eu/comm/external_relations/north_dim/index.htm, 12.2.2007.

218 7. Ratstreffen, „Nyborg Communiqué“, Abs. 3, 22./23.6.1998, online dokumentiert, URL: http://www.cbss.st/documents/cbsspresidencies/6danish/dbaFile3003.html, 12.2.2007.

${ }^{219}$ Auf diese Interessenkonflikte verweist die Neue Zürcher Zeitung am 28.12.1999, (N.N.): „Die ,Nördliche Dimension“ auf Eis gelegt", online dokumentiert, URL: http://wwwx.nzz.ch/format/articles/180.html, 2.3.2007.
} 


\subsubsection{Der 1. Aktionsplan}

Der 1. AP für den Zeitraum von 2000 bis 2003 stellt erstens die Perspektive der EU auf die Herausforderungen dieses Raumes dar und weist zweitens die operative Linie für den gegebenen Zeitraum aus, wobei die EU die Programmatik als ,political recommendation to be taken into account by relevant actors whenever appropriate“220 verstanden wissen will. Dies liest sich wie eine Absichtserklärung, die Entwicklung der politischen und wirtschaftlichen Strukturen der Region unter Beschränkung der eigenen Partizipation auf ein Minimum zu prägen, was allerdings auf die Interdependenzen zwischen EU und Staaten bzw. Staaten untereinander ausgerichtet ist. ${ }^{221}$ Die Einbindung intergouvernementaler Organisationen dieser Region wird ausdrücklich angestrebt, während eine Einbindung subnationaler Akteure lediglich als Möglichkeit dargestellt ist ${ }^{222}$ und im 1. AP lediglich am Schluss der Liste der Tätigkeitsfelder thematisiert wird.

Dennoch benennt dieses Papier eben diese „regionale und grenzübergreifende Zusammenarbeit“ als „wesentliches Element“ für Frieden, Sicherheit und nachhaltige Entwicklung. ${ }^{223}$ U.a. heißt es hierzu, es müsse der Entwicklung und Vertiefung neuer und bestehender Kontaktnetze zwischen Akteuren unterschiedlicher politischer Ebenen und gesellschaftlicher Gruppierungen Priorität eingeräumt werden. Für die Unterstützung entsprechender Projekte, z.B. kultureller Austauschprogramme, Tourismus-Zusammenarbeit oder grenzübergreifender Landwirtschaftsprojekte, stellt die EU - damals wie heute - finanzielle Mittel in Form verschiedener Regional- wie Struktur-Fonds zur Verfügung, wie im 1. AP im einzelnen ausgewiesen. ${ }^{224}$ Da die Union eigene Initiativen in diesem Papier nicht vorschlägt - sondern sich, wie erwähnt, auf die Unterstützung gegebener Projekte konzentriert -, ist mit diesem für die Ostseeregion maßgeblichen Aktionsplan eine auch vertikale Integration konzeptionell nicht ausgearbeitet. Referenzen an den „Ausschuss der Regionen“ der EU oder auch an bereits umfangreich bestehende regionale subnationale Institutionen enthält der 1 . AP nicht. Die in dieser Region seinerzeit bereits verhältnismäßig dichten gesellschaftlichen Vernetzungen werden damit kaum honoriert.

\footnotetext{
220 „NDAP“, Abs. 5, S. 3.

${ }^{221}$ Siehe „NDAP“, Abs. 7, S. 4.

${ }^{222}$ Siehe NDAP, Abs. 22, S. 7.

${ }^{223}$ Siehe NDAP, Abs. 90, S. 33.

${ }^{224}$ Siehe NDAP, Abs. 98 ff., S. 35 ff..
} 


\subsubsection{Energie im 1. Aktionsplan}

„Energie“ wird an oberster Stelle der Tätigkeitsfelder geführt, auf die dieser 1. AP ausgerichtet ist. Handlungsbedarf ergibt sich nach Einschätzung der EU in erster Linie aus folgendem Grund:

The energy sector in the region faces ongoing structural reforms, in particular in the perspective of integration with the single market. The region is potentially important for the EU as a source of gas and as a transit region for gas and oil. To this end, investments in infrastucture and field development will be necessary. ${ }^{225}$

Infolgedessen zielt der Plan auf den Ausbau und die Verbesserung der Netze (primär in den assoziierten Staaten) sowie die Verbindung der nationalen Märkte zu einem regionalen und die Anbindung an einen europäischen Markt ab. Entsprechend wolle die EU u.a. ,,assist Estonia, Latvia, Lithania and Poland to integrate their energy markets and networks and to connect them with those of the enlarging EU، ${ }^{3226}$. - Umweltfreundlichere Energiegewinnung und -nutzung werden gleichermaßen als Ziele ausgegeben, in den einzelnen Maßnahmen jedoch nicht erneut aufgegriffen. Ebenso wie „Nukleare Sicherheit““ wird „Umweltschutz“ im 1. AP separat thematisiert und somit nicht wie in der Kopenhagener Erklärung in einen unmittelbaren Zusammenhang mit der Energieversorgung gestellt.

Die Initiative für die Ausarbeitung konkreter Maßnahmen wird dem CBSS übertragen:

The Commission and the Member States concerned will participate actively in the activities of the Group of Senior Energy Officials, mandated by the ministers of the Baltic Sea region to define and manage the regional energy cooperation programme and thus contribute to the implementation of this Action Plan. ${ }^{227}$

Demzufolge behält sich die EU an eigenen Aufgaben neben MonitoringTätigkeiten und Anwendung der Finanzinstrumente vor, in Energiefragen einen Meinungsaustausch mit Russland aufzunehmen, wobei die Region letztlich auf die Funktion einer Plattform reduziert wird:

The EU and Russia should open discussions on interconnecting EU and Russian electricity infrastructures and markets in order to achieve a common understanding of the way forward. ${ }^{228}$

Abschließend wird die Zielvorgabe ausgegeben, „to establish a common view on how to enhance security of gas supply and most economically connect the

\footnotetext{
${ }^{225}$ NDAP, Abs. 27, S. 9.

${ }^{226}$ NDAP, Abs. 34, S. 11.

${ }^{227}$ NDAP, Abs. 34, S. 10.

${ }^{228}$ NDAP, Abs. 34, letzter Gliederungspunkt, S. 12.
} 
baltic Sea Region gas markets", wobei das regionale bestmöglich in das im Entstehen begriffene transeuropäische Netz einzubinden sei. ${ }^{229} \mathrm{Im}$ Ganzen bringt der 1. AP zum Thema Energie damit im Wesentlichen das Interesse der EU zum Ausdruck, die Ostseeregion sowie die übrigen mit der ND erfassten Gebiete wirtschaftlich für den eigenen Markt zu erschließen.

\subsubsection{Der 2. Aktionsplan}

Im 2. AP, beschlossen auf der Basis einer grundsätzlich positiven Auswertung der Entwicklung der vorangegangenen Jahre, finden sich Formulierungen, die auf eine geänderte Einschätzung der Bedingungen des internationalen Systems schließen lassen. Während die übergeordneten Zielsetzungen des 1. AP beibehalten sind, sind die Schwerpunkte in diesem Dokument, gültig von 2004 bis 2006, durchaus verschoben. Dies zeigt sich zum einen in einer deutlicheren Betonung von EU-Interessen in diesem Raum, zum anderen aber auch in der Erkenntnis, Erfolg für die Verfestigung der ND in der EU-Politik stütze sich nicht nur auf die staatlichen Ebenen:

Ihr Erfolg hängt davon ab, dass sich alle beteiligten Akteure auf nationaler, regionaler und lokaler Ebene, in den Reihen der Wirtschaft und der Zivilgesellschaft allgemein aktiv einbringen. ${ }^{230}$

Entsprechend hebt dieser AP eine Reihe von Institutionen der Ostseeregion hervor, auf deren Arbeit die ND-Politik aufbauen müsse. Bezogen auf $\mathrm{Zu}$ sammenarbeit in umweltpolitischen Fragen bspw. heißt es, „[b]ei dieser Arbeit müssen die Partner im Rahmen der Nördlichen Dimension die Überwachungsberichte der Europäischen Union, der HELCOM, der Ostsee-Agenda 21

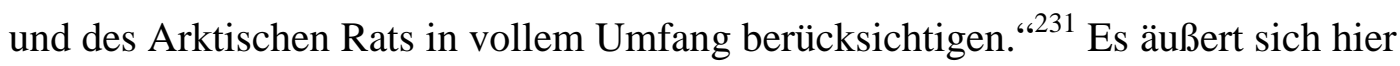
ein Paradigmenwechsel: von der Verwaltung und Anregung intergouvernementaler Zusammenarbeit durch die EU hin zum Aufgreifen jeglicher Formen der Zusammenarbeit auch non-gouvernementaler Art, um dadurch die Interdependenzen $\mathrm{zu}$ vertiefen und $\mathrm{zu}$ stärken. Deutlicher noch wird dies in der Darstellung des Kapitels „Grenzüberschreitende Zusammenarbeit“, wonach die Verantwortung für erfolgreiche Zusammenarbeit nicht zuletzt bei den betroffenen

\footnotetext{
${ }^{229}$ NDAP, Abs. 35, S. 12.

${ }^{230}$ EU-Kommission: Zweiter Aktionsplan für die Nördliche Dimension, 2004-06, Einleitung, S. 2. Der allgemeine, einführende Teil des 2. NDAP ist in allen Sprachen der EU-Mitglieder veröffentlicht.

${ }^{231}$ 2. AP, Kap. 3.3 „Umwelt, nukleare Sicherheit und natürliche Ressourcen“, S.10.
} 
Regionen selbst liege, so dass der 2. AP den folgenden operativen Schwerpunkt setzt:

Schaffung weiterer Anreize für die enge Einbeziehung lokaler Akteure, Bevölkerungsgruppen und Verwaltungen zur Stärkung der Subsidiarität und der lokalen Eigenverantwortung für Projekte. Bessere Ergebnisse lassen sich durch die Ausrichtung an bestehenden Beispielen für eine dreigliedrige Zusammenarbeit und durch die Nutzung der Sachkenntnis von regionalen und Subregionalen Organisationen wie die subregionale Zusammenarbeit der Ostseeanrainerstaaten, die Union der Ostseestädte und der regionale Rat für die Barentssee erzielen. ${ }^{232}$

Indirekt wird damit die Integrationsleistung des CBSS in doppelter Hinsicht hervorgehoben, da nicht nur sein Wirken für sich genommen positiv Erwähnung findet, sondern ihm auch maßgebliche Bedeutung für den Erfolg der EU-Politiken eingeräumt wird. Verglichen mit dem vorangegangenen AP zeigt sich im 2. eine gesteigerte Wertschätzung regionaler Identitätsbildung außerdem in der Berücksichtigung des „Ausschuss der Regionen“ der EU, dessen Arbeit in die ND-Politik zu integrieren sei. ${ }^{233}$

\subsubsection{Energie im 2. Aktionsplan}

Im Hinblick auf die Energiepolitik markiert der 2. AP im Gegensatz zum 1. unumwunden die EU-Interessen, die mit der ND zu verwirklichen seien. Um die Versorgungssicherheit des Kontinents und auch die der Staaten in diesem Raum zu gewährleisten, werden mit dem 2. AP der Bau entsprechender Infrastruktur propagiert und eine langfristige Kooperation mit Russland anvisiert. Als künftige Aufgabe ist daher beschrieben:

Entwicklung der Strom- und Erdgasleitungsnetze in der Region der Nördlichen Dimension als Beitrag zur Wettbewerbsfähigkeit im EU-Binnenmarkt und zur Sicherheit der Energieversorgung in ganz Europa. Die Partner im Rahmen der [n ND] arbeiten an [...] der Verwirklichung der vollständigen Integration der beitretenden Länder in die für die EU prioritären Stromleitungsachsen [...]. ${ }^{234}$

Während also als grundsätzliches Ziel definiert ist, neben der Versorgungssicherheit des europäischen Kontinents auch die derjenigen von der ND erfassten Staaten zu gewährleisten, steht im 2. AP dennoch das Interesse der EU an einer engen Verbindung mit Russland im Mittelpunkt, auf dessen Gasvorräte nach eigenem Bekunden angewiesen ist.

\footnotetext{
232 2. AP, Kap. 3.4 „Grenzüberschreitende Zusammenarbeit“", hier S. 12.

${ }^{233}$ Siehe 2. AP, Kap. 4 „Überwachungs- und Überprüfungsmechanismen“, hier S. 16; erwähnt sei hier, dass allerdings keineswegs grenzübergreifende „Euro-Regionen“, sondern subnationale Einheiten im AdR vertreten sind.

234 2. AP, Kap. 3.1.2 „Energie“, S. 6.
} 
Ziel der Energiepartnerschaft ist hauptsächlich die verstärkte Sicherheit der Energieversorgung für die EU und die Verbesserung der Investitionsbedingungen im russischen Energiesektor [...]. ${ }^{235}$

In diesem Sinne finden sich unter den operativen Prioritäten in Bezug auf Strom und Gas zahlreiche, die auf eine Vernetzung des Kontinents mit Russland ausgerichtet sind. Neben anderen Verbindungslinien findet die in der Folgezeit stark umstrittene Pipeline von Russland nach Deutschland hier ausdrücklich Erwähnung:

Implementation of the North European Gas Pipeline, which i spart of one the [...] priority axes and also one of the projects defined as being of ,common interest" in the EU-Russia Energy Dialogue. An improtant element of the North European Gas Pipeline is the possibility of building spur lines, from the main trunk [... ${ }^{236}$

\subsection{Politischer Prozess, der im Pipeline-Projekt mündet}

Den CBSS-Dokumenten seit dessen Gründung wiederholt zu entnehmen, ist ein Ausbau der regionalen Gasnetze in aller Interesse. Im einzelnen war dafür nicht ausschließlich die Bedarfsdeckung der leitende Gedanke, sondern aus Sicht der baltischen Staaten wie Polen war damit auch die Möglichkeit verbunden, bei einem Verlauf der Leitungen durch ihre Territorien Transitgebühren zu erheben. Russland setzt diese Situation in eine komfortable Verhandlungsposition, da es aufgrund seiner unvergleichlich großen Gasreserven als Anbieter für den europäischen Binnenmarkt keinen ernstzunehmenden Konkurrenten hat.

Polnische Vorbehalte gegen den Beschluss sind sicherlich als Ausdruck historisch bedingter Skepsis gegenüber deutsch-russischen Verträgen zu verstehen, reflektieren aber auch Verärgerung darüber, nicht an dem Projekt beteiligt worden zu sein. ${ }^{237}$ In Schweden hingegen werden erheblich Vorbehalte gegen die Pipeline gehegt. Umweltpolitische Bedenken tragen dazu bei, doch insbesondere wird in der Öffentlichkeit eine Diskussion über Risiken für die schwedische Sicherheitsund Verteidigungspolitik geführt. Allgemein wird die Gefahr gesehen, Russland

\footnotetext{
235 2. AP, Kap. 3.1.2 „Energie“, S. 6.

236 2. AP, Anhang: Specific activities to be pursued in addressing the priority objectives set in the Action Plan, Kap. 1.2, S. 23.

${ }^{237}$ Vgl. Leicht, Robert: „,Am Gelde hängt, zum Gelde drängt doch alles““, in: Die Zeit online, Nr. 50 / 2005, URL: http://www.zeit.de/online/2005/50/schroeder_montagskolumne, 3.3.2007.
} 
könne die Pipeline zu Spionagezwecken für den gesamten Ostseeverkehr missbrauchen. $^{238}$

Eine Äußerung wie die Gerhard Schröders, die Ostseeregion sei als Handelspartner für Deutschland wichtiger als die USA ${ }^{239}$, vermag noch zu suggerieren, Deutschland wolle sich nachdrücklich in die Zusammenarbeit der Region und damit auch im CBSS einbinden. Der Weg zum Vertrag zwischen Russland und Deutschland lässt dies jedoch als bloßes Lippenbekenntnis erscheinen und offenbart, dass beide sich an die im CBSS eingegangenen Verpflichtungen - Lösungen im Sinne aller Mitglieder $\mathrm{zu}$ suchen -, nicht unbedingt gebunden fühlen. Sehen sich die nordischen, zunehmend auch die baltischen Staaten als eng zusammengehörig, was sich durchaus in einer Art Koalitionsbildung in der Ostseekooperation widerspiegelt, ${ }^{240}$ fristet Russland gewissermaßen ein Einzelgängerdasein in der Region, da es sich nicht auf Koalitionen stützen kann, die sich aus anderweitigen vertraglichen Bindungen ergeben. Da auch für Deutschland andere internationale Bindungen gegenüber der Ostseekooperation Vorrang genießen, verwundert es im Grunde genommen nicht, dass eine bilaterale Lösung gesucht wurde, zumal die deutsche Position auch den Interessen der EU entgegenkam.

Die eingangs dieser Untersuchung geäußerte Vermutung jedoch, auf Zusammenkünften des CBSS wäre - u.U. unter Vermittlung des Sekretariats - an einer Lösung im Sinne aller Mitglieder gearbeitet worden, lässt sich nicht bestätigen. In den Dokumenten der Organisation jedenfalls findet sich kein entsprechender Hinweis; auch auf ministerieller Ebene scheint dieses Thema nicht multilateral erfasst worden zu sein. Trotz der immensen regionalen Bedeutung sind Verhandlungen lediglich bilateral geführt worden, so dass ein Ergebnis erzielt wurde, das für die Region als erheblicher Rückschlag gesehen werden kann. Drastisch formuliert dies Vytautas Landsbergis in einem Beitrag für „Baltinfo“, das Mitteilungsblatt des CBSS, demzufolge vom „russischen Energie-Imperialismus“ gegenwärtig die größte Bedrohung für die Region ausgehe und der die Gefahr sieht, die Nördliche könne sich zu einer „Russischen Dimension“ wandeln.

\footnotetext{
${ }^{238}$ So z.B. Diskussionsbeitrag in der schwedischen Tageszeitung Dagens Nyheter vom 8.11.2006, in dem aus militärstrategischen Erwägungen für einen geänderten Verlauf der Pipeline argumentiert wird, URL: http://www.dn.se/DNet/jsp/polopoly.jsp?a=592441, 3.3.2007.

${ }^{239}$ Zitiert bei Nienhuysen, Frank: „Ein Meer verschiedener Interessen“, in: Süddeutsche Zeitung, 1.7.2000, S. 8.

${ }^{240}$ Vgl. Hubel / Gänzle, S. 6.
} 
Vorwürfe erhebt er allerdings nicht gegen den CBSS, sondern gegen die EU aufgrund deren Unterstützung für das Pipeline-Projekt.

Thus, if all this takes place, we may find that we, on the eastern Baltic coast from Poland to Estonia, have once again been sold politically. To whom? - that is well known. By whom? - unfortunately by Germany, but the entire EU must bear some responsibility for being so childishly naïve. [...] As a consequence, therefore, if the EU is a body based on solidarity rather than on selfishness, it should now consider the question of alternative energy supplies for this part of the Union as a matter of immediate urgency. ${ }^{241}$

Vermutlich ist dies bezüglich der „russischen Dimension“ allzu schwarz gemalt, doch es wird hier zurecht darauf verwiesen, dass genau die Errungenschaften, die mit der Ostsee-Kooperation verbunden sind - Fortschritte in der Verfestigung einer regionalen Identifikation und Schärfung eines Bewusstseins für den wechselseitigen Nutzen von Kooperation -, nicht zum Tragen kommen. Hierin drückt sich eine Machtpolitik aus, die von russischer Seite gegenwärtig recht unverblümt betrieben wird, die bei Schröder aber schlichtweg auf kurzsichtige Profilierungssucht zurückzuführen sein muss, gern als „Macher“ gesehen zu werden. Immerhin deutet sich in der - vor seiner Wiederwahl getätigten Aussage, er habe noch ,[i]rgendetwas Größeres, vielleicht noch mit Putin“242 vor, ein in der Außenpolitik sehr auf die Regierungschefs zugeschnittenes Politikverständnis an. Die Entscheidung offenbart jedenfalls, dass für den GazpromVertrag mit Russland auch von deutscher Seite eine Identifikation mit den übrigen Ostseeanrainern gänzlich hintan gestellt wurde.

\subsection{Zwischenbetrachtung}

$\mathrm{Da}$ in der ND bzw. insbesondere dem 2. AP klare Prioritäten vorgegeben sind, zu denen Interessenkonflikte mit und unter den Mitgliedstaaten auf der Hand liegen, gehen hiervon keineswegs nur integrative Impulse aus. Während im CBSS konsensual über die Gegebenheiten der Region befunden wird im Bestreben, Trennungen aufzuheben, kommt der Arbeit dieser Organisation offenbar zugute, keine eigenen Interessen $\mathrm{zu}$ vertreten und überdies die Mitglieder nicht an Entschlüsse binden zu können. Demgegenüber birgt die Interessenpolitik der EU das Risiko, Spaltungen zwischen ihren Mitgliedern zu verursachen. Insbesondere dem 2. AP der EU ist eine Spannung immanent zwischen dem Ziel, regionale

\footnotetext{
${ }^{241}$ Landsbergis, Vytautas, in Baltinfo Nr. 75, Okt. 2005, S. 10 f., hier S. 11.

${ }^{242}$ Zitiert von Leicht, Robert, ebd..
} 
Integration vorantreiben und dadurch den Interessen der Mitglieder zu Geltung verhelfen zu wollen, sowie dem Ziel, die eigene Position als wirtschaftlicher und machtpolitischer Akteur gegenüber anderen $\mathrm{zu}$ untermauern. Da das Partikularinteresse Deutschlands an der besagten Gasleitung aus Russland den EUInteressen näher kommt als denen der baltischen Staaten, kann gerade auf der Grundlage des 2. AP der ND eine nationale Entscheidung wider die regionalpolitische Selbstverpflichtung fallen - eine Selbstverpflichtung Deutschlands durch seine CBSS-Mitgliedschaft.

Auf die mit der Unterzeichnung des Kyoto-Protokolls eingegangenen Verpflichtungen war im 1. AP nur beiläufig hingewiesen, wohingegen das folgende Papier auf diese Vorgaben vermehrt Bezug genommen hat. Sowohl für Energie- als auch Umweltpolitik wird hierin die Umsetzung des Protokolls zu Klimaschutzbelangen angemahnt, wobei das in den CBSS-Strukturen bereits beschlossene „Experimentierfeld“ aufgegriffen wird. ${ }^{243}$ In der Dringlichkeit von Herausforderungen dieser Art, die nicht an nationale Grenzen gebunden sind und in der Ostseekooperation auf der politischen Agenda einer Vielzahl von Akteuren an oberer Stelle rangieren, ist offenbar durch die Zusammenarbeit im CBSS ein regionales Problem- und Verantwortungsbewusstsein geschärft worden. Indem sich der CBSS hiermit in die EU einbringt - stärker noch als andere Organisationen der Ostseeregion -, verleiht er deren Nördlicher Dimension insbesondere im 2. AP gewissermaßen ein Profil auch vertikaler politischer und gesellschaftlicher Verflechtung, das auf anderem Wege weitaus schwieriger zu erlangen wäre.

Hinsichtlich der Bedingung für eine Zivilisierung des Systems, dass zunehmende wechselseitige Abhängigkeiten Alleingänge einzelner Akteure irrational werden lassen, wirkt sich die EU-Politik der ND sehr ambivalent aus: Sie lässt gemeinsame Problemlösungen suchen, wirkt diesen aber u.U. aufgrund dezidierten eigenen Interesses entgegen. In weniger deutlicher Form waren diese Spannungen im 1. AP angelegt, da die EU selbst noch nicht gleichermaßen deutlich Position bezogen hatte. Mit der Arbeit des CBSS geht eine solche Tendenz nicht einher; sofern einzelne Mitglieder von einer auf diesem Forum formulierten, einstmals gemeinsamen programmatischen Zielsetzung im Lauf der

\footnotetext{
${ }^{243}$ Vgl. 2. AP, Anhang, Kap. 1.2 „Energy“, hier S. 24, sowie Kap. 3.1 „Environment“, hier S. 33.
} 
Zeit abweichen, verbleibt der CBSS - wenn überhaupt - in der Vermittlerrolle zwischen den Mitgliedern.

Die für die Region aufgezeigte ambivalente Wirkung, die von der NDProgrammatik ausgeht, lässt allerdings daran zweifeln, dass der EU selbst an einer Kohärenz dieser Region wirklich gelegen ist. Es ist Lange zuzustimmen, der 2001 in einer Analyse über die ND zu der Synthese kommt, die EU-Programmatik habe zwar den CBSS ein wenig verdrängt, sei jedoch nicht zu einer konzisen Ostpolitik geworden. $^{244}$

\section{Schlussfolgerungen}

Relevant für die fortschreitende Zivilisierung des Systems im Ostseeraum ist die Schaffung einer Ordnung, aus der den einzelnen Akteuren ein Ausscheren erschwert und unattraktiv gemacht wird. Dies ist formal durch die Einbindung der östlichen Anrainerstaaten in die Vertragswerke des Westens geschehen, wobei die EU hinsichtlich eines breiten Themenspektrums die Hauptrolle spielt. Anarchie des Systems ist dadurch erheblich minimiert, was in der Vorbereitung zu einem großen Teil auf den Schultern des Ostseerats getragen wurde. Durch die informelle, aber kontinuierliche Zusammenarbeit auf den verschiedenen staatlichen Ebenen hat dieser fraglos dazu beigetragen, den jungen Staaten den Weg zu Internationalen Organisationen zu ebnen. Hierbei kommt ihm zugute, dass er in den EU-Organen in mancher Hinsicht von Beginn an als wichtigste Regionalorganisation gesehen und daher in einem engen Kontakt mit ihr stand und steht.

Teilen muss sich der CBSS diese Lorbeeren allerdings mit dem Nordischen Ministerrat, der ebenfalls von der EU gesondert in die Kooperation einbezogen wird und der sich außerdem auf eine bewährte Tradition mit vorzeigbarer Erfolgsgeschichte und starkem Rückhalt in den Bevölkerungen seiner Mitgliedstaaten stützen kann. So konnte der NMR schon zu Beginn der '90er Jahre seine Wurzeln an der Ostküste des Mare Baltikum schlagen, so dass er sich bei Gründung des CBSS dort bereits etabliert hatte. Offenbar ist es dem „Norden“

\footnotetext{
${ }^{244}$ Siehe Lange, Peer H.: „Die ,Nördliche Dimension“. Europäische Energieversorgung und sicherheit”, in: Internationale Politik, Nr. 1, 2001, S. 29-36, wenn auch schon vor einigen Jahren geäußert, ist diesem heute nach wie vor zuzustimmen.
} 
gelungen, zu einem Gravitationszentrum der Region zu werden, das dem CBSS an integrativem Einfluss nach wie vor voraus ist. Die enge Vernetzung der nordischen und baltischen Staaten, etwas weniger intensiv auch mit Polen, weist auf ein Phänomen hin, dass zunehmend auch im CBSS zu bemerken ist: In der Tat ist es das Verdienst dieser Organisation, Russland als Gleichen unter Gleichen in ihren Reihen $\mathrm{zu}$ behandeln, doch damit wird suggeriert, lediglich Russland habe eine Solitärstellung unter den Anrainerstaaten inne. Diese Sonderstellung Russlands hat sich jedoch doppelter Hinsicht abgeschwächt, denn zum einen tritt es zunehmend gegenüber der EU als bestimmender Verhandlungspartner (zumal in Energiefragen) auf, und zum anderen ist auch Deutschland in die Kooperation der Ostseeanrainerstaaten nur mäßig eingebunden. Gegenüber dieser auf der Ausspielung von hard power fußenden Entwicklung ist der Einfluss des CBSS verschwindend gering. Von Nachteil wirkt sich auf die in seinen Gremien ausgearbeiteten Zielsetzungen durchaus aus, dass die bisweilen EU aufgrund ihrer eigenen Interessen die Arbeit des CBSS konterkariert.

Die Tatsache, dass die volle Aufmerksamkeit der Arbeit des CBSS dem Ausloten gemeinsamer Interessen und kooperationsfähiger Themen gilt, stellt sich als Manko heraus. Ernsthafte Probleme, die für Unsicherheit sorgen, zumal, wenn sie bilateraler Natur sind, bleiben der Tagesordnung fern; Rückschläge in der wechselseitigen Abhängigkeit können vom CBSS somit nicht abgewendet werden.

Risikofaktoren, die nicht staatengebunden sind, werden tatsächlich als solche wahrgenommen und ausdauernd auf der Agenda gehalten und durch die verschiedenen Gremien hindurch behandelt, was - wie in TF-OC - auch Erfolge zeitigt; auch die Zusammenarbeit in Umweltschutzfragen legitimiert sich durch vorweisbare konkrete Ergebnisse. Es leistet der Ostseerat einen gewichtigen Beitrag zu der Entwicklung, Themen jeder Art in ihrer Bedeutung herauszustellen, so dass er zu einem Bewusstseinswandel bei den Beteiligten Akteuren beizutragen vermag.

Darüber hinaus ist festzuhalten, dass die Gegebenheiten in der Region, mit denen sich die Verantwortlichen zur Zeit der Gründung des CBSS konfrontiert sahen, allzu günstig waren, als dass dieser Organisation weltbewegende Leistungen attestiert werden könnten. Der Konflikt der Ideologien, der sich jahrzehntelang in dieser Region manifestiert hatte, war 1992 im wesentlichen bereits beigelegt, denn die östlichen Anrainerstaaten hatten ihre Hinwendung zum 
Westen bereits zuvor deutlich werden lassen. Nicht nur von der günstigen Ausgangslage profitiert die Arbeit des CBSS, sondern sie steht und fällt auch erheblich mit dem Engagement einzelner Staaten. Diesbezüglich tun sich namentlich Schweden und Finnland und auch Norwegen hervor, die trotz ihrer Eingliederung in EU (Norwegen nur bedingt) und NMR dem Ostseerat große Aufmerksamkeit widmen. In Anbetracht dieser Abhängigkeit wird zusätzlich deutlich, dass der Erfolg des CBSS von seinen Mitgliedern abhängt. Im jeweiligen Engagement lässt sich das Interesse erkennen, Zusammenarbeit um der wirtschaftlichen Prosperität willen voranzutreiben, und da allseits unverdrossen befürwortet wird, die Privatwirtschaft in die Kooperation mit einzubinden.

Hinsichtlich der Entwicklung der gesellschaftlichen Verflechtungen ist die geringe Institutionalisiertheit unbedingt $\mathrm{zu}$ begrüßen. In Ermangelung einer Durchsetzungskraft gegenüber den Staaten, läuft der CBSS nicht Gefahr, bei der Formulierung eigener Ziele gesellschaftliche Vernetzungen zu hemmen oder in bestimmte Bahnen zu lenken. Dabei profitiert die Zusammenarbeit von der großen geographischen Nähe aller Akteure, die sich nicht durch Ausschlussverfahren gegenüber außen abgrenzen, sondern die Hinwendung zu dieser Region als naturgegeben $\mathrm{zu}$ verstehen scheinen. Hier zeigt sich, dass grenzübergreifende Abhängigkeiten nicht auf allen Ebenen gegeben $\mathrm{zu}$ sein brauchen, indem die Hinwendung der bundesdeutschen Regierung meist unbedeutend, das Engagement für Schleswig-Holstein jedoch eine Selbstverständlichkeit zu sein scheint. Da die Einbindung zahlreicher Akteure jedweder Provenienz im Ostseerat bewusst vorangetrieben wird, trägt er zu diesem Aspekt der Zivilisierung fraglos bei.

In der Ambivalenz seiner Arbeit erscheint der CBSS vor allem als Spiegelbild des Geschehens in der Ostseeregion, nicht aber als Schrittmacher. Impulse gehen zwar unbestreitbar von der Zusammenarbeit in diesem Gremium aus, doch da die Umsetzung letztlich in nationaler Verantwortung liegt, vermag diese Organisation den Rhythmus des Geschehens nicht vorzugeben. Auf die Reduktion der Bedeutung von Konfliktbedeutung hat der Ostseerat lediglich mittelbaren Einfluss. 


\section{Quellen- und Literaturverzeichnis}

\section{Quellen}

1. Schriftstücke des CBSS, auf dessen Website dokumentiert und chronologisch, nach Themenfeldern sowie CBSS-Gremien systematisiert, abrufbar unter www.cbss.st/documents/ sowie unter www.cbss.st/summits/ für die Gipfeltreffen

- Terms of Reference of the Council of the Baltic Sea States (1992)

- Terms of Reference of the Council of the Baltic Sea States (revised 2005)

- 1992 CBSS 1st Ministerial Session - Copenhagen Declaration

- 1994 CBSS 3rd Ministerial Session, Tallinn Communiqué

- 1996 CBSS 4th Ministerial Session, Kalmar Communiqué

- 1997 CBSS 6th Ministerial Session, Riga Communiqué

- 1999 CBSS 6th Ministerial Session, Palanga Communiqué

- 2004 CBSS 12th Ministerial Session, Pori Communiqué

- 2nd Meeting of the CBSS Energy Ministers, Helsinki 1999

- Principles and Guidelines for Third Party Participation, 1999

- Note to Observers and Special Participants, 2002

- Terms of Reference of the Secretariat of the CBSS (2004)

- Priorities of the Russian Presidency of the CBSS in 2001-2002

- CSO Annual Report 1993/1994

- CSO Annual Report 1995/1996

- CSO Annual Report 1996/1997

- CSO Annual Report 2001/2002

- Baltic Sea States Summit, Kolding (2000): Review of structure and working methods of the CBSS

- Baltic Sea States Summit, Visby (1996): Presidency Declaration

- Establishment Agreement of a CBSS Secretariat (1998)

- Information and Communication Strategy for the Council of the Baltic Sea States, 2005 
- Website der EU-Kommission zur ND und sämtlichen entspr. Dokumenten, URL: http://europa.eu/comm/external_relations/north_dim/.

- CBSS-Sekretariat (Hg.): Informationsbroschüre „Innovative Cooperation for a Dynamic Region“, Stockholm 2005.

- „Baltinfo“, Nr. 45, Februar 2002.

- Baltinfo“, Nr. 41, Oktober 2001.

- Deutscher Bundestag, Drucksache 16/3210, „Große Anfrage“: „Konsequenzen der Auswanderung Hochqualifizierter aus Deutschland“ am 30.10.2006.

- Deutscher Bundestag, DS 14/4026, Bundesregierung am 30.8.2000 in einer Antwort auf die Große Anfrage aus der FDP-Fraktion.

- Deutscher Bundestag: Plenarprotokoll, DS 14/150, S. 14708.

- $\quad$ Schleswig-Holsteinischer Landtag, Plenarprotokoll 16/24, 24.2.06.

- Energy Charter Secretariat (Hg.): The Energy Charter Treaty and Related Docouments, Brüssel 2004.

- Abschlussbericht der „Baltic Ring Study“, online dokumentiert, URL: http://www.lps.lv/nozares/energy/elektr/parsk/balticring.htm, 15.2.2007.

- Nordischer Ministerrat (Hg.): Handlingsplan for det nordiske energisamarbejde 2006-2009, Kopenhagen 2005

- Website der Nordischen Kooperation, URL: http://www.norden.org/.

- Website des Auswärtigen Amts, URL: http://www.auswaertigesamt.de/diplo/de/AAmt/Abteilungen/Europaabteilung.html, 1.3.2007.

- Website des Bundesministeriums für Wirtschaft und Technologie, URL: http://www.bmwi.de/BMWi/Navigation, 19.2.2007.

- Homepage der Task Force on Organised Crime, URL: http://www.balticseataskforce.fi.

- Homepage des Internationalen Strafgerichtshofs, URL: http://www.icccpi.int/about/ataglance/establishment.html, 28.11.2006.

- Trittin, Jürgen: Rede am 27.04.2004, URL: http://www.bmu.de/reden/doc/5820.php, 5.12.2006.

- UNDP (Hg.): „Human Development Report 2006“, Vorwort S. vi, URL: http://hdr.undp.org/hdr2006/pdfs/report/HDR06-complete.pdf, 5.12.2006. 
- Schwedische Regierung: Ekonomisk utveckling och samarbete i Östersjöregionen, Skr. 1999/2000:7, 30.9.1999.

- Amt für Veröffentlichungen der Europäischen Gemeinschaften (Hg.): „Regionen: Statistisches Jahrbuch 2006“, Luxemburg 2006.

- Website des US-Außenministeriums, URL: http://www.state.gov/p/eur/rt/epine/, 2.2.2007.

- Website der Baltic Sea Chamber of Commerce Association, URL: http://www.bcca.ws/cm2f/default.asp?id=19, 4.2.2007.

- Website der russischen Regierung, URL: http://www.president.kremlin.ru/eng/priorities/21817.shtml, 9.2.2007.

\section{Sekundärliteratur}

- Boehmer, Charles / Gartzke, Erik / Nordstrom, Timothy: „Do Intergovernmental Organizations Promote Peace?“, in: World Politics, Nr. 57, Heft 1, Okt. 2004, S. 1-38.

- Bøtcher, Bjarke W.: „Is the CBSS sufficiently well known to the public?“, in: Baltinfo Nr. 71, März 2005, S. 8.

- Brockhaus Enzyklopädie, 24 Bde, Mannheim 1990 ${ }^{19}$, Bd. 12, S. 244 f..

- Browning, Christopher / Joenniemi, Pertti: „Regionality beyond Security? The Baltic Sea Region after Enlargement”, in: Cooperation and Conflict, Nr. 39, Heft 3, 2004, S. 233-253.

- Friedrichs, Jörg: European Approaches to International Relations Theory. A House with many Mansions, London 2004.

- Gerner, Kristian / Karlsson, Klas-Göran: Nordens Medelhav: östersjöområdet som historia, myt och projekt, Stockholm 2002.

- Haas, Peter M. / Keohane, Robert O. / Levy, Marc A.: Institutions for the Earth. Sources of Effective International Environmental Protection, Cambridge u.a., 1993.

- Herdegen, Matthias: Völkerrecht, München $2004^{3}$.

- Holm, Eric: High Politics and European Integration. From EMU to CSFP, London 2000, S. 1. 
- Hubel, Helmut / Gänzle, Stefan: „Der Ostseerat: Neue Funktionen subregionaler Zusammenarbeit im Kontext der EU-Osterweiterung“, in: Aus Politik und Zeitgeschichte, Nr. 19-20, 2002, 3-11.

- Hubel, Helmut: „The Baltic Sea Subregion after dual Enlargement“, in: Cooperation and Conflict, Nr. 39 (3), 2004, S. 283-298.

- Joenniemi, Pertti: „Security in Northern Europe: The contest between different understandings“, in: Österreichische Zeitschrift für Politikwissenschaft, Nr. 25, Heft 4, 1996, S. 431-441.

- Nye, Joseph: Soft Power. The Means to Success in World Politics“, New York 2004

- Keck, Otto: „Der neue Institutionalismus in der Theorie der Internationalen Politik“, in: Politische Vierteljahresschrift, Nr. 4, 1991, S. 635-653.

- Kell, Georg: „Über die Einhegung der Macht. Die Einbindung von Unternehmen und NGOs in globale Ordnungsstrukturen“, in: HerbertQuandt-Stiftung (Hg.): „Jenseits des Staates? ,Außenpolitik‘ durch Unternehmen und NGOs“, 21. Sinclair-Haus-Gespräch, Bad Homburg v.d. Höhe, 2004, S. 58-64.

- Keohane, Robert O.: After Hegemony. Cooperation and Discord in the World Poltical Economy, Princeton, 1984.

- Keohane, Robert O.: „Correspondence“, in: International Security, Nr. 15, Heft 2, 1990, S. 192-194.

- Keohane, Robert O. / Nye, Joseph S.: Power and Interdependence, New York u.a. $2001^{3}$, (1. Aufl. 1976).

- Keohane, Robert O.: „Accountability in World Politics“, in: Scandinavian Political Studies, Nr. 29, Heft 2, 2006, S. 75-87.

- Knudsen, Olaf F.: 'Institutions'vs 'Power': Baltic Perspectives on Regional Security, Gdansk / Berlin, 2004.

- Krohn, Axel: Eine neue Sicherheitspolitik für den Ostseeraum. Perspektiven regionaler Rüstungskontrolle und Zusammenarbeit, Opladen 1993.

- Landsbergis, Vytautas, in Baltinfo Nr. 75, Okt. 2005, S. 10 f..

- Lange, Peer H.: „Die ,Nördliche Dimension“. Europäische Energieversorgung und sicherheit", in: Internationale Politik, Nr. 1, 2001, S. 29-36. 
- Mangels-Voegt, Birgit: „Erneuerbare Energien - Erfolgsgaranten einer nachhaltigen Politik?“, in: Bundeszentrale für Politische Bildung (Hg.): Aus Politik und Zeitgeschichte, B37/2004, S. 12-17.

- Menzel, Ulrich: Zwischen Idealismus und Realismus. Die Lehre von den Internationalen Beziehungen, Frankfurt a. M. 2001.

- Mearsheimer, John J.: im Interview mit „International Relations“, Nr. 20, Heft 1, 2006, S. 105-123.

- Mearsheimer, John J.: im Interview mit „International Relations“, Nr. 20, Heft 2, 2006, S. 231-243.

- Olljum, Alar: „Reflections On Baltic Sea Co-operation“, in: Baltinfo, Nr. 35, Februar 2001.

- Pevehouse, Jon C.: "With a Little Help from my friends? Regional Organizations and the Consolidation of Democracy", in: American Journal of Political Science, Nr. 46, Heft 3, 2002, S. 611-626.

- Pfetsch, Frank R.: Internationale Politik, Stuttgart u.a. 1994.

- Reinalda, Bob u. Verbeek, Bertjan: „The issue of decision making within international organizations“, in: dies. (Hg.): Decision Making Within International Organizations, London u.a. 2004, S. 9-42.

- Schimmelpfenning, Frank: „Starke Anreize, ambivalente Wirkungen: Die Europäisierung Mittel- und Osteuropas“, in: Buchstein, Hubertus u.a. (Hg.): Leviathan. Berliner Zeitschrift für Sozialwissenschaft, Bd. 2, Berlin 2004, S. 250-268.

- Schymik, Carsten: „Nordische Sonderwege nach Europa“, in: Aus Politik und Zeitgeschichte, Nr. 47, 2004, S. 10-15.

- Stålvant, Carl-Einar: „Baltic Sea co-operation: Moving forward?“, in: Baltinfo, Nr. 28, März 2000.

- Tibi, Bassam: Die neue Weltunordnung, München 2001.

- Unckel, Per: im Interview mit Baltinfo, Nr. 72, Mai 2005, S. 1 ff..

- Unser, Günther: Die UNO. Aufgaben und Strukturen der Vereinten Nationen, München $1997^{6}$.

- Vitkus, Gediminas: Changing Security Regime in the Baltic Sea Region, Vilnius 2002. 
Zeitungsartikel

- $\quad$ von Altenbockum, Jasper: „Auf dem Weg zur modernen Hanse - Russlands Annäherung an Europa führt über eine ,Nördliche Dimension ““, Frankfurter Allgemeine Zeitung, 7.7.1998, S. 16.

- $\quad$ von Altenbockum, Jasper: „Meer der Möglichkeiten“, in: Frankfurter Allgemeine Zeitung, 4.11.1998, S. 1.

- Donath, Klaus-Helge: „Die Balten als Statisten“, in: taz - die tageszeitung, 24.1.1998, S. 2.

- Henningsen, Bernd: „Glänzende Perspektiven der Ostsee-Region nutzen. Deutschland muss aus seiner Mitläuferrolle herausfinden“, in: Focus, Nr. 28, 10.7.2000, S. 54.

- Johannsmeier, Birgit: „Zündstoff im Baltikum. Streit um die geplante deutsch-russische Gasleitung“, in: Deutscher Bundestag (Hg.): Wochenzeitung „Das Parlament“, Nr. 49-50, 5.12.2005.

- Leicht, Robert: „,Am Gelde hängt, zum Gelde drängt doch alles““”, in: Die Zeit online, Nr. 50 / 2005, URL: http://www.zeit.de/online/2005/50/schroeder_montagskolumne, 3.3.2007.

- Nienhuysen, Frank: „Ein Meer verschiedener Interessen“, in: Süddeutsche Zeitung, 1.7.2000, S. 8 .

- Rietig, Thomas: „Ein Mare Nostrum für die EU“, in: Associated Press Worldstream, Visby/Bonn, 1.5.1996.

- Rietig, Thomas: „Der sanfte Riese und Klaus Stoertebeker - Ostseegipfel diente Deutschland zum Austarieren politischer und geographischer Unwuchten in Europa“", in: Associated Press Worldstream, Visby, 5.5.1996.

- Walter, Gerd: „Der Ostseeregion gehört die Zukunft“, in: Focus Nr. 32, 9.8.99, S. 50.

- Welzer, Harald: „Schluss mit nutzlos! Die Geisteswissenschaften werden gebraucht, um die Welt neu zu denken. Doch dafür müssen sie mutiger werden“, in: DIE ZEIT, Nr. 5, 25.1.2007, S. 43.

- (N.N.): ,Ostsee-Sekretariat in Stockholm eröffnet“, in: Frankfurter Allgemeinen Zeitung, 21.10.1998, S. 8. 